\title{
Upscaling Microstructured Emulsification Devices
}

Sami Şahin 


\section{Thesis committee}

\section{Promotor}

Prof. Dr C.G.P.H. Schroën

Personal chair at Food Process Engineering

Wageningen University

\section{Other members}

Prof. Dr V. Fogliano, Wageningen University

Dr A.T. Poortinga, Eindhoven University of Technology

Dr M. Rayner, Lund University, Sweden

Dr V. van Steijn, Delft University of Technology

This research was conducted under the auspices of the Graduate School VLAG (Advanced studies in Food Technology, Agrobiotechnology, Nutrition and Health Sciences) 


\section{Upscaling Microstructured Emulsification Devices}

\section{Sami Şahin}

Thesis

submitted in fulfilment of the requirements for the degree of doctor

at Wageningen University

by the authority of the Rector Magnificus

Prof. Dr A.P.J. Mol,

in the presence of the

Thesis Committee appointed by the Academic Board

to be defended in public

on Monday 30 May 2016

at 1.30 p.m. in the Aula. 
Sami Şahin

Upscaling Microstructured Emulsification Devices 128 pages.

PhD thesis, Wageningen University, Wageningen, NL (2016) With references, with summary in English 
To my parents 



\section{Table of contents}

Chapter 1 Introduction and thesis outline 1

Chapter 2 Microfluidic EDGE emulsification: the importance of interface interactions on droplet formation and pressure stability

Chapter 3 Partitioned EDGE devices for high throughput production of monodisperse emulsion droplets with two distinct sizes

Chapter 4 Droplet formation mechanisms in partitioned EDGE devices: geometry and viscosity effects

Chapter $5 \quad$ Upscaling microfluidic emulsification to industrially relevant throughputs: the importance of (sub-) structure design

Chapter 6 High throughput production of double emulsions using packed bed premix emulsification

Chapter 7 General discussion

Summary

Acknowledgements

About the author

List of publications 



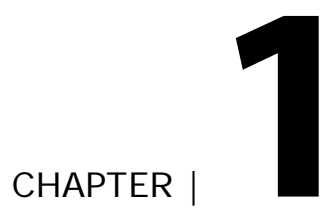

Introduction and thesis outline 


\subsection{Food structures}

The structure of any product is mostly determined by structural elements that are typically in the micrometre, and sometimes even nanometre range. These structural elements can for instance be small particles, or droplets, and in order to be able to control the complete structure of a product, control over these microstructures is needed. Some examples are the size of crystallites in metals that influences their mechanical properties, ${ }^{1}$ the particle size of chromatography resins that determines the separation behaviour, ${ }^{2}$ and the amount, size, and size distribution of particles in a paint that co-determine its spreadability and drying behaviour. ${ }^{3,4}$

This is yet more relevant in food that even in its simplest form consists of many structure elements; starch granules, protein particles, bubbles, complexes, crystals, droplets, just to name a few. ${ }^{5}$ In order to make stable and delicious products, all these structures need to be controlled in one way or another and for this various processes are available, as will be described later in more detail for droplet formation.

Improved understanding of food structure and function has led to the discovery of new (milder) production techniques that eventually need to be translated into new processing equipment, minimizing the (heat) damage to the raw materials used and leading to better food products. Especially in the field of emulsification there are a lot of new and emerging technologies that can be applied to food, as well as many other fields such as pharma, personal care, lubricants etc.

Emulsions are part of many processed foods, and not only the chemical composition but also the physical properties play an important role in the perception, functionality, digestibility and shelf life of the foods. Most of these attributes change during processing, and to obtain an acceptable product, the process needs to be controlled on various levels.

In this chapter, we first describe emulsions in general terms such as their use, characterization, and preparation techniques; and next the state of the art for emulsification including the use of microfluidic devices is given. The chapter is concluded with the aim and outline of the thesis. 


\subsection{Emulsions}

Emulsions are dispersions of immiscible liquids, having very limited or no mutual solubility, such as oil and water. Emulsions can be classified as simple (e.g. o/w and w/o) and multiple emulsions; the latter ones are emulsions of emulsions and more complex, e.g. w/o/w and o/w/o double emulsions.

Emulsions, mainly the simple ones, are part of our daily life in numerous products. Some products such as milk are natural emulsions, but many more such as wall paints, lotions, shampoos, creams, medicines, mayonnaise, margarine, salad dressings, and ice cream, are manufactured from individual components, namely oil, water and emulsifiers that are used to form and stabilize interfaces. To date, double emulsions have very limited commercialization, but they hold great potential for a wide range of applications such as reducing fat/oil and salt intake, controlled delivery, encapsulation and release of nutrients and flavours in food. ${ }^{6,7}$

\subsection{Emulsion characterization and stability}

For emulsion characterization, droplet size and size distribution are used, which codetermine the stability, texture, viscosity, colour, appearance, taste, visual and sensorial perception of the products. Emulsion stability itself will influence the mentioned quality attributes and can be the determining factor for product shelf life. For example, emulsions with smaller droplets are more stable against creaming, and monodisperse emulsions are claimed to be more stable. ${ }^{8}$ Saito et al. ${ }^{9}$ have found that monodisperse emulsion droplets of around $40 \mu \mathrm{m}$ were more stable against thermal processing compared to polydisperse ones of the same average size.

Clearly, controlling droplet size and size distribution can lead to different products and possibly also to novel products with tailored properties. However, the number of studies involving monodisperse emulsions is limited due to the lack of preparation techniques. Please note that various microfluidic devices can make very monodisperse emulsions, but their productivity is too low for emulsion characterisation. For these reasons, preparation of monodisperse emulsions at larger quantities is of interest to 
both academic and industrial research. The chronology and state of the art for emulsion preparation techniques, with their main characteristics, are briefly described in the following section.

\subsection{Emulsion preparation}

\subsubsection{Classic techniques}

Emulsions are conventionally produced with high pressure homogenizers, colloid mills and rotor-stators that are described in Fig. 1.1. These devices utilize excessive mechanical forces to homogenize a coarse starter emulsion. The energy efficiency of these devices is very low, and over $95 \%$ of the energy input is generally lost as heat. ${ }^{10}$ The droplet size distribution can get narrower by repeated passage of the emulsion through the device; however, this increases the energy usage further and allows only for limited control, if any, on droplet size. Besides, the high mechanical stress in conventional homogenizers make them unsuitable for the preparation of double emulsions, which are inherently fragile.

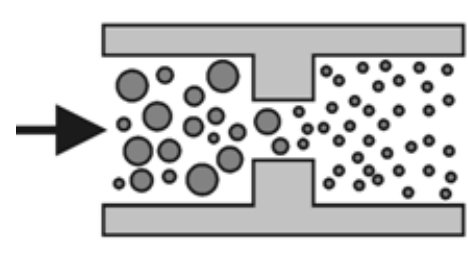

(a)

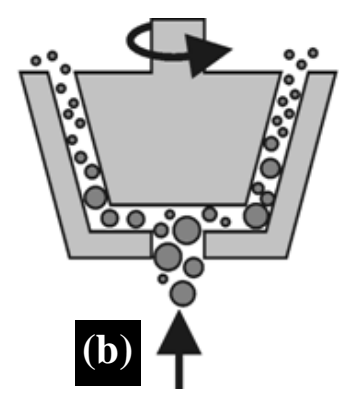

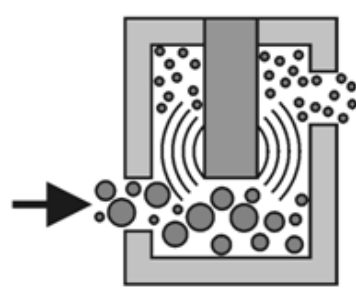

(c)

Fig. 1.1 Schematic representation of conventional emulsification systems: (a) high pressure homogenizer, in which a coarse emulsion is refined by pushing it through a narrow hole, (b) rotor-stator system/colloid mill, in which a coarse starter emulsion is refined through a shear field generated by a rotating device, (c) ultrasound homogenizer uses cavitation of bubbles to generate high energy fields that lead to droplet formation and break-up. ${ }^{11}$ 


\subsubsection{Emerging techniques}

To overcome the issues associated with conventional systems, alternative emulsification technologies have been proposed and developed in the last decades (Fig. 1.2). Some of these emerging emulsification techniques, are still in their infancy (e.g. microfluidics) and some have already reached a certain level of maturity (e.g. membrane systems), as will be discussed in the next sections. Both membrane emulsification (ME) and droplet-based microfluidics may exploit shear forces to directly make droplets or refine larger ones, while spontaneous droplet formation can only be targeted in microfluidic devices, as is described in greater detail in the next two sections.

\section{Membrane emulsification}

The industrial use of membranes for separation purposes dates back to the 1960s; they are widely used for water purification, dairy processing, and chemical separations amongst others. In the late 1980s, membranes were proposed for the production of emulsions and cross-flow ME was introduced by Nakashima and co-workers for the preparation of monodisperse o/w emulsions. ${ }^{12,13}$ In cross-flow ME, the dispersed phase is pushed through the membrane pores and the emerging droplets are sheared off by

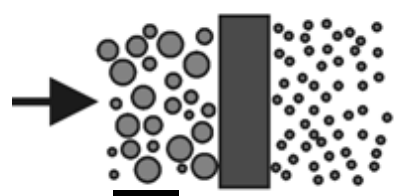

(a)

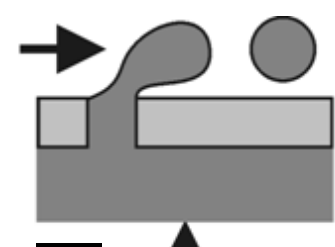

(b) 4

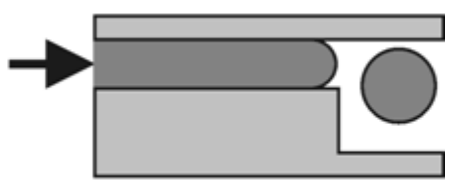

(c)

Fig. 1.2 Schematic representation of emerging emulsification techniques: (a) premix emulsification in which a coarse emulsion is homogenized by passing through a porous medium, (b) direct emulsification, cross flowing continuous phase shears off the emerging droplets from the membrane pores or microfluidic junctions, (c) spontaneous emulsification where the dispersed phase confined in a shallow area transforms into a spherical droplet at the exit of the confined space, no cross-flow is needed. ${ }^{11}$ 
the cross-flowing continuous phase (Fig. 1.2b). Both phases need to be accurately dispensed to control the droplet size, and in general, cross-flow ME is not suitable for emulsions with high dispersed phase fractions.

In 1996, Suzuki and co-workers introduced premix membrane emulsification or membrane homogenization, ${ }^{8}$ in which a coarse emulsion is passed through a membrane or porous medium to break-up the initially large droplets into smaller ones. The process can be repeated until the desired droplet size and size distribution are reached. ${ }^{14}$ Compared to cross-flow mode, premix ME was found to have less control over droplet size, resulting in lower monodispersity; however it does allow higher dispersed phase fractions as part of the starter emulsion. ${ }^{15,16}$

To date, membrane emulsification has been studied extensively, and considerable understanding of the underlying mechanisms was gained. It was shown to deliver reasonably monodisperse emulsions at considerable throughputs. ${ }^{16-18}$ In 2000, a low fat spread made by membrane emulsification was launched by Morinaga Milk Industry Co. Ltd in Japan. To the best of our knowledge, it is the first and only food product in the market made by membrane emulsification.

However, there are certain principle issues that once solved are expected to lead to more industrial applications. Pore activation and/or the interplay between the pores, wettability of the membrane surface and cleanability are determining factors for membrane emulsification; and membrane fouling is a severe problem, especially for pre-mix emulsification. ${ }^{19-21}$

To alleviate this, sieves with engineered pores much larger than the intended droplet size, were introduced for premix emulsification and studied as such $^{22,23}$ or in combination with glass beads that form a packed bed. ${ }^{24-26}$ The system, with and without beads, was shown to be much less sensitive to fouling and deliver two orders of magnitude higher production capacity than those reported for SPG membranes, which are the golden standard for membrane emulsification.

Most studies on membrane emulsification are for single emulsions, but the technology does allow preparation of double emulsions, either in cross-flow or premix mode. ${ }^{27-29}$ However, it should be stated that the insights in the preparation of double emulsions are very limited. 


\section{Microfluidic emulsification}

Advances in micromachining technology have opened up new possibilities in several research fields, mostly in electronics but also other applications have been commercialized. One of them is droplet-based microfluidics that enables formation of monodisperse droplets in a controlled manner. They have been applied regularly in the field of sensing, where only few droplets need to be made. However, the technology holds the promise that it can also make many droplets, and can do so at much lower energy consumption compared to the conventional technologies. ${ }^{30}$ In order to reach this, amongst others, the throughput needs to be increased, and this requires a thorough understanding of the underlying droplet formation mechanisms.

Microfluidic droplet generators can be grouped into two main categories based on their droplet formation mechanism: shear-based and interfacial tension-driven (i.e. spontaneous). The term 'shear-based' arises from the fact that the shear exerted by the continuous phase flow is essential for droplet formation and needs to be controlled to control droplet size, as is the case for cross-flow membrane emulsification. T- and Yjunctions, and flow focusing devices are the predominant examples of shear-based devices. ${ }^{31-34}$ From a single droplet formation unit they all can produce very monodisperse droplets at rates up to several thousands per second. However, their parallelization is difficult because both continuous and dispersed phase flows need to be controlled precisely, and that is hard to realize for each parallelized unit and consequently the product becomes polydisperse. ${ }^{35-37}$

Unlike shear-based systems, interfacial tension-driven or spontaneous emulsification devices only require control over the dispersed phase flow; continuous phase flow is not needed for droplet formation. ${ }^{38}$ Besides, the droplet size is independent of pressure (within a certain range), allowing for some fluctuation in flow and thereby leading to a wider window of stable operation. Their relative insensitivity to flow or pressure fluctuations makes them better candidates for mass parallelization. At the same time, they have lower productivity per droplet formation unit than shear-based devices and therefore require relatively large areas for large-scale production. ${ }^{36,38}$

Microchannels (MCs) and EDGE systems are the two most common spontaneous emulsification devices. ${ }^{39-41}$ Straight-through MCs and EDGE devices are considered as viable concepts for upscaling; straight-through MCs enable efficient integration of 
many droplet formation units, and within the EDGE systems multiple droplets can be produced simultaneously from one unit. In general, straight-through MCs are very appropriate when $\sim 30 \mu \mathrm{m}$ droplets are targeted, but for smaller droplets productivity decreases drastically, mainly due to low pore activation as a result of hydrodynamic coupling effects (i.e. pressure fluctuations). In EDGE systems the wide droplet formation units absorb the pressure fluctuations, therewith preventing coupling effects and allowing stable operation, even for small droplets. Thanks to this unique feature, EDGE devices have a better prospect in regard to upscaling, and are therefore the focal point of this thesis. For further information, the reader is referred to a review on spontaneous emulsification systems, ${ }^{30}$ a general review on upscaling of microfluidic devices, ${ }^{37}$ and an industrial perspective on microfluidic droplet generation. ${ }^{42}$

\section{Microfluidic EDGE (Edge-based Droplet GEneration) Devices}

Microfluidic EDGE emulsification was introduced by our group in 2009, and has been studied ever since. ${ }^{41}$ As mentioned, with EDGE devices, multiple monodispersed droplets can be produced simultaneously from a single droplet formation unit, the socalled plateau, which makes the technique unique. Droplet formation from a typical plateau is depicted in Fig. 1.3; the pressurized oil flows through the dispersed phase channel onto the plateau and upon reaching the edge of the plateau droplets are generated in the continuous phase channel. The droplet diameter scales with the height of the plateau, droplets being 6 times larger.

The reported EDGE devices were made from silicon/glass and few were semi-metal devices. ${ }^{43,44}$ The droplet formation units were successfully parallelized in a flat chip, and promising results were obtained for both single and multiple emulsions, and foams. ${ }^{38,45}$ However, the production rates do not suffice for industrial product volumes and require further improvement.

Previous investigations revealed that wettability, ingredient selection, and material choice can influence the droplet formation behaviour and frequency, which makes $a b$ initio prediction of emulsification behaviour difficult. ${ }^{30,46}$ The current knowledge base on these matters is not good enough to derive scaling guidelines for designing a large-scale EDGE emulsification process, and is therefore addressed in this thesis. 


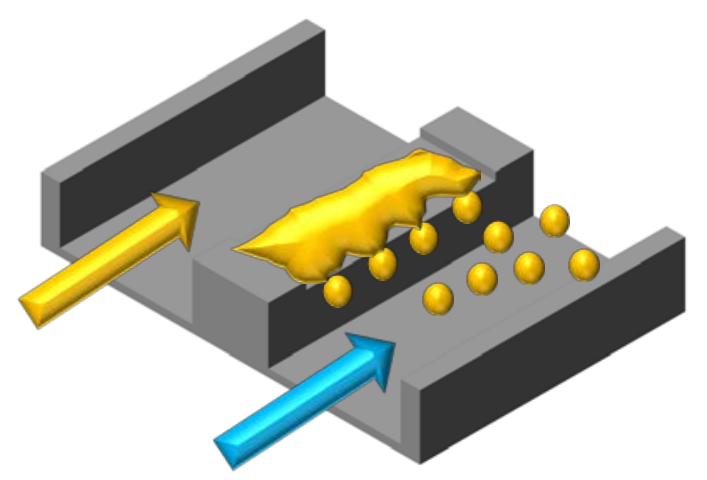

Fig. 1.3 Schematic illustration of multiple monodisperse droplets forming simultaneously from a typical droplet formation unit (i.e. plateau) in EDGE devices.

\subsection{Research aim}

This thesis aims at upscaling microstructured emulsification techniques, particularly microfluidic EDGE devices for single emulsions and packed bed premix emulsification for double emulsions. As mentioned previously, to reach upscaling many aspects need to be combined, not just the production rate but also geometry design, product properties, and interface interactions (both liquid/liquid and solid/liquid) need to be related to droplet formation behaviour and throughput, as is specified below in the thesis outline.

\subsection{Thesis outline}

In chapter 1, the current state of affairs of emulsification processes is introduced, and various aspects that are important for upscaling microstructured emulsification devices are identified.

Chapter 2 illustrates the effect of interface interactions (liquid/liquid and liquid/solid) on droplet formation and pressure stability in microfluidic EDGE emulsification. Guidelines for successful emulsification are presented in terms of construction material, emulsion ingredients, and their interactions. 
In chapter 3, a novel microfluidic EDGE design, so-called partitioned EDGE containing micron-sized partitions on the main plateau, is introduced, aiming at increasing the droplet generation rate. Droplet formation characteristics of the device are studied, and a design strategy for an upscaled emulsification device is proposed.

Chapter 4 elucidates the mechanism of droplet formation in partitioned EDGE devices further. The effects of liquid viscosities and partitioned plateau geometry on droplet size and size distribution are discussed.

In chapter 5, based on the design strategy proposed in chapter 3, the upscaled multi-EDGE design is presented, including estimations for its productivity and pressure stability.

Chapter 6 explores packed bed premix emulsification to prepare food grade double emulsions. Droplet break-up is characterized through pore Reynolds number and compared to that of single emulsions.

In chapter 7, the implications of our main findings are discussed in a broader sense, and various upscaling strategies for microstructured emulsification systems from literature are compared. Finally, the thesis is concluded with a concise summary, bibliographic and personal data.

\section{References}

1 D. J. Dunstan and A. J. Bushby, Int. J. Plast., 2014, 53, 56-65.

2 S. Tuomo, K. Ari, K. Jarmo and M. Heikki, in Ion Exchange and Solvent Extraction, ed. A. K. SenGupta, CRC Press, 2011, pp. 145-169.

3 A. Tzitzinou, J. L. Keddie, J. M. Geurts, A. C. I. A. Peters and R. Satguru, Macromolecules, 2000, 33, 2695-2708.

4 A. Overbeek, J. Coatings Technol. Res., 2010, 7, 1-21.

5 P. Walstra, Physical Chemistry of Foods, Marcel Dekker, New York, 2003.

6 G. Muschiolik, Curr. Opin. Colloid Interface Sci., 2007, 12, 213-220.

7 L. Sapei, M. A. Naqvi and D. Rousseau, Food Hydrocolloids, 2012, 27, 316-323.

8 K. Suzuki, I. Shuto and Y. Hagura, Food Sci. Technol. Int. Tokyo, 1996, 2, 43-47. 
9 M. Saito, L. J. Yin, I. Kobayashi and M. Nakajima, Food Hydrocolloids, 2006, 20, 1020 1028.

10 D. J. McClements, Food emulsions : principles, practices, and techniques, CRC Press, Boca Raton, FL, 1999.

11 E. A. van der Zwan, 2008. Emulsification with microstructured systems - process principles (PhD Thesis wageningen University), Wageningen, 2008.

12 T. Nakashima, M. Shimizu and M. Kukizaki, Key Eng. Mater., 1991, 61-62, 513-516.

13 T. Nakashima, M. Shimizu and M. Kukizaki, Adv. Drug Deliv. Rev., 2000, 45, 47-56.

14 G. T. Vladisavljevic, M. Shimizu and T. Nakashima, J. Memb. Sci., 2004, 244, 97-106.

15 G. T. Vladisavljević and R. A. Williams, Adv. Colloid Interface Sci., 2005, 113, 1-20.

16 S. M. Joscelyne and G. Trägårdh, J. Memb. Sci., 2000, 169, 107-117.

17 C. Charcosset, I. Limayem and H. Fessi, J. Chem. Technol. Biotechnol., 2004, 79, 209-218.

18 A. Nazir, K. Schroën and R. Boom, J. Memb. Sci., 2010, 362, 1-11.

19 A. Trentin, M. Ferrando, F. López and C. Güell, Desalination, 2009, 245, 388-395.

20 J. Surh, Y. G. Jeong and G. T. Vladisavljević, J. Food Eng., 2008, 89, 164-170.

21 D. M. Lloyd, I. T. Norton and F. Spyropoulos, J. Food Eng., 2015, 166, 316-324.

22 A. Nazir, K. Schroën and R. Boom, J. Memb. Sci., 2011, 383, 116-123.

23 A. Nazir, K. Schroën and R. Boom, Chem. Eng. Sci., 2013, 93, 173-180.

24 E. A. van der Zwan, C. G. P. H. Schroën and R. M. Boom, AIChE J., 2008, 54, 2190-2197.

25 A. Nazir, R. M. Boom and K. Schroën, Chem. Eng. Sci., 2013, 92, 190-197.

26 A. Nazir, R. M. Boom and K. Schroën, Chem. Eng. Sci., 2014, 116, 547-557.

27 Y. Mine, M. Shimizu and T. Nakashima, Colloids Surfaces B Biointerfaces, 1996, 6, 261268.

28 M. Shima, Y. Kobayashi, T. Fujii, M. Tanaka, Y. Kimura, S. Adachi and R. Matsuno, Food Hydrocolloids, 2004, 18, 61-70.

29 S. van der Graaf, C. G. P. H. Schroën and R. M. Boom, J. Memb. Sci., 2005, 251, 7-15.

30 A. A. Maan, K. Schroën and R. Boom, J. Food Eng., 2011, 107, 334-346.

31 T. Thorsen, R. W. Roberts, F. H. Arnold and S. R. Quake, Phys. Rev. Lett., 2001, 86, $4163-$ 4166.

32 S. Van Der Graaf, M. L. J. Steegmans, R. G. M. Van Der Sman, C. G. P. H. Schroën and R. M. Boom, Colloids Surfaces A Physicochem. Eng. Asp., 2005, 266, 106-116. 
33 M. L. J. Steegmans, K. G. P. H. Schroën and R. M. Boom, Langmuir, 2009, 25, 3396-3401.

34 S. L. Anna, N. Bontoux and H. A. Stone, Appl. Phys. Lett., 2003, 82, 364-366.

35 G. T. Vladisavljević, I. Kobayashi and M. Nakajima, Microfluid. Nanofluid., 2012, 13, 151178.

36 D. Bardin, M. R. Kendall, P. A. Dayton and A. P. Lee, Biomicrofluidics, 2013, 7, 034112.

37 K. Schroën, O. Bliznyuk, K. Muijlwijk, S. Sahin and C. C. Berton-Carabin, Curr. Opin. Food Sci., 2015, 3, 33-40.

38 K. van Dijke, G. Veldhuis, K. Schroën and R. Boom, Lab Chip, 2009, 9, 2824-2830.

39 T. Kawakatsu, Y. Kikuchi and M. Nakajima, J. Am. Oil Chem. Soc., 1997, 74, 317-321.

40 I. Kobayashi, M. Nakajima, K. Chun, Y. Kikuchi and H. Fujita, AIChE J., 2002, 48, 16391644.

41 K. C. Van Dijke, G. Veldhuis, K. Schroën and R. M. Boom, AlChE, 2009, 56, 833-836.

42 C. Holtze, J. Phys. D Appl. Phys., 2013, 46, 114008-9.

43 A. A. Maan, K. Schroën and R. Boom, Microfluid. Nanofluid., 2013, 14, 187-196.

44 A. A. Maan, R. Boom and K. Schroën, Microfluid. Nanofluid., 2013, 14, 775-784.

45 K. C. van Dijke, K. Schroën, A. van der Padt and R. Boom, J. Food Eng., 2010, 97, 348-354.

46 A. A. Maan, S. Sahin, L. H. Mujawar, R. Boom and K. Schroën, J. Colloid Interface Sci., 2013, 403, 157-159. 


\section{Microfluidic EDGE emulsification: the importance of interface interactions on droplet formation and pressure stability}

This chapter has been accepted for publication as Sahin, S., Bliznyuk, O., Rovalino Cordova, A., \& Schroën, K. Microfluidic EDGE emulsification: the importance of interface interactions on droplet formation and pressure stability. Sci. Rep. 6, 26407 (2016). 


\section{Abstract}

The fact that interaction of components with interfaces can influence processes is wellknown; e.g. accumulation of deposits on heat exchangers and fouling of membranes lead to additional resistances against heat and mass transfer, respectively. In microfluidic emulsification, the situation is even more complex. Generally speaking, component accumulation at the solid/liquid interface is not desired since this may change wettability, while at the liquid/liquid interface component accumulation is a necessity to keep emulsions stable. For successful emulsification both aspects need to be well balanced, and that is investigated in this paper for o/w emulsions prepared in microfluidic EDGE devices.

We used different oil/emulsifier combinations (e.g. alkanes, vegetable oil, surfactants and proteins) and observed differences in droplet formation behaviour including operational pressure stability. We discuss the observed differences in relation to the interface interactions, and compare our findings with those presented in literature. The results show that an appropriate combination of construction material and emulsion components is needed to achieve successful emulsification in microfluidic EDGE devices. Based on this, we provide guidelines that are also relevant for any microfluidic device in which two phases are combined. 


\subsection{Introduction}

Emulsions are mixtures of oil and water and used in many product formulations in food and other industries. To form and stabilize emulsions, emulsifiers are utilized. Proteins, particularly milk proteins, are widely used as food emulsifiers. Conventionally, (food) emulsions are prepared using high pressure homogenizers and colloid mills, which apply high shear stress to break-up initially large emulsion droplets into smaller ones. ${ }^{1}$ The time scale for droplet break-up is very short, leading to a situation in which proteins cannot stabilize the entire newly formed interfaces, and droplets coalesce. ${ }^{2}$ To remediate this, repeated homogenization cycles are used in combination with excess amounts of protein (compared to monolayer coverage), which are both not desired from an economical point of view. Alternatively, low molecular weight surfactants can be added, but from a 'clean label' standpoint that is not desired.

The classical emulsification technologies are known to yield rather wide droplet size distribution with a typical coefficient of variation (CV) of $40 \%$, which makes the resulting emulsions physically less stable. ${ }^{3}$ Further, they are known for their high energy consumption and extremely low energy efficiency. As much as $95 \%$ of the energy input is lost as heat, which can lead to degradation of heat-sensitive ingredients.

In the last two decades, microstructured emulsification systems (i.e. membranes and microfluidic devices) have been introduced for producing monodisperse emulsions at low energy consumption. ${ }^{1,4,5}$ Unlike homogenization, in most microfluidic systems droplets are directly produced at their final size, at much lower energy input which allows the use of heat and shear-sensitive components.

Microfluidic emulsification devices can be divided into two categories based on the droplet formation mechanism: shear-based ${ }^{6-8}$ and spontaneous or interfacial tension driven..$^{9-11}$ In shear-based systems both phases need to be controlled to control the droplet size, while in spontaneous systems only the dispersed phase needs to be controlled. For an overview of microfluidic emulsification systems, we refer the interested reader to recent reviews. ${ }^{1,4,5,12}$

In the current study we consider a spontaneous emulsification system, the so-called EDGE device. It differs from other microfluidic techniques because multiple droplets are generated from one droplet formation unit. Because of its specific layout, which is 
presented in greater detail in the experimental section, EDGE devices can be used to chart the effect of component-surface interactions. For droplet formation, it is crucial that the surfaces of the droplet formation units are wetted by the continuous phase, and the wettability remains unchanged over time. Wettability can be influenced by the interaction of both surfactants and oils with the surface, and this interaction can, particularly on charged surfaces, be very complex. For o/w emulsification with silicon microchannels, Kobayashi et al. ${ }^{13}$ showed that monodisperse emulsions could be prepared successfully using anionic and non-ionic surfactants, while cationic surfactants resulted in either polydisperse emulsions (i.e. non-uniform wettability) or continuous outflow of the dispersed phase (i.e. wetting of the surface by the dispersed phase). According to these authors, the nature of the hydrophilic group of the surfactant is responsible for the observed difference. This pioneering study clearly indicates the importance of choosing the right surface-surfactant combination for successful emulsification.

As mentioned previously proteins are widely used as emulsifiers, and their adsorption onto solid/liquid interface will influence droplet formation in microfluidic (EDGE) devices. Protein adsorption is complex and determined by, amongst others, charge and hydrophobic interactions. Besides, structural rearrangements and dehydration of the solid surface may play a role. ${ }^{14}$ Globular proteins, as used in this study, adsorb to a large variety of surfaces (i.e. hydrophilic/hydrophobic) even at unfavourable electrostatic conditions.

There are only few studies that used proteins in microfluidic emulsification devices. Van Dijke et al. ${ }^{2}$ reported successful preparation of emulsions using whey protein concentrate and skim milk in EDGE devices. With straight-through microchannels, Saito et al. ${ }^{15}$ could prepare monodisperse emulsions when using bovine serum albumin (BSA), $\beta$-lactoglobulin ( $\beta$-lac), soybean flour, and whey protein, while this was not possible with $\gamma$-globulin, lysozyme and egg white protein. These authors related the differences to net electrical charges of the proteins, which is in line with the explanation given for low molecular weight surfactants by Kobayashi et al. ${ }^{13}$

In our view, it is not only the charge effect that needs to be considered for wettability change, but rather the interactions of surface active components and oils with interfaces. However, this aspect has not been considered yet in microfluidics literature, 
and it is expected that the scattered and contradicting opinions in literature on the right combinations of emulsion components and construction materials are at least partly caused by this. Therefore, in this work we used rigorously cleaned glass microfluidic EDGE chips, to systematically investigate emulsification with various oil emulsifier combinations. From the observations, we could deduce guidelines for successful operation, identifying combinations of construction material and ingredients that can safely be used.

\subsection{Experimental}

\subsubsection{Chemicals}

For the preparation of o/w emulsions, hexadecane $\left(\mathrm{C}_{16} \mathrm{H}_{34}\right.$, ReagentPlus ${ }^{\circledR}$, 99\%, SigmaAldrich), viscous paraffin (MERCK) and sunflower oil purchased from a local supermarket were used as dispersed phases. Sunflower oil was filtered through 0.45 $\mu \mathrm{m}$ filters before use. As continuous phases, $0.5 \% \mathrm{w} / \mathrm{w}$ sodium dodecyl sulphate (SDS) and $2 \% \mathrm{w} / \mathrm{w}$ Tween 20 solutions, and $5 \% \mathrm{w} / \mathrm{w}$ solutions of several proteins were used: whey protein isolate ( $>90 \%$, BiPRO, Davisco), which consists of $72 \% \beta$-lactoglobulin, $24 \%$ a-lactalbumin, and 4\% BSA; calcium-depleted a-lactalbumin (>95\%, Davisco); $\beta$-lactoglobulin ( $>95 \%$, obtained by selective precipitation of commercial WPI); and bovine serum albumin (95\%, Sigma). All aqueous solutions were prepared using Ultrapure MilliQ water and filtered using $0.22 \mu \mathrm{m}$ filters. The $\mathrm{pH}$ of the protein solutions was $\sim 7$, and no adjustment was made unless otherwise stated.

\subsubsection{Design and fabrication of microchips}

The microfluidic EDGE chips were made of glass using deep reactive ion etching (DRIE) technique (Micronit Microfluidics, Enschede, The Netherlands). Fig. 2.1 depicts the layout of the microchips and the droplet formation unit with its respective dimensions; the chips consist of five identical shallow plateaus of $2 \mu \mathrm{m}$ deep (black rectangles on the left) bridging the dispersed and continuous phase (meandering) channels that are $175 \mu \mathrm{m}$ deep and $400 \mu \mathrm{m}$ wide. The shallow plateaus and deep channels were etched into two separate glass substrates which were afterwards bonded together. The closed chips were oxidized to make them hydrophilic and suitable for o/w emulsification. 


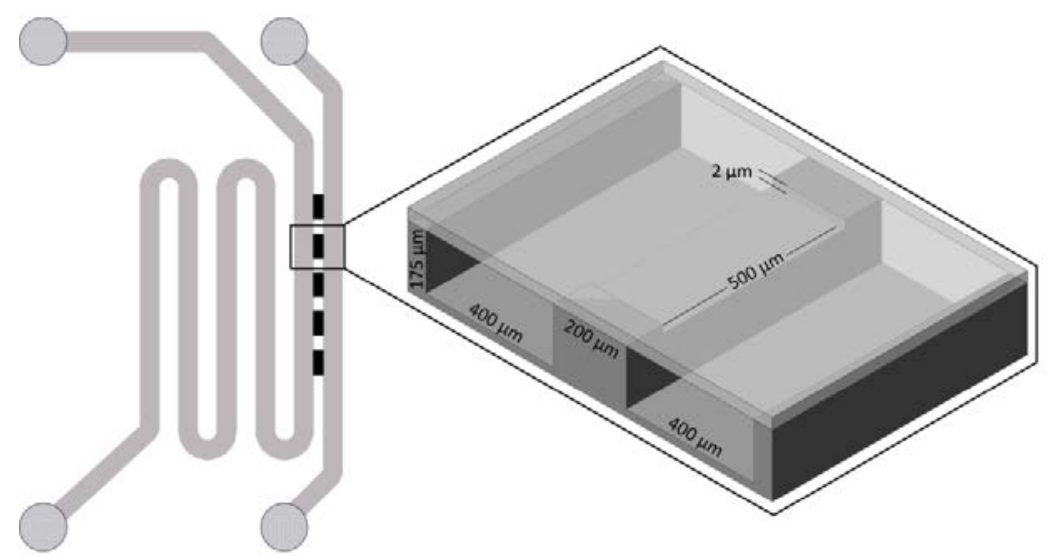

Fig. 2.1 The layout of EDGE microchips consisting of five identical plateaus with dimensions of $200 \times 500 \times 2 \mu \mathrm{m}$ (length $\times$ width $\times$ height), each separated by $300 \mu \mathrm{m}$ bonding space. The plateaus are positioned between two deep channels which were 175 $\mu \mathrm{m}$ deep and $400 \mu \mathrm{m}$ wide.

\subsubsection{Cleaning of microchips}

Before their first use, microchips were placed in a furnace and baked at $550{ }^{\circ} \mathrm{C}$ for 2 hours. To clean the microchips after use, they were flushed with ethanol first and sonicated for an hour in piranha solution $\left(\mathrm{H}_{2} \mathrm{SO}_{4} 96 \%-\mathrm{H}_{2} \mathrm{O}_{2} 33 \%\right.$ mixture, 3:1 v/v ratio).

\subsubsection{Experimental setup and emulsification}

The microchip was placed in a Fluidic Connect PRO chip holder (Micronit Microfluidics, Enschede, The Netherlands), and the channel inlets and outlets of both phases were connected to the outside world through 1/16" OD PEEK tubing with an inner diameter of $0.030 "$. Both phases were introduced into the chip using a microfluidic flow control system (Elveflow ${ }^{\oplus}$, Paris, France). Owing to the design of the EDGE devices, the pressure drop inside the channels was $\sim 1$ mbar (negligible compared to that on the plateau), and because of this, all the plateaus operated at the same pressure drop. First the continuous phase (i.e. emulsifier solution) was fed into the chip through the respective channel and run for half an hour to allow emulsifiers to reach equilibrium on the plateau surface. Then, the oil was pushed through the dispersed phase channel, and 
the channel outlet was blocked after a steady oil flow developed. In this way, the continuously supplied oil was directed onto the plateau, through which it ended up in the continuous phase channel in the form of droplets. The formed droplets were carried to the channel exit by the continuous phase flow (please note that no crossflow is needed for droplet formation in EDGE emulsification). To ensure stable operation prior to analysis, the experiment was run for 5-10 minutes for each pressure applied to the dispersed phase, which henceforth will be referred to as 'applied pressure'.

During emulsification the microchip was placed on a microscope stage, and the droplet formation process was observed via a high-speed camera (MotionPro HS-4, IDT Inc., Tallahassee, FL, USA) connected to the microscope (Axiovert 200 MAT, Carl Zeiss B.V., Sliedrecht, The Netherlands). The microscope was equipped with a set of objectives up to $100 \times$ and an optavar with factors of $1 \times, 1.6 \times$ and $2.5 \times$, and the highspeed camera was able to acquire images at up to $5130 \mathrm{fps}$ at the maximum resolution of $512 \times 512$. The combination of frame rate and magnification was limited by the amount of the light, so the best combination was sought to acquire images for post processing.

\subsubsection{Image analysis}

The size and size distribution of the droplets were determined using image analysis software. The images used for sizing were always acquired at the same magnification to eliminate measurement errors inherent to pixel distribution. For each process condition, up to 50 droplets were analysed and averaged, which is an established procedure in our lab for the analysis of monodisperse droplets. The droplet size distribution was expressed in coefficient of variation, CV, which is defined as:

$\mathrm{CV}=\frac{\sigma}{d_{d r}} \times 100$

where $\sigma$ is the standard deviation and $d_{d r}$ is the number-average droplet diameter. Droplet formation frequency was determined by analysing 1000 subsequent frames that were acquired at 500-5000 fps. 


\subsection{Results and discussion}

\subsubsection{Emulsification behaviour}

Before discussing the results, it is important to describe the main characteristics of EDGE devices. Monodisperse droplets start forming at break-through pressure, and they become polydisperse at blow-up pressure; between these pressures, the droplet diameter is constant. At high viscosity ratios ( $>3)$, the droplet diameter is six times the plateau height; at lower viscosity ratios the droplet size increases with decreasing viscosity ratio. ${ }^{16}$ The results of low molecular weight surfactants are discussed first, followed by proteins. For the reader's convenience the results are presented in subsections which are in fact interdependent as will be made clear in the discussion.

\subsubsection{Low molecular weight surfactants}

Fig. 2.2 shows the average diameter of hexadecane and sunflower oil droplets as a function of applied pressure in the presence of Tween 20 and SDS. When using Tween 20, monodisperse hexadecane and sunflower oil droplets were obtained; the pressure range for sunflower oil was narrower than that for hexadecane. With SDS, monodisperse hexadecane droplets were stably produced, but sunflower oil droplet formation was only possible for a very narrow pressure range (40-60 mbar). Besides, sunflower oil droplets were larger than expected (15 compared to $12 \mu \mathrm{m}$ ) and more polydisperse; therefore, sunflower oil/SDS cannot be considered as a successful combination but is included in Fig. 2.2 to make the overview complete.

We attempt to explain the observed behaviour by taking the interaction of surfactants and oils with solid surfaces as a starting point. As mentioned, droplet formation units need to be wetted by the continuous phase for successful emulsification. It is known that SDS molecules do not adsorb tightly onto the hydrophilic glass surface, and can be displaced easily. When used with hexadecane, which does not interact strongly with hydrophilic glass surface, SDS molecules stay on the surface and enable formation of monodisperse droplets. Triglycerides, which are the main constituents of sunflower oil, can form tightly bound films on oxide surfaces such as glass. When given sufficient time, sunflower oil is able to replace SDS molecules from the glass surface and hinders monodisperse droplet formation. This is even more prominently visible when 
sunflower oil is introduced before SDS, making monodisperse droplet formation impossible.

The formation of an oil film in time may also explain contradicting results from literature, which report success and failure for seemingly the same (vegetable) oil/emulsifier combinations. Related to this, Sugiura et al. ${ }^{17}$ found for microchannel emulsification that SDS concentrations $<0.1 \%$ lead to larger polydisperse triolein droplets, and they accounted this to slow diffusivity of the surfactant. Although this explanation can be valid, we think that oil film formation is a more likely explanation (see also later sections).

Unlike SDS, Tween 20 can adsorb tightly onto the glass and cannot be displaced by oil, making the pre-adsorbed surfactant layers the real contact surface that favoured stable droplet formation for both oils (Fig. 2.2). Our findings in regard to surface-surfactant interactions are in line with the results of Maan et al. ${ }^{18}$ who noted changes in droplet formation when applying surface modification in EDGE microchips through selfassembled monolayers (SAMs). For instance, they observed a wider pressure stability with aldehyde terminated SAMs (more hydrophilic), and they did not observe stable droplet formation with phenyl terminated SAMs (more hydrophobic).

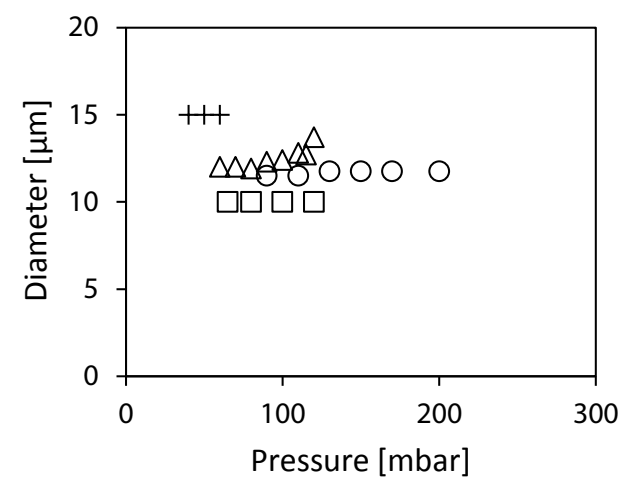

Fig. 2.2 Effect of oil/surfactant combinations on average droplet size and operational pressure stability: hexadecane/SDS $(\Delta)$, hexadecane/Tween $20(0)$, sunflower oil/SDS (+), sunflower oil/Tween $20(\square)$. The CVs for the presented data points are below $10 \%$, with the exception of sunflower oil/SDS for which the presented data have a CV $<20 \%$. 


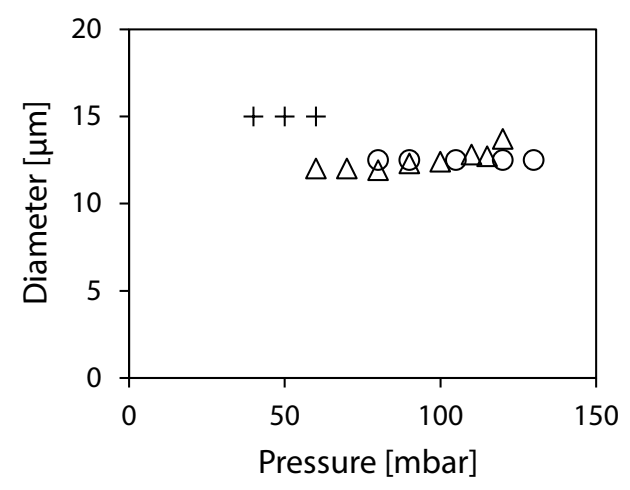

Fig. 2.3 Effect of oil on average droplet size as a function of applied pressure in the presence of $0.5 \%$ SDS solution as continuous phase; sunflower oil $(+)$, hexadecane $(\Delta)$, paraffin-hexadecane mixture (०). The CVs for the presented data points are below $10 \%$.

To check whether the unusually large sunflower oil droplets that were formed in the presence of SDS would also be found for an oil with similar viscosity, we tested a mixture of hexadecane and liquid paraffin. As shown in Fig. 2.3, the average droplet size and pressure range were very different from that found for sunflower oil. In fact, the droplet size and pressure range were comparable to those obtained for hexadecane, showing that the oil and its interactions with surfactant and surface determine successful operation. This is further investigated in the following section.

\subsubsection{Surface pre-treatment}

To further elucidate the influence of oil-emulsifier-surface interactions, we re-ran sunflower oil/SDS experiments using microchips that were first flushed with $5 \%$ WPI solution for half an hour, allowing protein to adsorb onto channel surfaces. Proteins adsorb rather irreversibly to the glass surface and under the conditions tested here this would result in a hydrophilic surface wetted by the continuous phase. For both untreated and pre-treated microchips, the average droplet sizes obtained as a function of applied pressure are shown in Fig. 2.4. When using pre-treated microchips, monodisperse sunflower oil droplets of $12 \mu \mathrm{m}$ could be prepared at a reasonable 


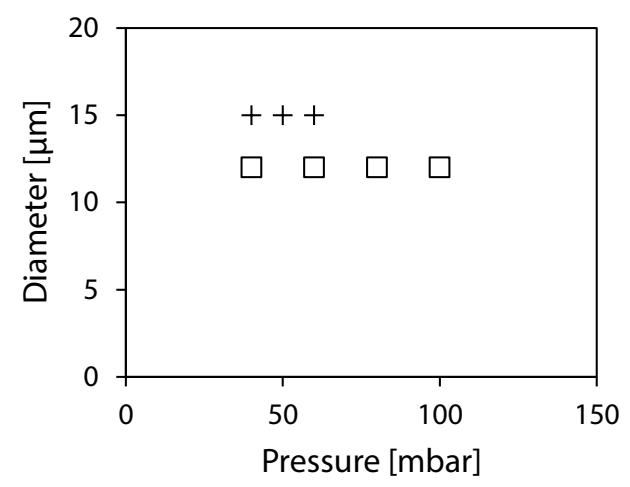

Fig. 2.4 Effect of device surface on droplet formation behaviour for sunflower oil/SDS combination; untreated glass chips $(+)$, glass chips pre-treated with WPI ( $\square$ ). Only the droplets prepared with surface-modified microchips were monodisperse, with CVs below $10 \%$.

pressure range, confirming that the larger polydisperse droplets obtained with untreated microchips were caused by the oil-surface interactions. This indicates once again that choosing the right combination is essential for successful emulsification. In this respect, surface modification methods, which are permanent and able to prevent undesired interactions, are of great relevance. ${ }^{18-21}$

\subsubsection{Proteins as emulsifiers}

We now discuss emulsification with various proteins; in Fig. 2.5 the average sizes of hexadecane (Fig. 2.5a) and sunflower oil (Fig. 2.5b) droplets were plotted as a function of applied pressure. Monodisperse droplets of both oils were successfully produced when using $5 \%$ solutions of $\mathrm{WPI}, \mathrm{a}$-lac, $\beta$-lac and BSA at neutral $\mathrm{pH}$. Stable droplet formation was maintained over time, meaning that all proteins formed a hydrophilic film upon adsorption on the solid surface, and more importantly they could not be displaced by the dispersed phase during emulsification.

As with the surfactants, $12 \mu \mathrm{m}$ hexadecane and $10 \mu \mathrm{m}$ sunflower oil droplets were produced with proteins. With proteins droplet formation started at higher pressures, 

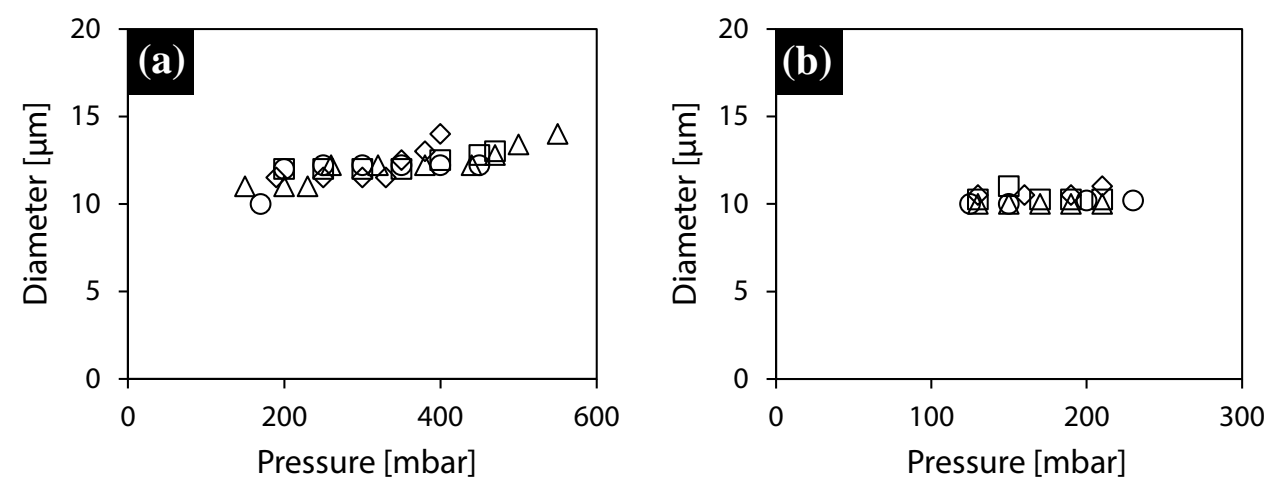

Fig. 2.5 Average droplet diameters as a function of applied pressure when using WPI (०), a-lac $(\Delta), \beta$-lac $(\square)$, and BSA $(\diamond)$ as emulsifiers; (a) hexadecane, and (b) sunflower oil. The CVs for the presented data points are below $10 \%$.

which was due to the higher Laplace pressures in the presence of proteins compared to SDS and Tween 20. ${ }^{2}$ The same also holds for the different starting pressures for different oils; with hexadecane having the higher interfacial tension of the two, droplet formation started at higher pressures. In general, all proteins resulted in wider pressure ranges than surfactants, which is more noticeable for hexadecane.

For sunflower oil emulsions all proteins performed similarly (Fig. 2.5b), while some differences were noted for hexadecane emulsions (Fig. 2.5a), as discussed next. Very similar droplet sizes and pressure ranges were obtained with $\beta$-lac and WPI, which is logical given the fact that $\beta$-lac is the main constituent of WPI. With a-lac, and BSA slightly different droplet sizes and pressure ranges were obtained, therewith indicating the importance of ingredient choice in relation to the process stability. Since the interaction of proteins with surfaces also depends on their charge, that is investigated next for BSA which is the most used protein in adsorption studies.

\subsubsection{Charge effects}

Depending on the $\mathrm{pH}$ of the solution, adsorbed proteins could be either tightly or loosely bound to the surfaces. Besides, the lateral interactions between molecules in adsorbed layers can change drastically with $\mathrm{pH}$. For our experimental system that could 
imply very different emulsification behaviour. We investigated this through emulsifying hexadecane and sunflower oil with BSA solutions at $\mathrm{pH} 3,4.8$ and 7; $\mathrm{pH} 4.8$ corresponds to the isoelectric point. Fig. 2.6 shows the average droplet sizes as a function of applied pressure.

At $\mathrm{pH} 3$ monodisperse hexadecane droplets were prepared at similar pressure stabilities and sizes as $\mathrm{pH} 7$ (Fig. 2.6a); however, it was not possible to prepare monodisperse sunflower oil droplets (not shown in the figure). At this $\mathrm{pH}$ the interaction between protein and surface is weak, and the adsorbed proteins can be replaced by sunflower oil that has strong interaction with the surface (leading to irregular droplet formation). This was not the case for hexadecane for which the interaction with the surface is not that strong as shown previously (hexadecane/SDS).

At the isoelectric point, much larger $(19 \mu \mathrm{m})$ but surprisingly very monodisperse droplets were found for both oils (Fig. 2.6a-b). Two possible explanations can be postulated to account for this observation: at the isoelectric point BSA is a poor emulsifier and this could have caused larger droplets, and/or other mechnanism(s) could be involved in droplet formation.
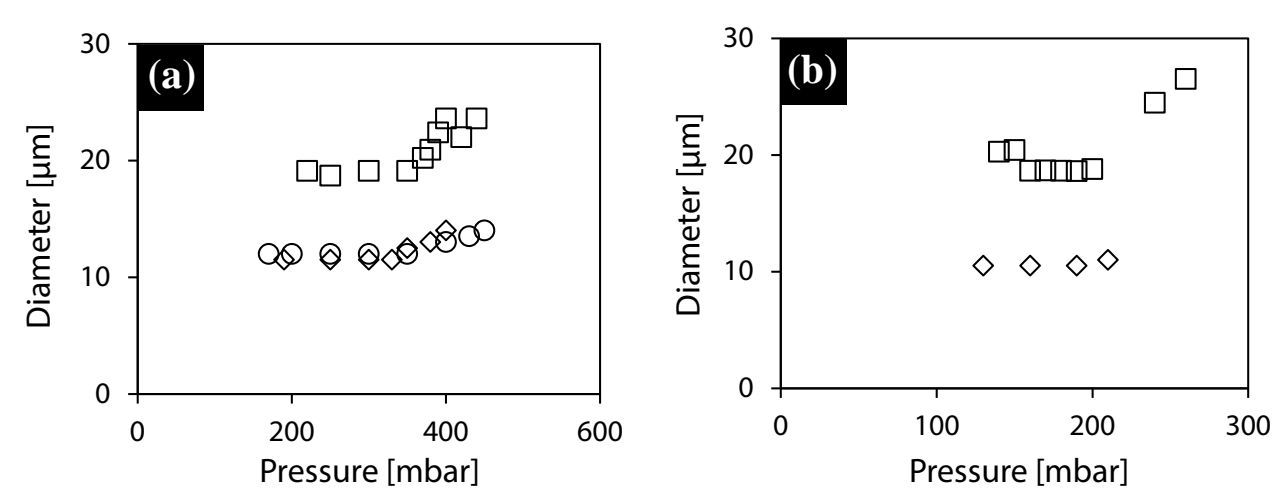

Fig. 2.6 Average diameters of monodisperse droplets produced with 5\% BSA solutions at $\mathrm{pH} 3(\circ), 4.8(\square)$ and $7(\diamond) ;(a)$ hexadecane and (b) sunflower oil. The CVs for the presented data points are below $10 \%$. 
In line with our findings for sunflower oil, Saito et al. ${ }^{15}$ could prepare monodisperse soybean oil droplets through microchannels using BSA at $\mathrm{pH}$ values above the isoelectric point, while they could not do so below the isoelectric point. The difference with our work could possibly be attributed to the different droplet formation geometries used; the much smaller microchannels are expected to be more sensitive to wettability changes, while EDGE devices are less sensitive to local instabilities.

\subsubsection{Pressure stability and system productivity}

The pressure range in which monodisperse droplet formation takes place can be narrower or wider depending on the components used. The pressure stability is not only important for operational stability but also for the productivity of the system. In general, the wider the pressure stability, the higher the droplet formation frequency will be. In this section we compare the frequencies at the maximum pressures as presented in Table 2.1.

We first evaluate the productivity of hexadecane in the presence of different emulsifiers (i.e. surfactants and proteins). With all protein systems (except BSA at pH 7) droplets were generated at much higher frequencies than with any of the surfactant systems, and this was caused by the remarkably wider pressure stabilities attained with protein systems (Table 2.1). The highest frequency was obtained with a-lac $(5500 \mathrm{~Hz})$, which is considerably higher than those measured for any other system. Although there is a link between the pressure stability and droplet formation frequency, differences between proteins cannot be explained solely based on that. For example, $\alpha$-lac at 440 mbar yielded more than twice as many droplets as $\beta$-lac at 470 mbar. Similarly, the droplet formation frequency obtained with BSA at 400 mbar was comparable to those obtained with SDS and Tween 20 at much lower pressures $(<200$ mbar). Therefore, we can conclude that the droplet formation frequency is also related to the structure and adsorption behaviour of the proteins at the solid/liquid and liquid/liquid interfaces. This inference is supported by the significantly higher productivity of hexadecane droplets using BSA at $\mathrm{pH} 3$ compared to $\mathrm{pH} 7$.

Compared to hexadecane, sunflower oil droplets formed at much lower rates, and this was a result of its much higher viscosity (by a factor of 15) and lower pressure ranges. Similar frequencies were obtained with all proteins, the only exception being BSA that 
gave the lowest frequency also for hexadecane. With Tween 20, the frequencies were similar as found with proteins, and SDS could not be used with sunflower oil as stated in earlier sections.

In summary, Table 2.1 clearly illustrates the differences in pressure stabilities and droplet formation frequencies, for which we hold both the interaction of the surfactant or protein with the solid/liquid and liquid/liquid interface responsible. Besides, the interaction of the oil with the solid/liquid interface is of great relevance for stable operation; strong interaction of the oil with the solid surface leads to irregular droplet formation. For this reason, when emulsifying an oil that has strong interaction with the surface, the emulsifier should be chosen such that it cannot be replaced from the surface by the oil.

Table 2.1 Maximum droplet formation frequencies obtained with different oil/emulsifier combinations.

\begin{tabular}{|c|c|c|c|c|c|c|}
\hline \multirow[b]{3}{*}{ Emulsifier } & \multicolumn{3}{|c|}{ Hexadecane } & \multicolumn{3}{|c|}{ unflower oil } \\
\hline & \multirow[b]{2}{*}{$\begin{array}{l}\text { Pressure } \\
\text { Range } \\
\text { [mbar] }\end{array}$} & \multicolumn{2}{|c|}{ @ maximum pressure } & \multirow[b]{2}{*}{$\begin{array}{l}\text { Pressure } \\
\text { Range } \\
\text { [mbar] }\end{array}$} & \multicolumn{2}{|c|}{ @ maximum pressure } \\
\hline & & $\begin{array}{l}\text { Diameter } \\
{[\mu \mathrm{m}]}\end{array}$ & $\begin{array}{l}\text { Frequency } \\
\text { per } 500 \mu \mathrm{m} \\
\text { plateau } \\
\text { width }[\mathrm{Hz}]\end{array}$ & & $\begin{array}{l}\text { Diameter } \\
{[\mu \mathrm{m}]}\end{array}$ & $\begin{array}{l}\text { Frequency } \\
\text { per } 500 \mu \mathrm{m} \\
\text { plateau } \\
\text { width [Hz] }\end{array}$ \\
\hline$\overline{S D S}$ & $60-115$ & 13 & 160 & $40-60$ & 15 & 12 \\
\hline $\mathrm{SDS} / \mathrm{WPI}^{a}$ & & & & $40-100$ & 12 & 67 \\
\hline Tween 20 & $90-200$ & 12 & 200 & $65-120$ & 10 & 50 \\
\hline WPI & $170-450$ & 12 & 1221 & $125-220$ & 10 & 28 \\
\hline a-lac & $150-550$ & 14 & 5500 & $130-210$ & 10 & 33 \\
\hline$\beta$-lac & $190-470$ & 13 & 1073 & $130-210$ & 10 & 28 \\
\hline BSA pH 7 & $190-400$ & 14 & 150 & $130-210$ & 11 & 8 \\
\hline BSA@pl & $220-440$ & 24 & 526 & $150-260$ & 26 & 31 \\
\hline BSA pH 3 & $190-450$ & 14 & 1255 & Polydispe & & - \\
\hline
\end{tabular}




\subsection{Conclusions}

We have shown that interactions between the oil, emulsifier and surface are decisive for the droplet formation behaviour in microfluidic EDGE devices, and we expect this also to be true for other microfluidic devices. Compared to surfactants, significantly higher pressure stabilities and productivities were achieved when proteins were used as emulsifiers. The performance of WPI suggests that pure proteins are not necessary for successful emulsification, which is advantageous from an industrial perspective. We strongly believe that our findings provide new leads for successful emulsification using microfluidic devices and for their upscaling, which requires consideration of construction material, product formulations, and throughput as a 'total package', not as individual aspects, as is common practice nowadays.

\section{References}

1 K. Schroën, O. Bliznyuk, K. Muijlwijk, S. Sahin and C. C. Berton-Carabin, Curr. Opin. Food Sci., 2015, 3, 33-40.

2 K. C. van Dijke, K. Schroën, A. van der Padt and R. Boom, J. Food Eng., 2010, 97, 348-354.

3 M. Saito, L. J. Yin, I. Kobayashi and M. Nakajima, Food Hydrocolloids, 2006, 20, 1020 1028.

4 A. A. Maan, K. Schroën and R. Boom, J. Food Eng., 2011, 107, 334-346.

5 G. T. Vladisavljević, I. Kobayashi and M. Nakajima, Microfluid. Nanofluid., 2012, 13, 151 178.

6 S. L. Anna, N. Bontoux and H. A. Stone, Appl. Phys. Lett., 2003, 82, 364-366.

7 D. R. Link, S. L. Anna, D. A. Weitz and H. A. Stone, Phys. Rev. Lett., 2004, 92, 054503.

8 S. Van Der Graaf, M. L. J. Steegmans, R. G. M. Van Der Sman, C. G. P. H. Schroën and R. M. Boom, Colloids Surfaces A Physicochem. Eng. Asp., 2005, 266, 106-116.

9 T. Kawakatsu, Y. Kikuchi and M. Nakajima, J. Am. Oil Chem. Soc., 1997, 74, 317-321.

10 I. Kobayashi, M. Nakajima, K. Chun, Y. Kikuchi and H. Fujita, AlChE J., 2002, 48, 16391644.

11 K. C. Van Dijke, G. Veldhuis, K. Schroën and R. M. Boom, AIChE, 2009, 56, 833-836.

12 A. A. Maan, A. Nazir, M. K. I. Khan, R. Boom and K. Schroën, J. Food Eng., 2015, 147, 1-7.

13 I. Kobayashi, M. Nakajima and S. Mukataka, Colloids Surfaces A Physicochem. Eng. Asp., 2003, 229, 33-41. 
14 C. A. Haynes and W. Norde, Colloids Surfaces B Biointerfaces, 1994, 2, 517-566.

15 M. Saito, L. J. Yin, I. Kobayashi and M. Nakajima, Food Hydrocolloids, 2005, 19, 745-751.

16 K. van Dijke, R. de Ruiter, K. Schroën and R. Boom, Soft Matter, 2010, 6, 321-330.

17 S. Sugiura, M. Nakajima, T. Oda, M. Satake and M. Seki, J. Colloid Interface Sci., 2004, 269, 178-185.

18 A. A. Maan, S. Sahin, L. H. Mujawar, R. Boom and K. Schroën, J. Colloid Interface Sci., 2013, 403, 157-159.

19 A. Arafat, M. Giesbers, M. Rosso, E. J. R. Sudhölter, K. Schroën, R. G. White, Y. Li, M. R. Linford and H. Zuilhof, Langmuir, 2007, 23, 6233-6244.

20 A. Arafat, K. Schroën, L. C. P. M. De Smet, E. J. R. Sudhölter and H. Zuilhof, J. Am. Chem. Soc., 2004, 126, 8600-8601.

21 M. Rosso, M. Giesbers, A. Arafat, K. Schroën and H. Zuilhof, Langmuir, 2009, 25, $2172-$ 2180. 



\section{Partitioned EDGE devices for high throughput production of monodisperse emulsion droplets with two distinct sizes}




\section{Abstract}

We present a novel microfluidic EDGE (Edge-based Droplet GEneration) device with regularly spaced micron-sized partitions, which is aimed at upscaling of o/w emulsion preparation. By this means, remarkably higher pressure stability was obtained, and two orders of magnitude higher droplet formation frequency was achieved compared to regular EDGE devices. Interestingly, we observed two different monodisperse droplet formation regimes for plateaus that were 2 micrometres in height, and to the best of our knowledge, no other microfluidic device has this ability. The average diameters of the droplets were 9 and $28 \mu \mathrm{m}$, both with a coefficient of variation (CV) below 5\%. Based on the experimental throughput and a plausible mass parallelization scenario, the amount of hexadecane that can be emulsified is estimated to be between 6 and 25 $\mathrm{m}^{3} \mathrm{~m}^{-2} \mathrm{~h}^{-1}$ depending on the required droplet size. With its high throughput potential and ability to produce uniform droplets of two different sizes, the partitioned EDGE device is promising for industrial emulsion production. 


\subsection{Introduction}

Emulsions are the basis of many products ranging from food to pharmaceuticals, cosmetics and chemicals amongst others. In general, conventional emulsification technologies can produce emulsions at high throughput but utilize brute force and can degrade heat and shear sensitive formulations. ${ }^{1}$ They are highly energy inefficient, with energy utilization for droplet formation reported to be as low as 1-5\%, and have poor control over the droplet size and size distribution. ${ }^{2,3}$

In comparison, microstructured emulsification systems (i.e. membranes and microfluidic devices) are very mild, have outstanding control on droplet size and distribution and offer great potential for the design of new products with unique features and/or functionality. ${ }^{4}$ To be complete, we like to mention that microfluidics can also be used to investigate other aspects related to emulsification such as the (dynamic) interfacial tension, which is linked with the droplet size, ${ }^{5}$ and emulsion stability. ${ }^{6}$

For emulsion production, most of these microstructured systems, maybe with the exception of membranes, have not been used at large-scale. In order for a new emulsification technology to be accepted, it needs to be able to handle considerable product flows, and droplet diameters need to be smaller than $10 \mu \mathrm{m}$ in most applications. ' Therefore, various efforts have been made to upscale microfluidic devices capable of producing monodisperse emulsions; here we summarize these attempts and refer the interested reader to some recent reviews for a broader overview..$^{8-10}$

Shear-based systems (T- and Y-junctions and flow focusing devices) allow very high frequencies from a single unit; however, mass parallelization of these systems is complex due to the necessity of very precise control over both phases at single droplet formation unit level in order to achieve uniform droplet size. ${ }^{4,11,12}$ Besides, when operating in parallel, cross-talk between neighbouring droplet formation units may occur, $^{13}$ in particular for the preparation of droplets smaller than $10 \mu \mathrm{m}$ in diameter. This greatly influences productivity and droplet monodispersity.

Interfacial tension-driven spontaneous emulsification devices ${ }^{14-16}$ (grooved and straight-through microchannels, and EDGE systems) require the control of dispersed 
phase only and are relatively easy to upscale through mass parallelization (in spite of their lower frequency per droplet formation unit compared to shear-based systems). Laboratory-scale parallelization of microchannels (MCs) was realized for $10 \mu \mathrm{m}$ droplets ${ }^{17}$ and larger ones up to $300 \mu \mathrm{m} .{ }^{18,19}$ However, preparation of smaller droplets, which requires smaller channels, could not be scaled out that successfully; the percentage of active MCs dropped dramatically and could be as low as a few percent. ${ }^{7}$ This is a consequence of local pressure differences and consequent interplay between the active and inactive channels, as described earlier by Abrahamse et al. $^{13}$ for microsieve emulsification.

The fraction of active pores or microchannels is influenced by a number of factors, such as porosity, channel geometry and dispersed phase viscosity. Reducing the porosity helps to increase the fraction of active pores albeit at the expense of larger sieve areas; alternatively, the devices can be made thicker to improve pore activation, although this requires higher pressures to produce emulsions. ${ }^{20,21}$ Considering the effect of channel geometry, symmetric straight-through oblong MCs outperform the circular ones but require a minimum aspect ratio of 3 for successful preparation of monodisperse droplets. ${ }^{22}$ Moreover, asymmetric straight-through MCs (with a slit connected to a circular channel) outperform the symmetric ones and allow emulsification of low viscosity oils, although the proportion of active channels is higher for higher dispersed phase viscosity. ${ }^{18,23}$ These authors attributed this to the higher upstream pressure induced by higher viscosity, which is more likely to overcome the capillary pressure, but it could also be explained as an additional resistance against flow in higher viscosity liquids which leads to better pore activation following the argument of Gijsbertsen-Abrahamse and co-workers. ${ }^{20}$

As compared to MCs, microfluidic EDGE systems introduced by the authors' group are less sensitive to pressure fluctuations due to the inherent geometry of this droplet formation unit, the so-called plateau which is able to produce multiple monodisperse droplets simultaneously. ${ }^{16}$ The system was parallelized successfully in plane on a chip with $100 \%$ efficiency of 196 droplet formation units, which was a promising start. ${ }^{24}$ Increasing the number of droplet formation points and overall droplet formation frequency are possible ways to increase the system productivity. The frequency increases with increased pressure stability, which can be achieved by imparting extra resistance on the plateau, as was seen by Maan and co-workers for the preparation of 
o/w and w/o emulsions using semi-metal EDGE systems. ${ }^{25,26}$ They observed fingering behaviour of the dispersed phase flowing on the plateau, which added to the overall resistance and resulted in a higher pressure stability. This was an important finding from an operational stability perspective; however, from a productivity point of view, the higher pressure stability was only relevant if it did not reduce the number of droplet formation points. ${ }^{25,26}$

The best results that were obtained by Maan and colleagues did show an increase in overall productivity, but it also left room for improvement. This inspired us to look into new plateau designs with engineered partitions to distribute and direct the flow on the plateau more evenly aiming at higher number of droplet formation points and ideally higher droplet formation frequency. We tested this experimentally for the preparation of oil-in-water emulsions with droplets $<10 \mu \mathrm{m}$. In particular, we investigated the flow behaviour on the plateau and the characteristics of droplet formation. In addition, we checked whether the partitioned plateau design is suitable for the emulsification of low viscosity oils ( $<1 \mathrm{mPa}$ ). Finally, the results obtained from partitioned EDGE devices were compared with regular EDGE devices and other spontaneous emulsification systems, from which design suggestions for a large-scale device were made.

\subsection{Experimental}

\subsubsection{Chemicals}

For the preparation of o/w emulsions, MilliQ ultrapure water with 0.5 wt\% sodium dodecyl sulphate (SDS, Merck, Hohenbrunn, Germany) was used as the continuous phase. As the dispersed phase, hexadecane $\left(\mathrm{C}_{16} \mathrm{H}_{34}\right.$, ReagentPlus ${ }^{\circledR}$, 99\%) from SigmaAldrich (Germany) and decane $\left(\mathrm{C}_{10} \mathrm{H}_{22}, \geqslant 95 \%\right)$ from Fluka (Germany) were used. The viscosity of hexadecane and decane at $20^{\circ} \mathrm{C}$ are 3.47 and $0.92 \mathrm{mPa}$, respectively. ${ }^{27}$ Unless otherwise mentioned, all experiments were conducted with hexadecane.

\subsubsection{Chip design}

The EDGE microchips were constructed on glass substrates using the deep reactive ion etching (DRIE) technique (Micronit Microfluidics, Enschede, The Netherlands). Fig. 3.1 shows the layout of the microchips used in our experiments: five plateaus (black 
rectangles) are positioned in between the dispersed phase and continuous phase (meandering) channels.

In this work, two different microchips were used with respect to plateau designs, one with and one without partitions. The regular design was previously reported by van Dijke et al. ${ }^{16}$ and Maan et al. ${ }^{26}$ and is denoted by EDGE-R. The other one had plateaus with micron-sized partitions, the so-called micro-plateaus, and is called EDGE-P. Fig. 3.2 schematically illustrates the various elements of these microchips.

In the fabrication of these chips, the dispersed and continuous phase channels $(175 \mu \mathrm{m}$ deep and $400 \mu \mathrm{m}$ wide) were etched in one glass substrate and the $2 \mu \mathrm{m}$ deep shallow plateaus were etched in another one (more specifications can be found in Table 3.1). The etched substrates were then bonded together, and the chips were oxidized to ensure their hydrophilicity and through that suitability for o/w emulsification.

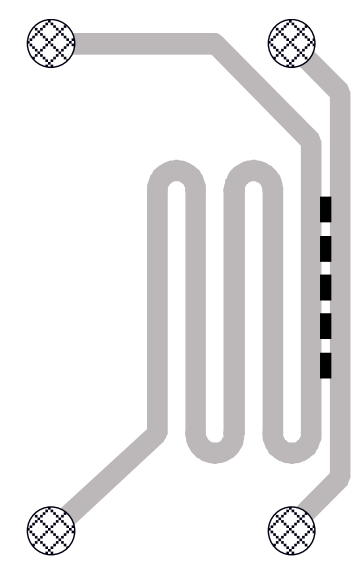

Fig. 3.1 The layout of EDGE microchips used, consisting of five shallow plateaus that are $2 \mu \mathrm{m}$ deep (black rectangles) placed between the dispersed and meandering continuous phase channels that are $175 \mu \mathrm{m}$ deep and $400 \mu \mathrm{m}$ wide. 

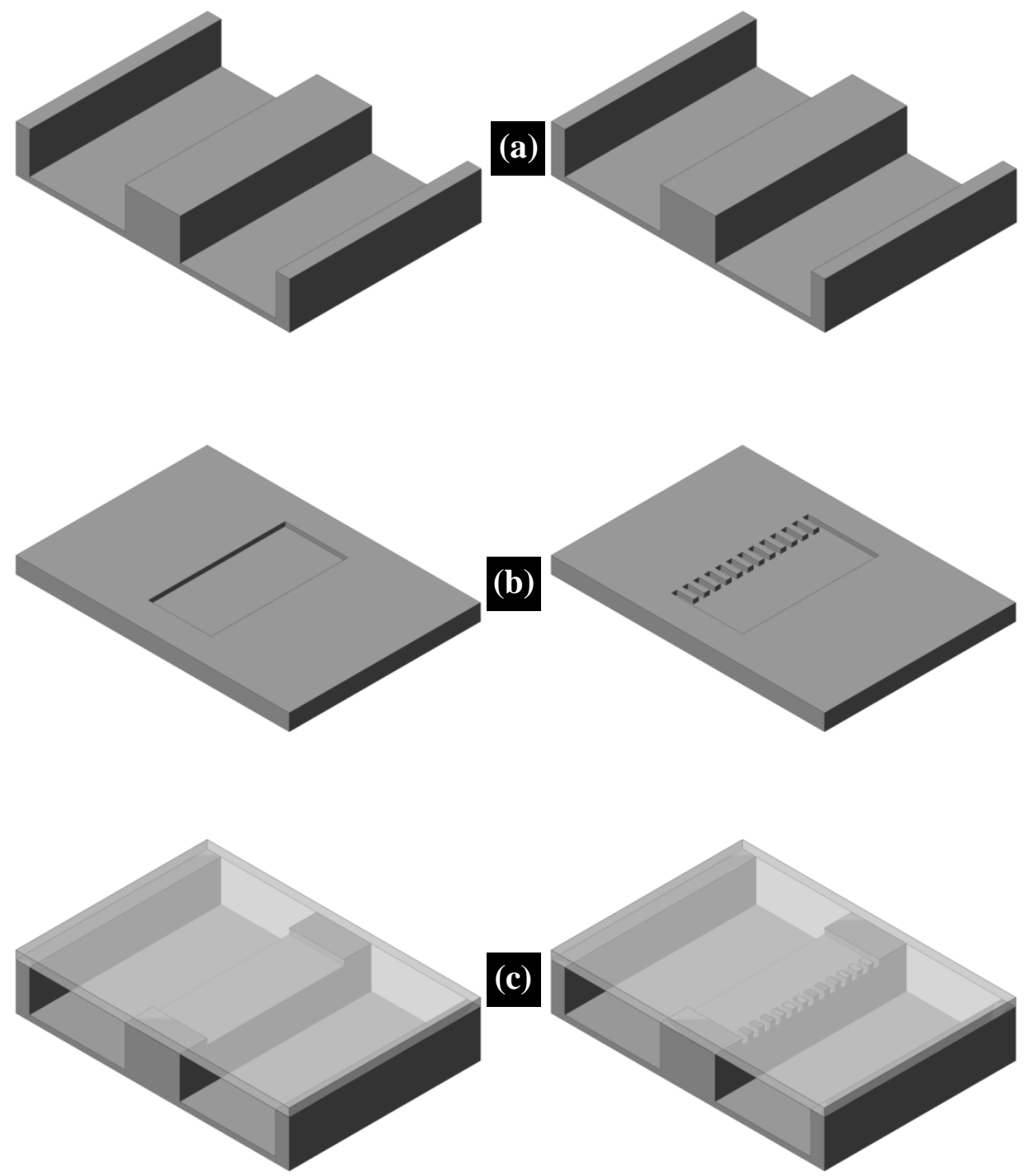

Fig. 3.2 Impression of the regular, EDGE-R (left), and partitioned, EDGE-P (right) microchips and their constituent elements. (a) Channels, $175 \mu \mathrm{m}$ deep and $400 \mu \mathrm{m}$ wide, were etched in the bottom plate, (b) plateaus, $2 \mu \mathrm{m}$ deep, were etched in the top plate, after which (c) the bottom and top plates were bonded together. In the figure, the dimensions are not drawn to scale. 
Table 3.1 Characteristics of (partitioned) plateaus and supply channels.

\begin{tabular}{lllll}
\hline & & Dimensions $[\mu \mathrm{m}]$ & & \\
\cline { 3 - 5 } Plateau & Number of & Micro-plateau & Main plateau & Channels \\
designs & micro-plateaus $[-]$ & {$[L \times W \times H]$} & {$[L \times W \times H]$} & {$[W \times H]$} \\
\hline EDGE-R & 0 & - & $200 \times 500 \times 2$ & $400 \times 175$ \\
EDGE-P & 33 & $30 \times 5 \times 2$ & $200 \times 500 \times 2$ & $400 \times 175$ \\
\hline
\end{tabular}

\subsubsection{Peripherals and emulsification procedure}

The microchip was placed in a Fluidic Connect PRO chip holder (Micronit Microfluidics, Enschede, The Netherlands) and all four holes of the chip (inlets and outlets of both phases, see Fig. 3.1) were connected to the outside world through 1/16" OD PEEK tubing with an inner diameter of 0.030". First the continuous phase was fed into the chip through the respective channel, and afterwards the oil was pushed through the dispersed phase channel. When the dispersed phase channel was filled and a steady flow developed, the channel outlet was blocked. By blocking the dispersed phase outlet, oil flowed continuously through the dispersed phase channel onto the plateau and ended up in the continuous phase channel in the form of droplets. For the injection of both phases into the chip, liquids in the respective reservoirs were pressurized through a digital pressure controller (Elveflow ${ }^{\circledR}$, Paris, France), which was operated by Elveflow ${ }^{\circledast}$ Smart Interface software (Elveflow ${ }^{\circledast}$, Paris, France). The accuracy of the set pressures was as low as 0.1 mbar. Depending on the dispersed phase pressure, the typical applied pressure for the continuous phase channel was between 1 and 8 mbar, enabling adequate flow inside the channel that removes the generated droplets.

During emulsification, the microchip was placed under a microscope that was equipped with a set of objectives up to $100 \times$, and an optavar with the factors of $1 \times$, $1.6 \times$ and 2.5× (Axiovert 200 MAT, Carl Zeiss B.V., Sliedrecht, The Netherlands). The droplet formation process was monitored via a high-speed camera (MotionPro HS-4, IDT Inc., Tallahassee, FL, USA) connected to the microscope. The high-speed camera was able to deliver images at up to $5130 \mathrm{fps}$ at the maximum resolution of $512 \times 512$. The combination of frame rate and magnification was limited by the amount of the 
light reaching the high-speed camera, so the best combination of both was sought. Before acquiring the images, the process was run for 5-10 minutes under the set conditions to ensure a stable operation. The acquired images were then analysed to characterize the droplet formation process.

\subsubsection{Chip cleaning}

Before their first use, chips were placed in a furnace and baked at $550{ }^{\circ} \mathrm{C}$ for 2 hours. To clean the chips after use, they were flushed with ethanol first and sonicated for an hour in piranha solution (a mixture of $\mathrm{H}_{2} \mathrm{SO}_{4} 96 \%$ and $\mathrm{H}_{2} \mathrm{O}_{2} 33 \%$ in 3:1 v/v ratio).

\subsubsection{Droplet size and size distribution}

The size distribution of the droplets was expressed in the form of coefficient of variation, $\mathrm{CV}$, which is defined as follows:

$\mathrm{CV}=\frac{\sigma}{d_{d r}} \times 100$

where $\sigma$ is the standard deviation of the droplet diameters and $d_{d r}$ is the numberaverage droplet diameter. The droplet diameters were measured using an image analysis software. For the analysis of very monodisperse droplets, 50 droplets were analysed for each process condition, which is an established procedure in our laboratory. For similarly sized droplets, the images were acquired at the same magnification to eliminate measurement errors inherent to pixel distribution.

\subsection{Results and discussion}

We pioneered the characteristics of the EDGE chips with partitioned plateau designs in this work. Among others, we investigated the filling behaviour of the plateaus, pressure stability, number of droplet formation points and frequencies and eventually compared the overall performance to that of regular plateaus. We round off by discussing an upscaling strategy. 


\subsubsection{Visualisation of various droplet formation phases}

\section{Invasion of the plateau and formation of small droplets}

Having launched the experiment as described earlier, the dispersed phase pressure was increased gradually, and the entire droplet formation process was monitored as a function of this pressure; Fig. 3.3 shows different stages, from the moment oil invaded the plateau to monodisperse droplet formation and the inception of blow-up.

The dispersed phase entered the main plateau at 55 mbar, the so-called invasion pressure (Fig. 3.3a). Upon slight increase in the applied pressure, the interface moved ahead evenly on the main plateau and reached the beginning of the micro-plateaus at 60 mbar, leading to complete filling of the main plateau including the far corners (Fig. 3.3b), unlike standard EDGE chips in which this area is not well used and semimetal EDGE systems that were not uniformly filled. ${ }^{25,26}$ The reason for complete oil filling of our partitioned plateau, prior to droplet formation from any of the microplateaus, was the higher flow resistance in the micro-plateaus compared to the rest of the plateau. The first droplets formed from a few micro-plateaus situated in the middle at 115 mbar, the so-called breakthrough pressure (Fig. 3.3c). Please note that droplet formation takes place at the dark black line; the actual partition walls are a bit longer than the actual plateau for construction reasons. With increasing applied pressure, the number of micro-plateaus generating droplets increased gradually and eventually all became active at 400 mbar (Fig. 3.3d). As expected, upon further increase in pressure, productivity of the micro-plateaus increased significantly (Fig. 3.3e). The produced droplets remained uniform until 1000 mbar, above which blow-up occurred (Fig. 3.3f). At even higher pressures, other interesting phenomena occurred that we will discuss later, but first we describe the filling behaviour of the plateau in more detail.

Fig. 3.4 shows a detailed analysis of the activation of the micro-plateaus as a function of the applied pressure on the dispersed phase. When certain micro-plateaus were activated at breakthrough pressure (115 mbar), they remained active while neighbouring micro-plateaus became active at higher pressures. Most probably, the active micro-plateaus created a pressure gradient leading to gradual activation of all micro-plateaus at 400 mbar. Thereafter all micro-plateaus operated stably until the socalled blow-up pressure was reached at 1000 mbar. The remarkable pressure stability 

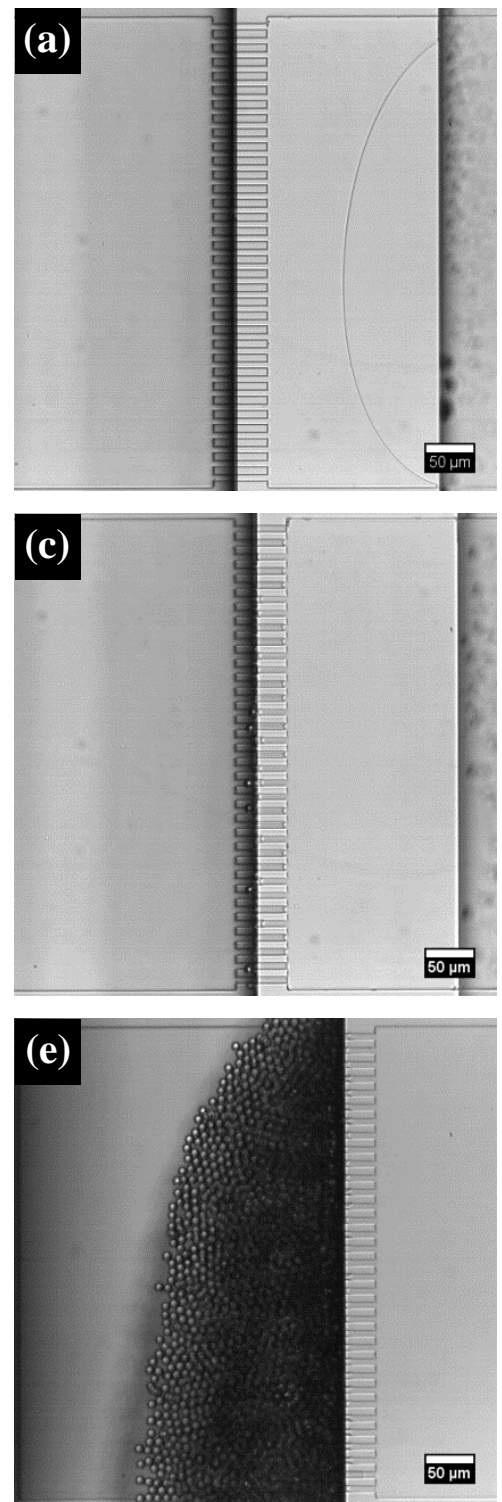
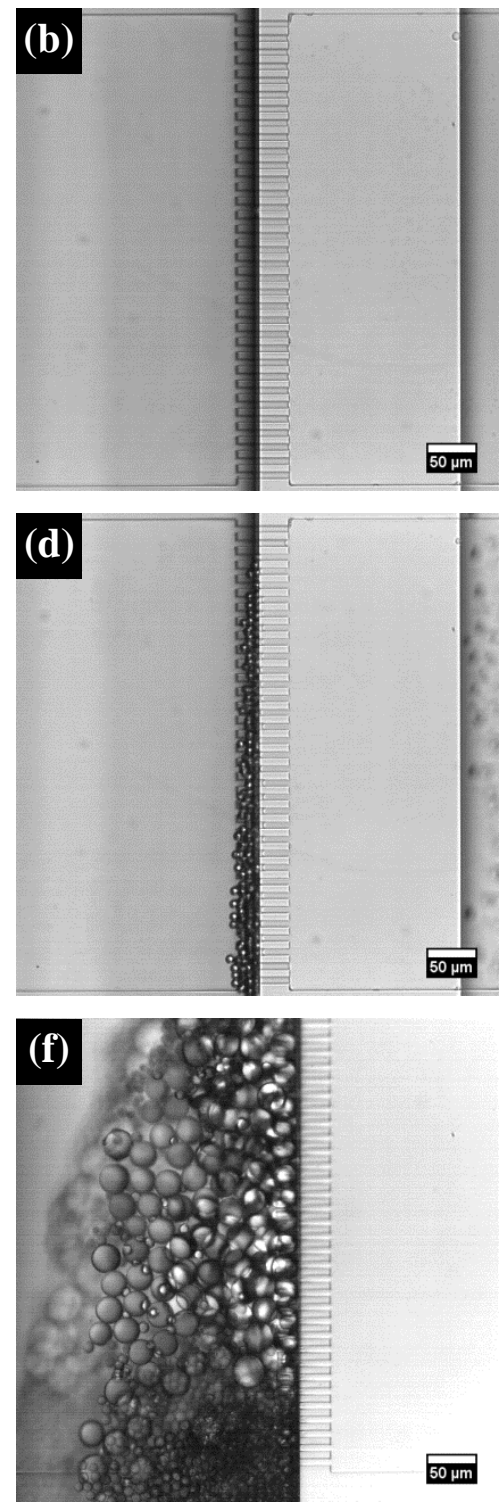

Fig. 3.3 Invasion of the partitioned plateau and droplet formation; (a) hexadecane entered the plateau, (b) the main plateau was filled further and eventually filled completely with hexadecane, (c) droplet formation started from few micro-plateaus at the dark black line which signifies the change from shallow to deep channel, (d) all micro-plateaus were involved in droplet formation, (e) many monodisperse droplets formed at high frequency below the blow-up pressure, and (f) some micro-plateaus blew up above 1000 mbar, resulting in polydispersity. 
was due to the higher flow resistance induced by the micro-plateaus, which allowed initially non-active micro-plateaus to be activated at higher pressures without blowing up the already active ones. This is also in line with the findings of GijsbertsenAbrahamse et al. ${ }^{20}$ who reported that more pores become active with increasing microsieve pore resistance in shear-based emulsification, albeit that the fraction of active pores was very low compared to what is found here. The $100 \%$ micro-plateau activation was also much higher as reported for straight-through MCs that produce similar-sized droplets. In addition, when compared to straight-through MCs that require a minimum aspect ratio of 3 for stable monodisperse droplet formation, the micro-plateaus with a markedly lower aspect ratio of 2.5 were capable of producing monodisperse droplets. Unlike straight-through MCs, the micro-plateaus are connected to the oil supply through a wide plateau, and we think that this creates a buffering zone that levels off pressure fluctuations, preventing a preferential flow to certain micro-plateaus, therewith leading to stable operation.

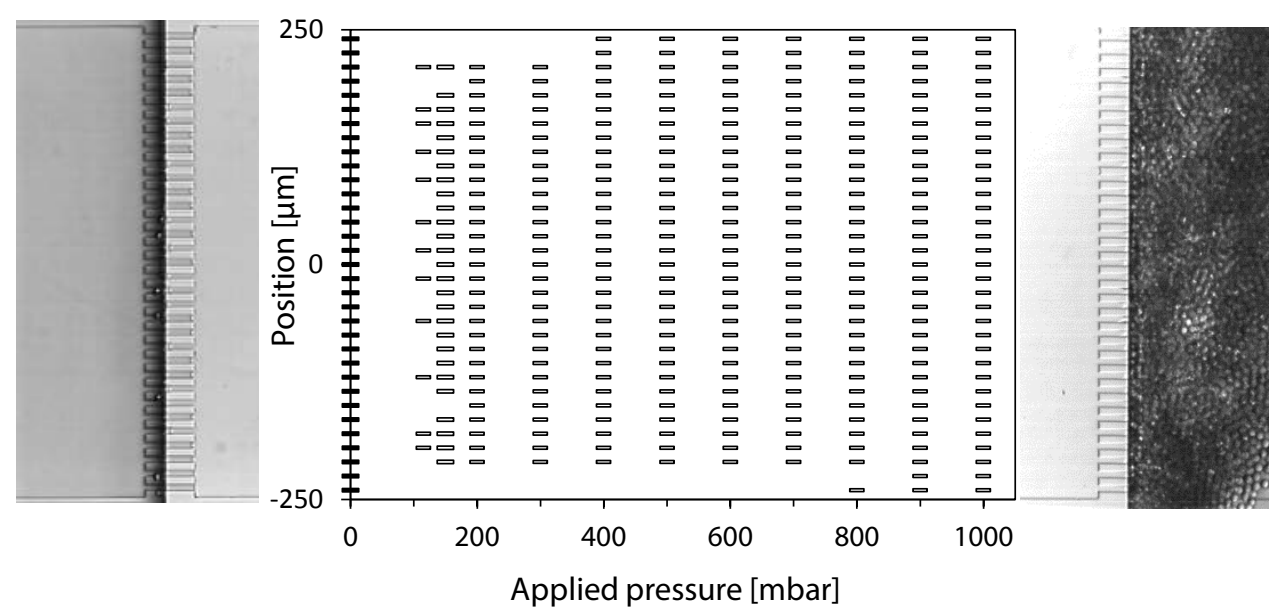

Fig. 3.4 Position of active micro-plateaus as a function of applied pressure. The filled symbols on the $y$-axis indicate the position of the micro-plateaus. 


\section{Blow-up and formation of large uniform droplets}

Above the blow-up pressure (1000 mbar), some of the micro-plateaus started producing approximately three times larger droplets (Fig. 3.3f). An additional increase of few hundred mbar in pressure resulted in blow-up of the remaining micro-plateaus but not in continuous outflow of the oil phase, unlike MCs. All micro-plateaus eventually blew up at 1400 mbar but surprisingly produced equal-sized larger droplets (Fig. 3.5a) for a wide pressure range up until 2100 mbar; neighbouring droplets did not hinder each other, deform or coalesce. At even higher pressures that we investigated (up to 4000 mbar), the droplets became and stayed polydisperse (Fig. 3.5b).

In the literature, the so-called balloon regime was reported by Tarchichi et al. ${ }^{28}$ for droplet formation in T-junctions, where they also found large uniform droplets at low dispersed phase velocities $\left(<6 \mathrm{~mm} \mathrm{~s}^{-1}\right)$. These authors associated this with the structural stability of the growing droplet's circular shape coupled with the high interfacial tension they used and suggested that the droplet formation mechanism in the balloon regime is similar to the capillary instability phenomenon. Although our observations may, at first glance, seem similar to the balloon regime, we believe that these larger uniform droplets were also formed spontaneously by interfacial tension effects. In comparison with the small droplets in the first monodisperse regime, the
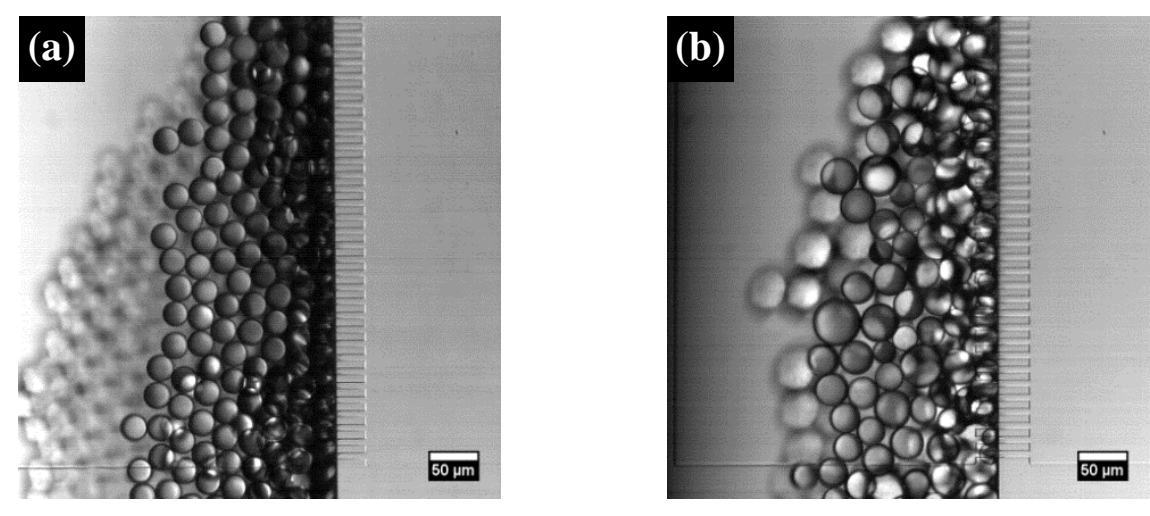

Fig. 3.5 Blow-up regime and formation of large uniform droplets: (a) all micro-plateaus blew up at 1400 mbar producing larger uniform droplets until 2100 mbar; droplets on the left side were out of focus, but they were the same size, and (b) uniformity of large droplets was impaired above 2100 mbar. 
high applied pressure may have kept the neck from collapsing, thereby allowing the droplet to grow larger before it detached. To elucidate this to some extent, we performed a series of preliminary experiments using different micro-plateau dimensions and viscosities of both phases. With decreasing viscosity ratio, the droplet size increased as found in the first regime and expected in spontaneous droplet formation processes such as $\mathrm{MC}^{29}$ and $\mathrm{EDGE}^{30}$ emulsification. At high continuous phase viscosity, the second monodisperse regime was not found. This can be attributed to higher flow resistance for a more viscous continuous phase that needs to invade the plateau area around the neck, in combination with droplet formation points that are so close together that they influence each other, leading to polydispersity. Upon increasing the width of the micro-plateaus, the second monodisperse regime was found as described earlier, indicating that the resistance against flow of the continuous phase does affect the second stable regime and that also hints at spontaneous droplet formation. We hope to reveal the actual mechanism in a follow-up publication.

\subsubsection{Droplet size (distribution) as a function of applied pressure}

Fig. 3.6a-b and c-d show the effect of applied pressure on droplet size and size distribution for partitioned and regular plateaus, respectively. As shown in Fig. 3.6a, the diameter of the very first droplets that formed at the breakthrough pressure of 115 mbar was $8 \mu \mathrm{m}$; their size only increased very marginally to $8.9 \mu \mathrm{m}$ at $300 \mathrm{mbar}$ and remained constant until 800 mbar. The coefficient of variation remained below 3\% from breakthrough pressure to 800 mbar. With further increase in pressure, the average droplet diameter increased to $9.2 \mu \mathrm{m}$ (at $900 \mathrm{mbar}$ ) and $9.3 \mu \mathrm{m}$ (at $1000 \mathrm{mbar}$ ) which also resulted in an increase in the coefficient of variation; please keep in mind that the actual value was still below $5 \%$.

As shown in Fig. 3.6c, EDGE devices with regular plateaus had a stable pressure range of 55-115 mbar, which is much narrower as for partitioned devices. The formed droplet diameters were $12 \mu \mathrm{m}$ leading to a scaling factor of 6 between the droplet diameter and plateau height, as previously reported. . $^{3,16,24,25,30}$ When compared to EDGE chips with regular plateaus of the same height, the partitioned EDGE system produced smaller droplets $(9 \mu \mathrm{m})$, resulting in a scaling factor of 4.5 , which would position them at the high end of the spectrum reported for microchannel emulsification (i.e. 2.5-4 
times the smallest dimension). It seems that the lower scaling factor compared to regular EDGE is analogous to that of MCs and related to the geometry of the microplateaus. ${ }^{31-33}$ We currently investigate this in a follow-up research through variation of the dimensions of the micro-plateaus.

The diameter of large droplets produced from 1400 to 2100 mbar was 28 micrometres, which corresponds to a scaling factor of 14 , which is much higher as found for regular plateaus and other microfluidic devices. However, it does show that it is possible to have two rather wide pressure ranges in one chip that allow the production of two completely different-sized emulsions, and this is a unique feature of the partitioned EDGE chips. Whether that is beneficial is to be seen; some thoughts on the productivity are shared in the last section.
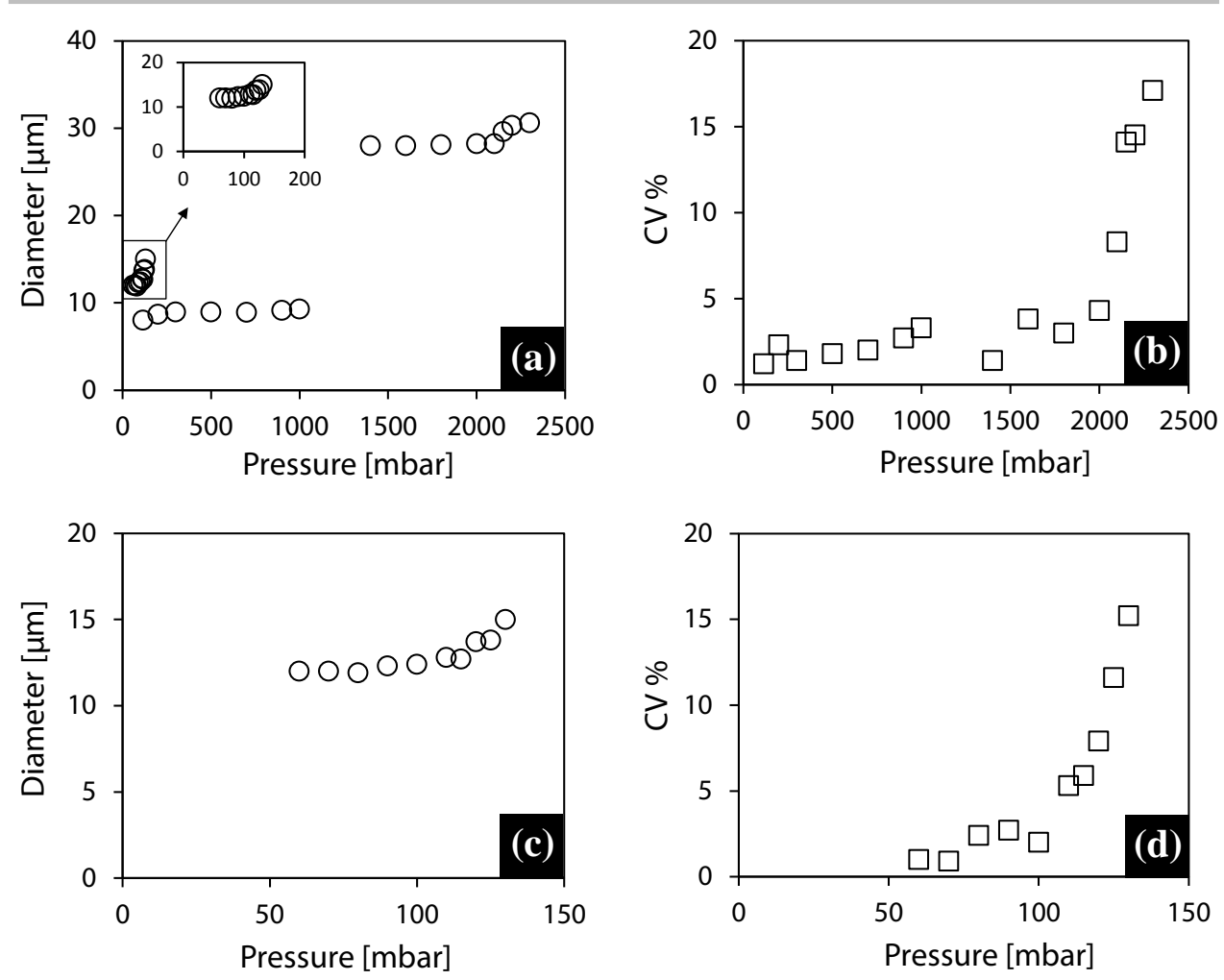

Fig. 3.6 Effect of applied pressure on droplet size and size distribution: (a-b) partitioned and (c-d) regular plateaus. The inset in (a) represents the data from (c) on a slightly different scale. 


\subsubsection{Pressure stability and system productivity}

Table 3.2 summarizes the pressure stability and productivity of regular and partitioned plateaus. Compared to regular ones, the partitioned plateau has remarkably wider pressure stability in the first monodisperse droplet formation regime (115-1000 mbar). In addition, a similarly wide pressure stability was observed for the second monodisperse droplet formation region obtained at higher pressures (1400-2100 mbar). This increased pressure stability led to significantly improved droplet formation frequencies. At the maximum pressure at which droplets were still monodisperse, a regular plateau of $500 \mu \mathrm{m}$ wide produced 160 droplets of $12 \mu \mathrm{m}$ per second, and a partitioned plateau of the same width, with 33 micro-plateaus, produced about 35000 small and 4500 larger uniform droplets per second. Interestingly, we observed that the droplet formation frequency per micro-plateau did not vary a lot among the microplateaus and was almost identical. The average frequency for $9 \mu \mathrm{m}$ droplets was 1049 $\mathrm{Hz}$ with minimum and maximum values of 909 and $1250 \mathrm{~Hz}$, respectively. Similarly, the average frequency for $28 \mu \mathrm{m}$ droplets was $137 \mathrm{~Hz}$ with minimum and maximum values of 123 and $142 \mathrm{~Hz}$, respectively, indicating that the chip was very uniform in performance. In straight-through MCs, one of the most promising spontaneous emulsification devices for mass producing uniform droplets, droplet formation frequency varied significantly from channel to channel, while the percentage of active channels was below $50 \%$ for the preparation of around $30 \mu \mathrm{m}$ droplets, ${ }^{18}$ which became even lower for smaller droplets. ${ }^{34}$

Table 3.2 Comparison of the pressure stability and productivity of the EDGE devices with regular and partitioned plateaus. ${ }^{a}$

\begin{tabular}{|c|c|c|c|c|}
\hline \multirow[b]{2}{*}{$\begin{array}{l}\text { Plateau } \\
\text { design }\end{array}$} & \multirow[b]{2}{*}{$\begin{array}{l}\text { Pressure } \\
\text { stability [mbar] }\end{array}$} & \multirow[b]{2}{*}{$\begin{array}{l}\text { Droplet } \\
\text { diameter }[\mu \mathrm{m}]\end{array}$} & \multicolumn{2}{|c|}{ Per $500 \mu \mathrm{m}$ plateau length } \\
\hline & & & $\begin{array}{l}\text { Maximum } \\
\text { frequency }[\mathrm{Hz}]\end{array}$ & $\begin{array}{l}\text { Hexadecane flux } \\
{\left[\mathrm{mL} \mathrm{h}^{-1}\right]}\end{array}$ \\
\hline$\overline{\text { EDGE-R }}$ & $55-115$ & 12 & 160 & 0.0005 \\
\hline EDGE-P [I] & $115-1000$ & 9 & 35000 & 0.05 \\
\hline EDGE-P [II] & $1400-2100$ & 28 & 4500 & 0.2 \\
\hline
\end{tabular}


Translation of the obtained droplet formation frequencies into overall productivity shows that the partitioned EDGE device has 100 fold higher oil flux than the standard EDGE device when producing small droplets, which is even 400 fold higher for larger droplets (see Table 3.2). When corrected for the oil viscosity, productivity of a single micro-plateau is similar to that of a single terrace in MC arrays reported by Kobayashi et al. ${ }^{17}$ for the production of $10 \mu \mathrm{m}$ soybean oil droplets. However, for the same surface area, the geometry of our droplet formation units allows us to place an order of magnitude more units. In general, a fair comparison of the amount of oil that can be emulsified using different emulsification systems is not that easy to make. For that, droplet size and oil viscosity should be of the same order of magnitude. A reasonable comparison of different microfluidic devices for preparing 5-10 $\mu \mathrm{m}$ droplets at larger scale was reported in a recent review, ${ }^{10}$ which is based on the performance of individual droplet formation units. Using a similar approach, the estimated productivity values for a large-scale partitioned EDGE device (as discussed in the upscaling section below, see also Table 3.3) are close to the highest productivity estimated for shearbased systems that yield much higher droplet formation frequency per droplet formation unit compared to other microfluidic systems.

\subsubsection{Process robustness}

The partitioned plateaus were tested for longer times to check whether they are prone to any operational instability that might develop in time. Without any cleaning procedure between the consecutive days, an experiment was run for a week albeit that we only could run during working hours. All micro-plateaus were active and worked regularly at the same frequency reported earlier. This indicates the robustness of the process, which is essential when upscaling a system.

The system was also checked for its ability to disperse low viscosity liquids using decane. As was the case for hexadecane, two stable monodisperse droplet formation regimes were observed, and all micro-plateaus were active. The maintained high micro-plateau efficiency differs from that of straight-through MCs, in which the fraction of active channels decreases with decreasing oil viscosity. 


\subsubsection{An upscaling scenario for partitioned EDGE device}

Although various options for upscaling of partitioned EDGE devices have been considered, the best option, in our opinion, would be the multi-EDGE design that is shown in Fig. 3.7. The plateaus could be etched in a single plane in such a way that it resembles straight-through MCs or microsieves. This can be realized by two directional etching of the target surface; micro-plateaus can be etched from one surface and the main plateaus can be etched from the other surface.

In this design, we assumed that the distance between the main plateaus is $15 \mu \mathrm{m}$ as is the distance between neighbouring micro-plateaus on the same plateau. Therefore, the distance between the centres of a micro-plateau and any surrounding microplateau would be $15 \mu \mathrm{m}$. The micro-plateaus were assumed to have the same dimensions as presented in Table 3.1 for the microchips used in this work $(L \times W \times H$, $30 \times 5 \times 2 \mu \mathrm{m})$. According to the micromachining industry experts we consulted, the intended dimensions are realistic and can be achieved using silicon-based substrates. These dimensions will result in a surface porosity of $4.4 \%$ on the micro-plateau side and $13.2 \%$ on the main plateau side, which is reasonable from a mechanical stability perspective. The feeding of the plateaus with oil and the collection of the formed droplets can be arranged through placing the chip into a standard module.

Table 3.3 shows the amount of oil that theoretically can be emulsified in the first and second regimes per square metre device area per hour. The calculated amounts were based on the frequencies given in Table 3.2, and we assumed 100\% micro-plateau activation. With the multi-EDGE design, it would be possible to emulsify 6 and 25 $\mathrm{m}^{3} \mathrm{~m}^{-2} \mathrm{~h}^{-1}$ hexadecane for the first and second stable regimes, respectively. It is clear that the amount of oil that can be dispersed is also dependent on the droplet size (and applied pressure). The droplet formation frequency in EDGE devices is inversely proportional to dispersed phase viscosity; ${ }^{3}$ when considering a food grade oil such as sunflower oil, this leads to approximately 15 fold lower productivity as shown in Table 3.3. For a food production line, typically $20 \mathrm{~m}^{3} \mathrm{~h}^{-1}$ product would need to be made. The proposed designs indicate that depending on the required oil fraction, the area needed for partitioned EDGE devices to deliver such product volumes would be in the range of few square metres, which makes them interesting for upscaling. 


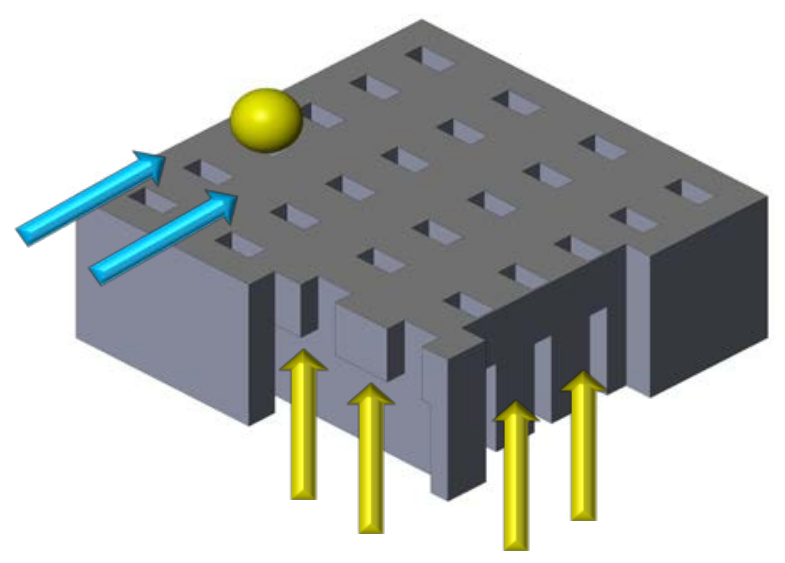

Fig. 3.7 Schematic representation of the multi-EDGE device. Oil is pushed from the bottom and to-be formed droplets are carried away by the cross flowing continuous phase on the plate surface. Please note that the cross-flow is not needed for droplet formation as such.

Table 3.3 Calculated productivity of the suggested upscaled multi-EDGE device with a surface area of $1 \mathrm{~m}^{2}$.

\begin{tabular}{lll}
\hline Oil type & $\begin{array}{l}\text { Droplet } \\
\text { diameter }[\mu \mathrm{m}]\end{array}$ & Productivity $\left[\mathrm{m}^{3} \mathrm{~h}^{-1}\right]$ \\
\hline Hexadecane & 9 & 6 \\
Sunflower oil $^{a}$ & 28 & 25 \\
& 9 & 0.4 \\
& 28 & 1.6 \\
\hline
\end{tabular}

${ }^{a}$ Calculation based on the experiments conducted with hexadecane.

\subsection{Conclusions}

The partitioned EDGE device has two orders of magnitude higher productivity than the regular EDGE devices. The design has shown a wide pressure stability at $100 \%$ microplateau activation and high monodispersity, also during long-term operation. Interestingly, we found two pressure ranges in which monodisperse droplets of two 
distinct sizes were formed, and this occurred for oils of different viscosities. All in all, the partitioned EDGE device combines high productivity with the advantages of other spontaneous emulsification devices such as high monodispersity and ease of control.

Based on our findings, we proposed a design strategy for a large-scale device. The amount of (vegetable) oil that can theoretically be emulsified using this device was calculated to be in the order of several cubic metres per hour per square metre device area. We believe that if built, the proposed device can be well suited for large-scale emulsification.

\section{References}

1 C. Charcosset, I. Limayem and H. Fessi, J. Chem. Technol. Biotechnol., 2004, 79, 209-218.

2 M. Saito, L. J. Yin, I. Kobayashi and M. Nakajima, Food Hydrocolloids, 2006, 20, 1020 1028.

3 K. C. van Dijke, K. Schroën, A. van der Padt and R. Boom, J. Food Eng., 2010, 97, 348-354.

4 V. Barbier, H. Willaime, P. Tabeling and F. Jousse, Phys. Rev. E, 2006, 74, 046306.

5 M. L. Steegmans, A. Warmerdam, K. G. Schroën and R. M. Boom, Langmuir, 2009, 25, 9751-9758.

6 T. Krebs, K. Schroën and R. Boom, Soft Matter, 2012, 8, 10650-10657.

7 I. Kobayashi, T. Takano, R. Maeda, Y. Wada, K. Uemura and M. Nakajima, Microfluid. Nanofluid., 2008, 4, 167-177.

8 A. A. Maan, K. Schroën and R. Boom, J. Food Eng., 2011, 107, 334-346.

9 G. T. Vladisavljević, I. Kobayashi and M. Nakajima, Microfluid. Nanofluid., 2012, 13, 151 178.

10 K. Schroën, O. Bliznyuk, K. Muijlwijk, S. Sahin and C. C. Berton-Carabin, Curr. Opin. Food Sci., 2015, 3, 33-40.

11 M. Hashimoto, S. S. Shevkoplyas, B. Zasońska, T. Szymborski, P. Garstecki and G. M. Whitesides, Small, 2008, 4, 1795-1805.

12 W. Li, E. W. K. Young, M. Seo, Z. Nie, P. Garstecki, C. A. Simmons and E. Kumacheva, Soft Matter, 2008, 4, 258-262.

13 A. J. Abrahamse, R. van Lierop, R. G. M. van der Sman, A. van der Padt and R. M. Boom, J. Memb. Sci., 2002, 204, 125-137.

14 T. Kawakatsu, Y. Kikuchi and M. Nakajima, J. Am. Oil Chem. Soc., 1997, 74, 317-321. 
15 I. Kobayashi, M. Nakajima, K. Chun, Y. Kikuchi and H. Fujita, AlChE J., 2002, 48, 16391644.

16 K. C. van Dijke, G. Veldhuis, K. Schroën and R. M. Boom, AIChE J., 2010, 56, 833-836.

17 I. Kobayashi, Y. Wada, K. Uemura and M. Nakajima, Microfluid. Nanofluid., 2010, 8, 255262.

18 G. Vladisavljević, I. Kobayashi and M. Nakajima, Microfluid. Nanofluid., 2011, 10, $1199-$ 1209.

19 I. Kobayashi, M. Neves, A., Y. Wada, K. Uemura and M. Nakajima, Green Process. Synth., 2012, 1, 353-362.

20 A. J. Gijsbertsen-Abrahamse, A. van der Padt and R. M. Boom, J. Memb. Sci., 2003, 217, 141-150.

21 A. J. Gijsbertsen-Abrahamse, A. van der Padt and R. M. Boom, J. Memb. Sci., 2004, 230, 149-159.

22 I. Kobayashi, S. Mukataka and M. Nakajima, J. Colloid Interface Sci., 2004, 279, 277-280.

23 G. T. Vladisavljević, I. Kobayashi and M. Nakajima, Powder Technol., 2008, 183, 37-45.

24 K. van Dijke, G. Veldhuis, K. Schroën and R. Boom, Lab Chip, 2009, 9, 2824-2830.

25 A. Maan, K. Schroën and R. Boom, Microfluid. Nanofluid., 2013, 14, 187-196.

26 A. A. Maan, R. Boom and K. Schroën, Microfluid. Nanofluid., 2013, 14, 775-784.

27 R. Schmidt, K. Griesbaum, A. Behr, D. Biedenkapp, H.-W. Voges, D. Garbe, C. Paetz, G. Collin, D. Mayer and H. Höke, in Ullmann's Encycl. Ind. Chem., Wiley-VCH Verlag GmbH \& Co. KGaA, 2000.

28 N. Tarchichi, F. Chollet and J.-F. Manceau, Microfluid. Nanofluid., 2013, 14, 45-51.

29 K. van Dijke, I. Kobayashi, K. Schroën, K. Uemura, M. Nakajima and R. Boom, Microfluid. Nanofluid., 2010, 9, 77-85.

30 K. van Dijke, R. de Ruiter, K. Schroën and R. Boom, Soft Matter, 2010, 6, 321-330.

31 S. Sugiura, M. Nakajima and M. Seki, Ind. Eng. Chem. Res., 2004, 43, 8233-238.

32 E. van der Zwan, K. Schroën and R. Boom, Langmuir, 2009, 25, 7320-7327.

33 K. C. van Dijke, K. C. Schroën and R. M. Boom, Langmuir, 2008, 24, 10107-10115.

34 I. Kobayashi, G. T. Vladisavljević, K. Uemura and M. Nakajima, Chem. Eng. Sci., 2011, 66, 5556-5565. 



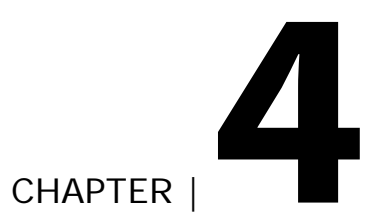

\section{Droplet formation mechanisms in partitioned EDGE devices: geometry and viscosity effects}

This chapter has been submitted for publication as Sahin, S., Rovalino Cordova, A., \& Schroën, K. Droplet formation mechanisms in partitioned EDGE devices: geometry and viscosity effects. 


\section{Abstract}

In earlier work we showed that partitioned EDGE devices were capable of producing very monodisperse droplets in two distinct sizes and had remarkable pressure stability. In the current study, we attempt to elucidate the underlying droplet formation mechanisms by systematically varying the geometry of the micro-plateaus and the viscosity of the liquids.

In the first regime, the effects of viscosity ratios and geometry on droplet size were similar to those reported for microchannels and regular EDGE devices; droplet size increased with decreasing viscosity ratio, and became relatively stable at high viscosity ratio.

For wide micro-plateaus no second regime was noted as was the case for standard EDGE, but for narrow micro-plateaus, regardless of the dispersed and continuous phase viscosities, two regimes of monodisperse droplet formation could be found, though at low viscosity ratios monodispersity was impaired. Therefore, we concluded that the micro-plateau resistance needs to be high enough to allow for the second regime to occur.

In the second regime, droplet size was mainly determined by the micro-plateau width. Particularly for very narrow micro-plateaus no marked effect of viscosity on droplet size was found, which is remarkable since the volume of the droplets is considerably larger than the volume of the micro-plateaus. Apparently, through the construction used, the main plateau is able to feed large amounts of oil onto the micro-plateau in a controlled way, and that explains the high pressure stability, also in the second regime. 


\subsection{Introduction}

Emulsions are used in everyday life as they are part of e.g. foods, pharmaceuticals, cosmetics and paints. Emulsion droplet size and size distribution influence many quality attributes such as texture, appearance and shelf-life; uniform size distribution has been shown to improve emulsion stability. ${ }^{1-4}$ However, controlling droplet size (distribution) is far from trivial in the conventional equipment that is now mostly used, such as high pressure homogenizers.

For the preparation of monodisperse emulsions, membrane emulsification was proposed by Nakashima et al., ${ }^{5}$ and the first results obtained with porous glass were promising. Through the advances in micromachining technology, a new generation of membranes and microfluidic devices were developed with precise geometries enabling the production of very monodisperse emulsions. This has opened up new opportunities for a wide range of application areas, but the productivity of these emerging technologies is in general rather low and the current knowledge base is not good enough to realize large-scale production. An overview of these microengineered emulsification techniques with their main characteristics can be found in some recent reviews. ${ }^{6-11}$

Because one microfluidic device has very low throughput, many would need to work in tandem to get reasonable amounts of product. If all these individual units need to have their own in- and outflow tubing, this leads to an unpractical situation, and in that view the EDGE device that was developed in our lab is an interesting option. In EDGE devices, many droplets are simultaneously generated from one droplet formation unit, ${ }^{12}$ and many units can be connected to a single feed tube. ${ }^{13}$

In order to increase the productivity of EDGE further, we have recently introduced partitioned EDGE devices in which droplet formation units contain additional structures. This seemingly small geometrical adjustment was shown to improve throughputs considerably ( factor of 100 compared to regular EDGE) due to higher pressure stability. Besides, it was found that at relatively low dispersed phase pressures $(<1$ bar) these devices produce small droplets, while they make large droplets at relatively high pressures (1-3 bar)..$^{14}$ The partitioned EDGE devices were even parallelised in recent work in which we introduced the so-called multi-EDGE, that was capable of producing droplets at high throughput (chapter 5). 
Since there is a clear effect of geometry on the behaviour of partitioned EDGEs, and they hold a promise for relatively easy scale-up, we investigate the design in detail through variation of not only the dimensions of the micro-plateaus but also the liquid viscosities that are known to influence droplet formation in microfluidic devices. This combined knowledge is expected to lead to elucidation of the droplet formation mechanism for the production of small and large droplets, and through that the design of partitioned EDGE devices can be tailored to the emulsion ingredients of choice.

\subsection{Experimental}

\subsubsection{Chemicals}

As a continuous phase $0.5 \% \mathrm{w} / \mathrm{w}$ SDS in MilliQ water and 20, 40,50\% w/w glycerolMilliQ mixtures were used. Hexadecane, decane, silicon oil, and a mixture of hexadecane and viscous paraffin were used as dispersed phases. In this way the viscosities of the two phases were individually varied within a considerable range (factor 6 for water phase, and 54 for oil phase), and even more so for the viscosity ratio (factor 333), as illustrated in Table 4.1.

Table 4.1 Viscosity of dispersed and continuous phases with their respective viscosity ratios. The symbols in brackets refer to the symbols in Fig. 4.2-4.

\begin{tabular}{|c|c|c|c|c|}
\hline & $\begin{array}{l}\text { MilliQ ( }) \\
\eta=1.0 \mathrm{mPa} s\end{array}$ & $\begin{array}{l}20 \% \text { Glycerol ( } \square) \\
\eta=1.74^{15} \mathrm{mPa} \mathrm{s}\end{array}$ & $\begin{array}{l}40 \% \text { Glycerol }(\Delta) \\
\eta=3.69^{15} \mathrm{mPa} \mathrm{s}\end{array}$ & $\begin{array}{l}50 \% \text { Glycerol (o) } \\
\eta=6.0^{15} \mathrm{mPa} \mathrm{s}\end{array}$ \\
\hline $\begin{array}{l}\text { Decane } \\
\eta=0.92^{16} \mathrm{mPa} \mathrm{s}\end{array}$ & 0.92 & 0.53 & 0.25 & 0.15 \\
\hline $\begin{array}{l}\text { Hexadecane } \\
\eta=3.47^{16} \mathrm{mPa} \mathrm{s}\end{array}$ & 3.47 & 1.99 & 0.94 & 0.58 \\
\hline $\begin{array}{l}\text { Hexadecane- } \\
\text { paraffin } \\
\eta=44.5^{17} \mathrm{mPa} \mathrm{s}\end{array}$ & 44.5 & 25.57 & 12.06 & 7.42 \\
\hline $\begin{array}{l}\text { Silicon oil } \\
\eta=50 \mathrm{mPa} \mathrm{s}\end{array}$ & 50 & 28.74 & 13.55 & 8.33 \\
\hline
\end{tabular}




\subsubsection{Chip design}

The partitioned EDGE microchips were made in glass by deep reactive ion etching (Micronit Microfluidics, Enschede, The Netherlands). The deep disperse and continuous phase channels, and the shallow plateaus (i.e. droplet formation units) were etched into two separate glass substrates which were later bonded together and diced. The layout of a microchip and dimensions are shown in Fig. 4.1; the dimension of the micro-plateaus are specified in Table 4.2 (the codes indicate the width of the microplateaus).

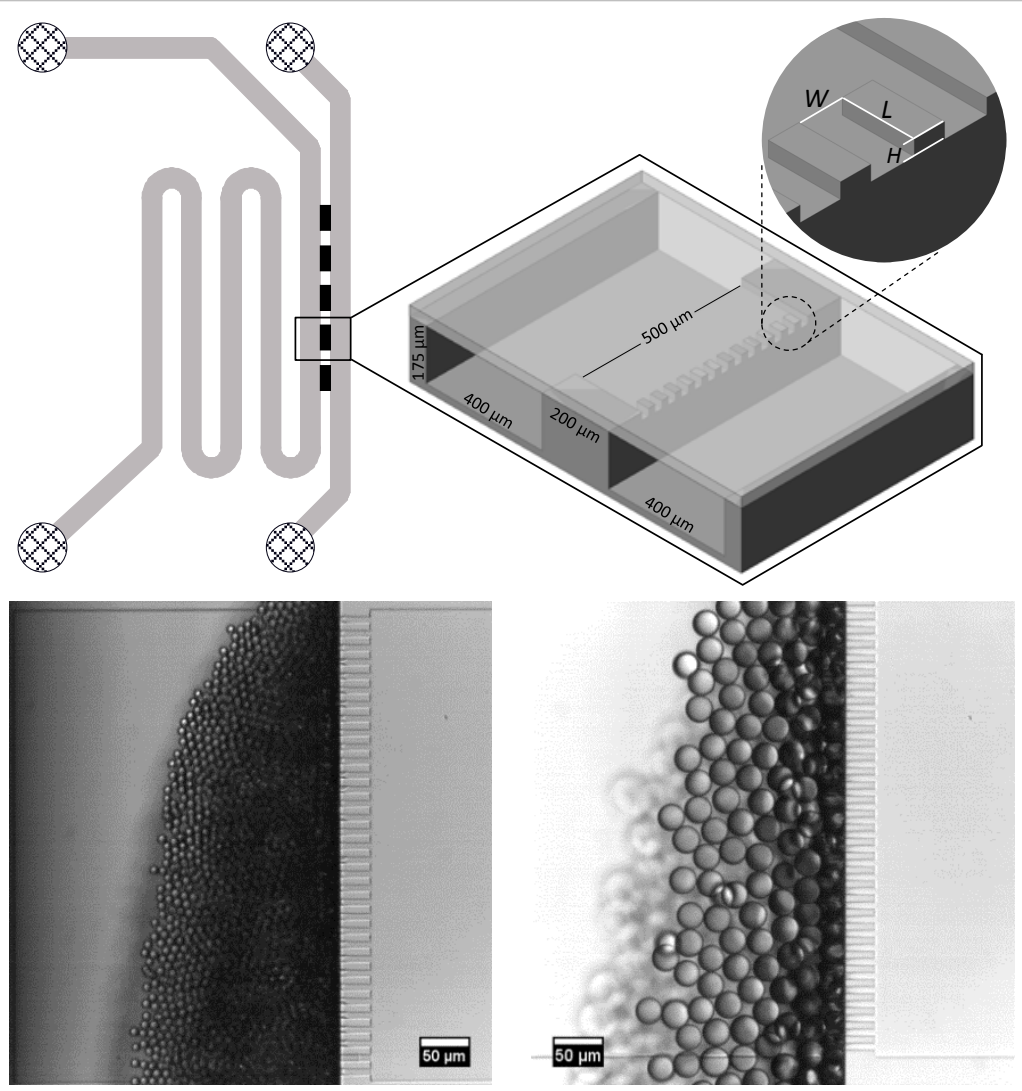

Fig. 4.1 The partitioned EDGE chip layout with five plateaus (black rectangles) placed between the deep continuous (meandering) and dispersed phase channels, and a close-up sketch of the micro-plateaus with their characteristic dimensions labelled on the top right. On the bottom, screen shots of monodisperse droplet formation (small on the left, large on the right). All plateaus operated at the same pressure drop, and all micro-plateaus were active. 
Table 4.2 Characteristic dimensions of the micro-plateaus.

\begin{tabular}{lll}
\hline & $\begin{array}{l}\text { Number of } \\
\text { micro-plateaus per } 500 \mu \mathrm{m}[-]\end{array}$ & $\begin{array}{l}\text { Dimensions of micro-plateaus } \\
{[L \times W \times H][\mu \mathrm{m}]}\end{array}$ \\
\hline EDGE-P 5 & 33 & $30 \times 5 \times 2$ \\
EDGE-P 20 & 17 & $30 \times 20 \times 2$ \\
EDGE-P 40 & 8 & $30 \times 40 \times 2$ \\
\hline
\end{tabular}

\subsubsection{Emulsification}

During emulsification, the chip holder was placed under a microscope (Axiovert 200 MAT, Carl Zeiss B.V., Sliedrecht, The Netherlands) connected to a high speed camera (MotionPro HS-4, IDT Inc., Tallahassee, FL, USA) so that droplet formation could be observed inline and recorded for post-processing (see also Fig. 4.1). Both phases were supplied inside the chip through PEEK tubing, with outer and inner diameters of 1/16" and $0.030 "$, respectively. The phase flows were controlled through the inlet pressures using a digital pressure controller (Elveflow ${ }^{\circledR}$, Paris, France). First the aqueous phase was pressurized into the chip, and the plateaus (and channels) were wetted by the continuous phase. Then, the oil was pushed into the chip and after the dispersed phase channel was completely filled this channel outlet was blocked. Thus, the oil was forced to flow continuously over the plateaus, and eventually transformed into spherical droplets when leaping into the deeper continuous phase channel (see also Fig. 4.1). Since EDGE is a spontaneous droplet formation technique, the flow of continuous phase is not needed for droplet formation, but it carries the droplets away. Owing to the specific design of EDGE chips, all plateaus operated at the same pressure drop, and all micro-plateaus were active. For the remainder of the text, unless otherwise mentioned, the 'applied pressure' refers to the dispersed phase pressure.

\subsubsection{Droplet size and size distribution}

To determine the average droplet size and size distribution, 20-50 droplets per data point were analysed by image analysis software, which is a standard procedure used in our lab for monodisperse droplets. Droplets with a CV below $10 \%$ were considered as monodisperse. 


\subsection{Results and discussion}

As mentioned earlier, ${ }^{14}$ the partitioned EDGE devices have similarities with regular EDGE devices, but also some unique features such as two monodisperse droplet formation regimes in both of which droplet formation is stable over a wide pressure range. In earlier work, only one geometry in combination with hexadecane and $0.5 \%$ SDS solution was studied. To understand the underlying mechanisms in greater detail, a wide range of liquids and three microchip designs were tested. We first present the results for each geometry, and then compare the results in terms of droplet size as function of viscosity ratio, followed by observations on process stability.

\subsubsection{Effect of micro-plateau design}

\section{EDGE-P 5}

For the narrowest micro-plateaus, the viscosity of both phases was systematically varied (and thereby also the viscosity ratio) and the obtained droplet size as function of applied pressure is shown in Fig. 4.2 for silicon oil (a) hexadecane (b) and decane (c).

We first look at the droplet formation behaviour in the first regime in which small droplets are formed. For silicon oil, monodisperse droplets could be produced successfully, and irrespective of the continuous phase viscosity the droplet sizes were the same. The continuous phase can intrude freely onto the micro-plateau, leading to rapid breakage of the neck, and droplet formation. When using less viscous hexadecane, monodisperse droplets were produced for all continuous phase viscosities, and the size increased with increasing continuous phase viscosity. Here the higher continuous phase viscosity results in less rapid inflow on the micro-plateau, leading to slower snap-off of the neck, and larger droplets. This effect was even greater for decane, the oil with the lowest viscosity, for which the droplet size increased with increasing continuous phase viscosity. These effects will be summarized in section 4.3.2.

For the second stable regime, in which much larger droplets are made and the mechanism is not well-known, there does not seem to be an effect of viscosity on droplet size, although some effects on droplet uniformity were noted. For silicon oil, 

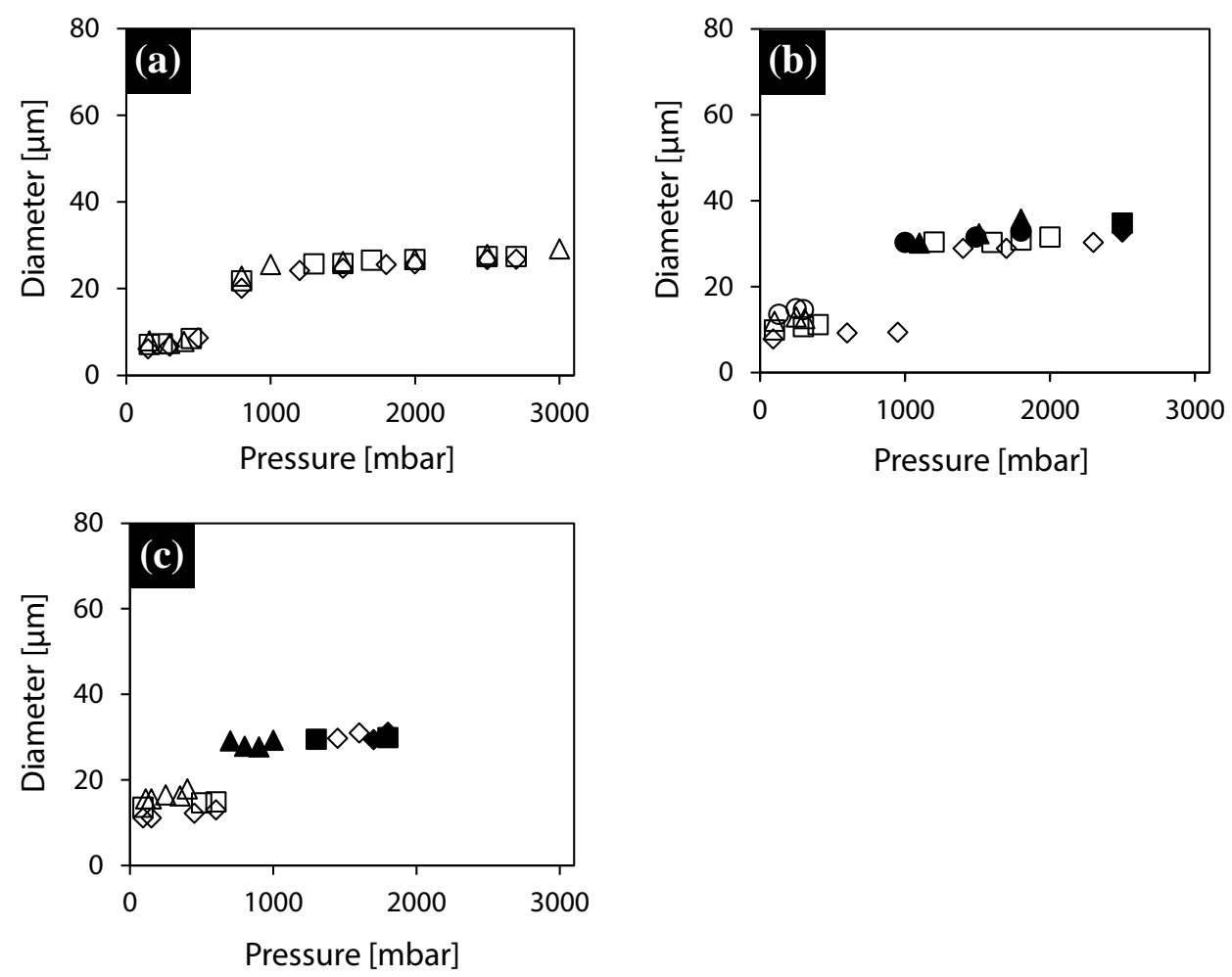

Fig. 4.2 Droplet size generated by EDGE P-5 as function of applied pressure for various continuous phase viscosities, going from low to high in the order of $\diamond, \square, \Delta, 0$. Open symbols denote monodisperse droplets with a $\mathrm{CV}<10 \%$, filled symbols denote polydisperse droplets with a CV between 10 and 20\%. (a) silicon oil, (b) hexadecane and (c) decane.

with very high viscosity, monodispersed droplets were produced for all continuous phase viscosities. For less viscous hexadecane, preparation of truly monodisperse droplets was only possible with low viscosity continuous phases (water and 20\% glycerol). At higher continuous phase viscosities, the average droplet sizes were similar, but they had a wider distribution (10-20\% CV, denoted with filled symbols). For decane with the lowest viscosity, only the continuous phase with the lowest viscosity (water) could be used to make monodisperse droplets. At higher continuous phase viscosities (20 and 40\% glycerol) the average droplet sizes were similar but considered polydisperse (CV 10-20\%). This indicates that the droplet formation mechanisms in 
both regimes are not the same and scaling rules need to be established, as will be discussed in greater detail in the viscosity ratio section.

\section{EDGE-P 20}

When using relatively wider micro-plateaus ( 20 vs $5 \mu \mathrm{m}$ ), it was expected that continuous phase intrusion would be facilitated by the wider micro-plateau, and through that also droplet formation would be enhanced. In effect, more successful combinations were found, but also quite a lot of detailed differences were noted as discussed next for the three oils used, going from high viscosity to low viscosity.

When emulsifying the mixture of hexadecane-paraffin, in both regimes droplet sizes were not dependent on the continuous phase viscosities, since all data points seem to merge into a master curve. However, the transition between the two regimes appears to be less sharp than found for the narrower micro-plateaus, and surely less sharp as found for the other two oils that are discussed later. Given our earlier observations of the two distinct regimes with a bidisperse transition range (i.e. combination of droplet sizes found in both regimes),,$^{14}$ it was surprising that this gradual transition allows production of monodisperse droplets of many different sizes during this gradual transition.

When using hexadecane, monodisperse droplets were found in both regimes for all viscosity ratios. Unlike in the narrower micro-plateaus, the continuous phase viscosity did not influence the droplet size in the first regime, most probably because of the lower resistance against inflow of the continuous phase (see also viscosity ratio section), while in the second regime a slight increase in droplet size was observed with increasing continuous phase viscosity. Besides, for all continuous phase viscosities droplet size seemed to increase as the applied pressure increased.

For low viscosity decane, in the first regime monodisperse droplets could be produced using all continuous phases, and the size seemed to be a week function of the continuous phase viscosity. In the second regime, more combinations could be used to make monodisperse emulsions as compared to the narrower micro-plateaus. And also here, as was found for hexadecane, there seemed to be an increase in droplet size with increasing continuous phase viscosity and applied pressure. 

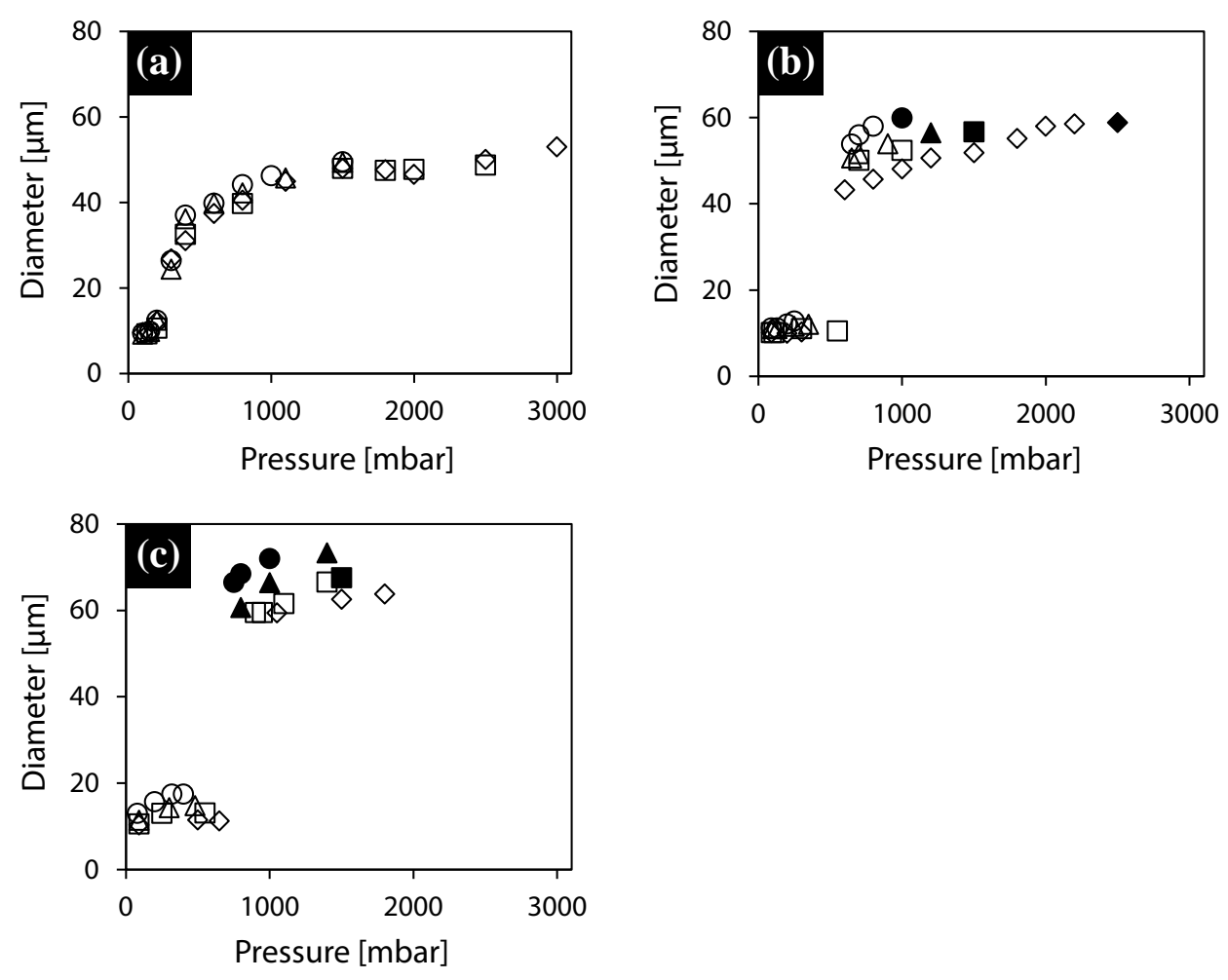

Fig. 4.3 Droplet size generated by EDGE P-20 as function of applied pressure for various continuous phase viscosities, going from low to high in the order of $\diamond, \square, \Delta, \circ$. Open symbols denote monodisperse droplets with a $\mathrm{CV}<10 \%$, filled symbols denote polydisperse droplets with a CV between 10 and 20\%. (a) paraffin-hexadecane, (b) hexadecane and (c) decane.

\section{EDGE-P 40}

With the widest micro-plateaus, only small monodisperse droplets could be prepared; a second regime of large monodisperse droplets was not observed. This is similar to what was observed for regular EDGE devices, albeit that the lowest pressure at which droplets can be made is slightly lower, and the pressure range is much narrower for regular EDGE devices. However, the droplet size obtained with partitioned EDGE devices (EDGE-P 40) increased with applied pressure, and did so more strongly for more viscous continuous phases (Fig. 4.4). The results will be discussed in more detail in the viscosity ratio section. 


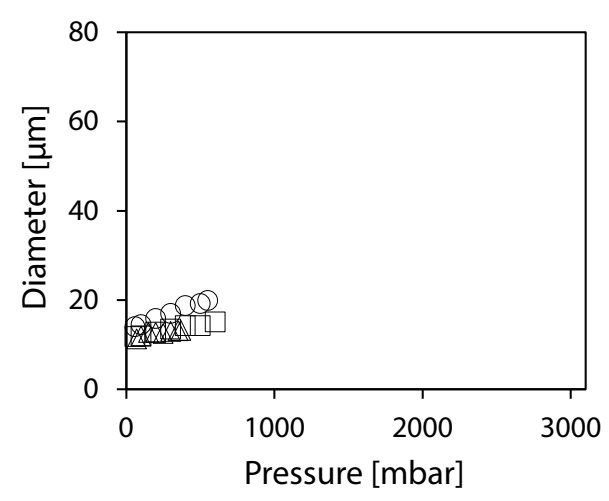

Fig. 4.4 Droplet size generated by EDGE P-40 as function of applied pressure for the following oil/continuous phase combinations: decane $/ 50 \%$ glycerol (০), decane/20\% glycerol ( $\square$ ), and hexadecane $/ 40 \%$ glycerol $(\Delta)$. The CV values for the presented data points are $<10 \%$.

\subsubsection{Effect of viscosity ratio}

To compile the effects that were noted with the three different geometries, we use a plot of dimensionless droplet diameter (droplet diameter/plateau height) versus the viscosity ratio (dispersed phase viscosity/continuous phase viscosity) as shown in Fig. 4.5. This approach has been used for other spontaneous droplet formation devices, and in general, at high viscosity ratios the droplet size was found to be constant and independent of the ratio (i.e. droplet size scales with the plateau height). When going to lower viscosity ratios, the droplet size starts increasing at a certain point which is termed the critical viscosity ratio. ${ }^{18-20}$

In the first regime (Fig. 4.5a), the widest micro-plateaus (EDGE-P 40) showed the typical behaviour described above, with a constant droplet size at high viscosity ratio. The critical viscosity ratio for the widest micro-plateaus was around 1, which is similar to that found for regular EDGE plateaus. ${ }^{19,20}$ For the narrower micro-plateaus, the critical viscosity ratio point was not as clear, although we did observe a decreasing dependency of droplet size on viscosity ratio at higher values.

The actual values that were found in the first regime are as expected. At high viscosity ratio the droplet size increased with increasing micro-plateau width, and similar to the regular plateaus a scaling factor of around 6 was found between the droplet size and 
plateau height for the widest micro-plateaus. This seems reasonable since the plateaus with the widest micro-plateaus resemble the regular plateaus most closely. Besides, our findings are in line with the work of Kawakatsu et al. ${ }^{21}$ for microchannel emulsification; they found that droplet size increases with increasing equivalent microchannel diameter.

At high viscosity ratios (i.e. above the critical viscosity ratio), wider micro-plateaus have relatively lower resistance against flow, and the dispersed phase can flow relatively freely, leading to collapse of the neck upon reaching a certain size. The narrower microplateaus have greater flow resistance, limiting outflow of the dispersed phase compared to the wider micro-plateaus, and therewith relatively stimulating inflow of the continuous phase. This leads to more rapid collapse of the neck and smaller droplets.

At low viscosity ratios the droplet size is determined by the viscosity ratio rather than the micro-plateau geometry, and for all geometries there seems to be similar dependency of droplet size on viscosity ratio. Under these conditions, the dispersed phase can flow so rapidly, that the resistance of the micro-plateau does not add to the stability, and the observed behaviour is only determined by the liquids. Compared to the flow of the dispersed phase, the continuous phase flow is that slow that it will prevent the liquid neck from breaking, therewith leading to larger droplets.

When thinking in terms of pressure gradients, higher continuous phase viscosities (below the critical ratio) generate steeper pressure gradients (lower pressures in the continuous phase on the micro-plateaus). ${ }^{18}$ As a result, oil supply to the micro-plateau increases and a larger volume of oil flows into the droplet. These effects are clearly a result of the ratio of viscosities, and our findings in the first regime are in line with the findings of van Dijke et al. ${ }^{18}$ for microchannel emulsification.

The effect of micro-plateau width on droplet size is even stronger in the second regime; it is not possible to obtain the second droplet formation regime when using very wide micro-plateaus (i.e. $40 \mu \mathrm{m}$ ); therewith confirming their geometric resemblance to the regular plateaus that also do not allow production of large monodisperse droplets. The intermediately sized micro-plateaus (EDGE-P 20) showed a steady decrease of droplet size as function of viscosity ratio, possibly leading to constant droplet sizes at high 

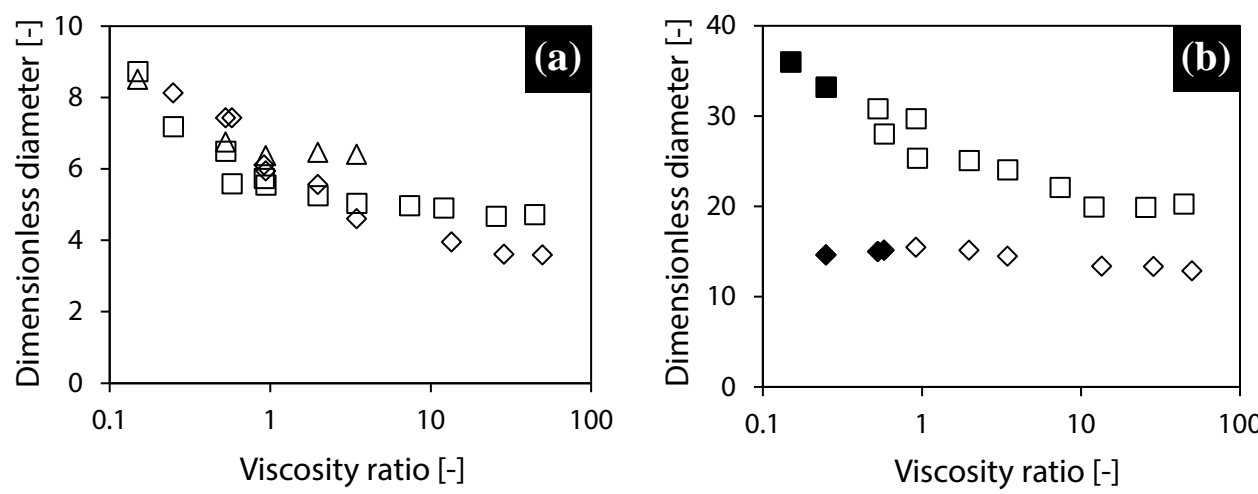

Fig. 4.5 Effect of viscosity ratio on droplet diameter as a function of applied pressure: (a) first regime, (b) second regime. The symbols refer to different plateaus: $(\diamond)$ EDGE-P 5, (口) EDGE-P 20, and $(\Delta)$ EDGE-P 40. Open symbols denotes monodispersity with a $C V<10 \%$, and the filled symbols denotes polydispersity with a CV between 10 and $20 \%$.

ratios. The droplet size generated by the narrowest micro-plateaus (EDGE-P 5) was hardly influenced by the viscosity ratio. This suggests that as the micro-plateaus become narrower the effect of viscosity ratio on droplet size fades away, and the flow confinement rules.

Again, when thinking in terms of pressure gradients, higher flow resistance in the micro-plateau will lead to higher pressures in the dispersed phase, that in turn will lead to better inflow of the continuous phase, and formation of smaller droplets. This also indicates that the architecture added to the standard EDGE device is essential for stable droplet formation as will be elaborated further in the next section in which the pressure stability will be discussed.

\subsubsection{Pressure stability}

Compared to regular EGDE devices, the pressure at which droplet formation starts is always considerably higher and the pressure range is wider for partitioned EDGE devices. The width of the pressure range in which monodisperse droplets are formed is important for process stability, flexibility and throughput. In general, wider pressure stability leads to higher droplet formation frequency (at the same oil viscosity). As 
shown in Fig. 4.2-3, remarkable pressure stabilities were observed; however, some appreciable differences were also noticed.

In the first regime, wider pressure ranges were obtained with the narrower microplateaus, which have higher flow resistance. Also for longer micro-plateaus, wider pressure ranges were observed (results not shown), suggesting that higher flow resistance in micro-plateaus results in wider pressure ranges in the first regime. Similarly, Sugiura et al. ${ }^{22}$ and van Dijke et al. ${ }^{23}$ reported that longer channels (i.e. higher flow resistance) result in more stable droplet generation in microchannel emulsification.

In the second regime, a mixed effect is observed, as was also discussed in the viscosity ratio section. The narrow micro-plateaus add considerable extra resistance, which leads to wider pressure ranges, and constant droplet size. This is no longer the case for the intermediate micro-plateaus in which droplet formation is more dominated by the viscosity of the liquids. It seems that the narrow EDGE is stable and is suited for any liquid, while the wider EDGE is stable when used at higher viscosity ratio.

\subsection{Conclusion}

We studied the emulsification characteristics of partitioned EDGE devices using different micro-plateau widths in combination with a wide range of liquids with different viscosities. Monodisperse droplets with two distinct sizes were successfully prepared over remarkably wide pressure ranges. Our findings for the first regime in which small droplets are made, are in good agreement with the findings of other spontaneous emulsification geometries of which the droplet size was assessed as function of viscosity ratio. The second droplet formation regime showed different characteristics depending on the flow resistance of the micro-plateaus.

Our findings suggest that, due to their wide pressure ranges, full activation of microplateaus, and flexibility in regard to the liquids used, partitioned EDGE devices are good candidates for application on larger scale. 


\section{References}

1 B. Abismaïl, J. P. Canselier, A. M. Wilhelm, H. Delmas and C. Gourdon, Ultrason. Sonochem., 1999, 6, 75-83.

2 M. Saito, L. J. Yin, I. Kobayashi and M. Nakajima, Food Hydrocolloids, 2006, 20, 10201028.

3 G. Vladisavljevic, J. Memb. Sci., 2003, 225, 15-23.

4 D. J. McClements, Food emulsions : principles, practices, and techniques, CRC Press, Boca Raton, FL, 1999.

5 T. Nakashima, M. Shimizu and M. Kukizaki, Key Eng. Mater., 1991, 61-62, 513-516.

6 S.-Y. Teh, R. Lin, L.-H. Hung and A. P. Lee, Lab Chip, 2008, 8, 198-220.

7 A. Nazir, K. Schroën and R. Boom, J. Memb. Sci., 2010, 362, 1-11.

8 A. A. Maan, K. Schroën and R. Boom, J. Food Eng., 2011, 107, 334-346.

9 G. T. Vladisavljević, I. Kobayashi and M. Nakajima, Microfluid. Nanofluid., 2012, 13, 151 178.

10 K. Schroën, O. Bliznyuk, K. Muijlwijk, S. Sahin and C. C. Berton-Carabin, Curr. Opin. Food Sci., 2015, 3, 33-40.

11 K. Muijlwijk, C. Berton-Carabin and K. Schroën, Trends Food Sci. Technol., 2016, 49, 51 63.

12 K. C. Van Dijke, G. Veldhuis, K. Schroën and R. M. Boom, AIChE, 2009, 56, 833-836.

13 K. van Dijke, G. Veldhuis, K. Schroën and R. Boom, Lab Chip, 2009, 9, 2824-2830.

14 S. Sahin and K. Schroën, Lab Chip, 2015, 15, 2486-2495.

15 N. S. Cheng, Ind. Eng. Chem. Res., 2008, 47, 3285-3288.

16 R. Schmidt, K. Griesbaum, A. Behr, D. Biedenkapp, H.-W. Voges, D. Garbe, C. Paetz, G. Collin, D. Mayer and H. Höke, in Ullmann's Encycl. Ind. Chem., Wiley-VCH Verlag GmbH \& Co. KGaA, 2000.

17 A. Nazir, R. M. Boom and K. Schroën, Chem. Eng. Sci., 2014, 116, 547-557.

18 K. Van Dijke, I. Kobayashi, K. Schroën, K. Uemura, M. Nakajima and R. Boom, Microfluid. Nanofluid., 2010, 9, 77-85.

19 K. van Dijke, R. de Ruiter, K. Schroën and R. Boom, Soft Matter, 2010, 6, 321-330.

20 A. A. Maan, K. Schroën and R. Boom, Microfluid. Nanofluid., 2013, 14, 187-196.

21 T. Kawakatsu, G. Trägårdh, Y. Kikuchi, M. Nakajima, H. Komori and T. Yonemoto, J. Surfactants Deterg., 2000, 3, 295-302.

22 S. Sugiura, M. Nakajima and M. Seki, Langmuir, 2002, 18, 5708-5712.

23 K. C. van Dijke, K. Schroën and R. Boom, Langmuir, 2008, 24, 10107-10115. 



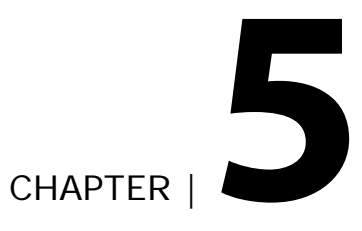

\section{Upscaling microfluidic emulsification to industrially relevant throughputs: the importance of (sub-) structure design}

This chapter has been submitted for publication as Sahin, S., Strofyllas, M., \& Schroën, K. Upscaling microfluidic emulsification to industrially relevant throughputs: the importance of (sub-) structure design. 


\section{Abstract}

In emulsion production, microfluidics offer advantages in regard to energy usage, resource utilization, and product design. This potential can only be realized if high throughputs can be achieved, and that is still challenging. In this paper, we introduce and evaluate the performance of an upscaled microfluidic EDGE device for the preparation of emulsions with $\sim 10 \mu \mathrm{m}$ droplets. The fluxes show that industrial use of microfluidic emulsification could be within reach. 


\subsection{Introduction}

Microfluidics is a multidisciplinary field at the intersection of engineering, physics, chemistry and nanotechnology, dealing amongst others with the flow behaviour of fluids at the submillimeter scale. It offers great potential for a diverse range of applications, such as drug discovery and delivery, chemical analysis and synthesis, high-throughput screening, and point-of-care diagnostics. ${ }^{1-5}$ The major commercialized applications of microfluidics are in analysis; unique features at this scale allow instant analysis with reduced reagent volumes and at high resolution, leading to cost and energy efficient applications. As eloquently formulated by Whitesides, ${ }^{6}$ "As a technology, microfluidics seems almost too good to be true: it offers so many advantages and so few disadvantages (at least in its major applications in analysis)".

Microfluidics has also been extensively used to study the underlying mechanisms and dynamics of emulsion formation and stability. ${ }^{7}$ Besides, it was shown that very highly monodisperse emulsions can be produced using microfluidics. ${ }^{8,9}$ However, the peculiarity of microfluidics that only low fluid volumes are needed becomes the main drawback when trying to make considerable amounts of product. To overcome this, many units need to work in tandem without influencing each other, and that is far from trivial, especially when droplets smaller than $10 \mu \mathrm{m}$ are targeted.

Recently, we have introduced a novel microfluidic emulsification device, namely the partitioned EDGE device. ${ }^{10}$ Unlike the regular EDGE devices that consist of main plateaus only, the droplet formation unit in partitioned EDGE devices is a two-level structure, consisting of a main plateau and several micro-plateaus connected to that This concept was realised in flat chip geometry to allow optimal observation, and promising results were obtained; the pressure stability was enhanced considerably, thereby the productivity was increased $~ 100$ fold. In the current work, we translated these findings into a new design, the multi-EDGE, in which partitioned EDGE units are operated in parallel, aiming high throughputs per unit device area. We report on the experimental performance of the multi-EDGE design for o/w emulsification, and relate the findings to the suitability of this device for larger scale production. 


\subsection{Experimental}

Fig. 5.1a-d show schematic views of the multi-EDGE device. The micro-plateaus on the top and main plateaus at the bottom of the multi-EDGE device were fabricated in 400 $\mu \mathrm{m}$ thick silicon substrates through deep reactive ion etching (Cytocentrics B.V., The Netherlands). The multi-EDGE devices used in the experiments were $10 \times 10 \mathrm{~mm}$, with an effective emulsification area of $5 \times 6 \mathrm{~mm}$. More information on the device dimensions and number of (sub-) structures is given in Table 5.1. Please note that the height of the micro-plateaus and main plateaus in multi-EDGE devices were different from those used in the partitioned EDGE device in which micro- and main plateaus had the same height $\left(H_{1}=H_{2}\right)$. Ideally we would have liked to copy the partitioned EDGE design, but technical limitations did not allow us to make the main plateaus as shallow as the micro-plateaus ( $10 \mu \mathrm{m}$ vs $2 \mu \mathrm{m})$.

Prior to experimentation, the multi-EDGE devices were subjected to plasma oxidation to ensure their hydrophilicity and thus suitability for o/w emulsification. After that, the oxidized devices were placed into a custom-made emulsification module built in our mechanical workshop. In the experiments, hexadecane (ReagentPlus ${ }^{\circledR}$ 99\%, SigmaAldrich, Germany), and 0.5 wt\% sodium dodecyl sulphate (SDS, Merck, Germany) solution were used as dispersed and continuous phases, respectively. First, the continuous phase was run through the module to wet the device. Then the oil was pushed from the bottom, and the formed droplets were carried away by the cross flowing continuous phase at the top (Fig. 5.1f); please note that the cross flow is not needed for droplet formation. The flows were controlled through a microfluidic control system (Elveflow ${ }^{\circledast}$, France), and droplet formation was monitored using an inverted microscope (Axiovert 200 MAT, Carl Zeiss B.V., The Netherlands) connected to a highspeed camera (MotionPro HS-4, IDT Inc., USA). 

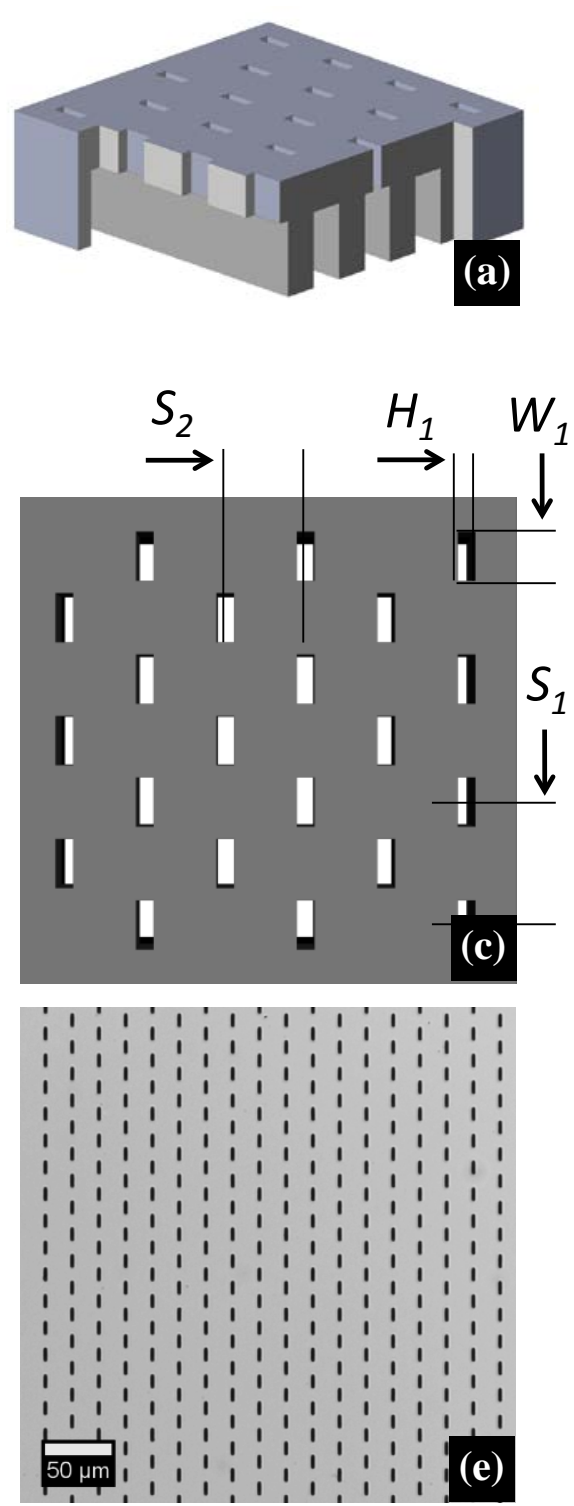
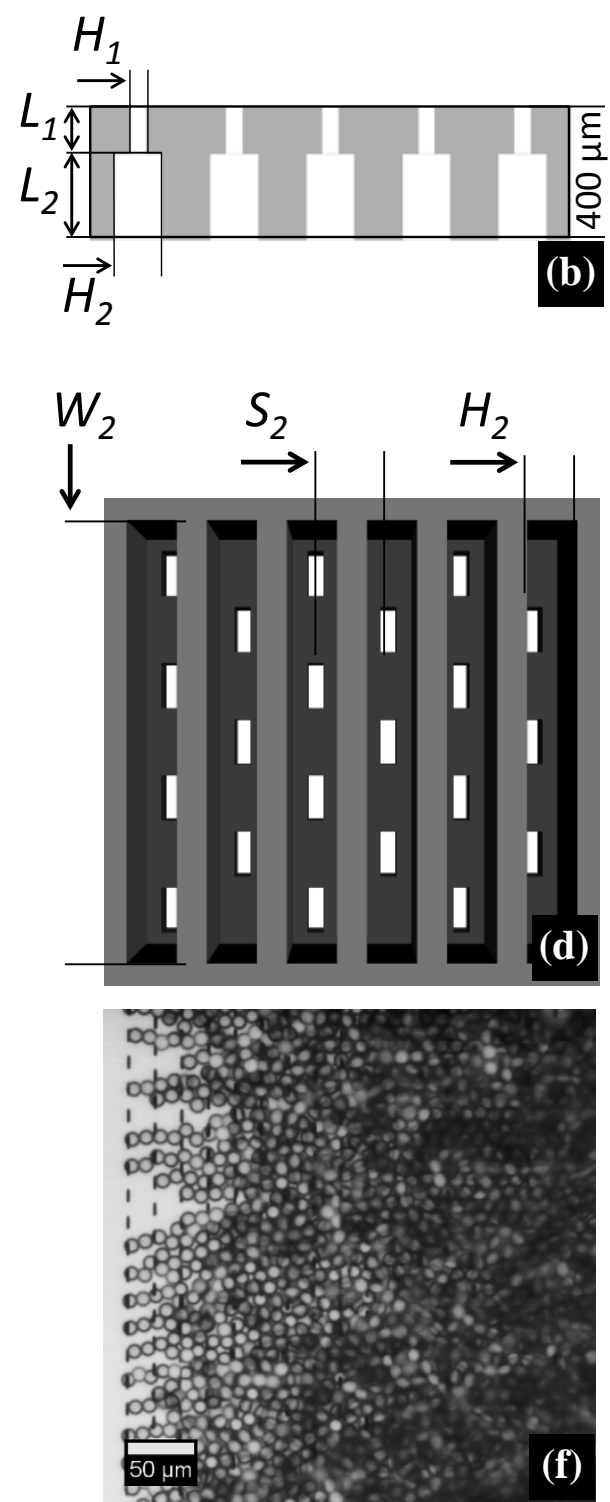

Fig. 5.1 (a) Schematic 3D representation of multi-EDGE device. Oil is pushed from the bottom side and the droplets emerge at the top side, (b) schematic section view, (c-d) schematic top and bottom views, respectively, and (e-f) Optical micrographs of the top side, before and during emulsification. Droplets are carried away from left to right by the cross flowing continuous phase; please note that the cross-flow is not needed for droplet formation. 
Table 5.1 Specifications of partitioned EDGE and multi-EDGE devices.

\begin{tabular}{|c|c|c|c|c|c|c|}
\hline \multirow[b]{2}{*}{$\begin{array}{l}\text { EDGE } \\
\text { Design }\end{array}$} & \multicolumn{3}{|c|}{ Micro-plateaus } & \multicolumn{3}{|c|}{ Main plateaus } \\
\hline & $\begin{array}{l}\text { Number } \\
{[-]}\end{array}$ & $\begin{array}{l}\text { Dimensions } \\
L_{1} \times W_{1} \times H_{1} \\
{[\mu \mathrm{m}]}\end{array}$ & $\begin{array}{l}\text { Space } \\
S_{1} \times S_{2} \\
{[\mu \mathrm{m}]}\end{array}$ & $\begin{array}{l}\text { Number } \\
{[-]}\end{array}$ & $\begin{array}{l}\text { Dimensions } \\
L_{2} \times W_{2} \times H_{2} \\
{[\mu \mathrm{m}]}\end{array}$ & $\begin{array}{l}\text { Space } \\
S_{2} \\
\mu \mathrm{m}]\end{array}$ \\
\hline $\begin{array}{l}\text { Multi-EDGE } \\
{[5 \times 2]}\end{array}$ & 100000 & $30 \times 5 \times 2$ & $15 \times 20$ & 300 & $370 \times 6000 \times 10$ & 20 \\
\hline $\begin{array}{l}\text { Multi-EDGE } \\
{[10 \times 2]}\end{array}$ & 75000 & $30 \times 10 \times 2$ & $20 \times 20$ & 300 & $370 \times 6000 \times 10$ & 20 \\
\hline $\begin{array}{l}\text { Partitioned } \\
\text { EDGE }[5 \times 2]\end{array}$ & 33 & $30 \times 5 \times 2$ & $15 \times-$ & 1 & $200 \times 500 \times 2$ & - \\
\hline
\end{tabular}

\subsection{Results and discussion}

Using multi-EDGE with $10 \times 2 \mu \mathrm{m}$ micro-plateaus, monodisperse hexadecane droplets were successfully produced over 8 hours, which was the longest time possible within working hours. Fig. 5.2 shows the droplet size as a function of applied pressure, and the very narrow droplet size distribution of the droplets produced at 130 mbar together with a micrograph. Droplet formation started at $95 \mathrm{mbar}$ and remained monodisperse up to 130 mbar, above which blow-up events occurred, as indicated by the filled symbols.

The fraction of active micro-plateaus and the droplet formation frequency were calculated through analysis of 75 micro-plateaus in the first three rows; observation of the other rows was obscured due to the abundance of droplets (Fig. 5.1f). Both the number of active micro-plateaus and droplet formation frequency (similar for all active micro-plateaus) increased rather linearly with pressure (Fig. 5.3a-b), and thus both contributed to the flux increase (Fig. 5.3c). At the maximum pressure for monodisperse droplet formation (130 mbar), $80 \%$ of the micro-plateaus were active with an average frequency of $58 \mathrm{~Hz}$, amounting to $272 \mathrm{~L} \mathrm{~m}^{-2} \mathrm{~h}^{-1}$ oil flux (assuming uniform performance over the entire surface of the device). 

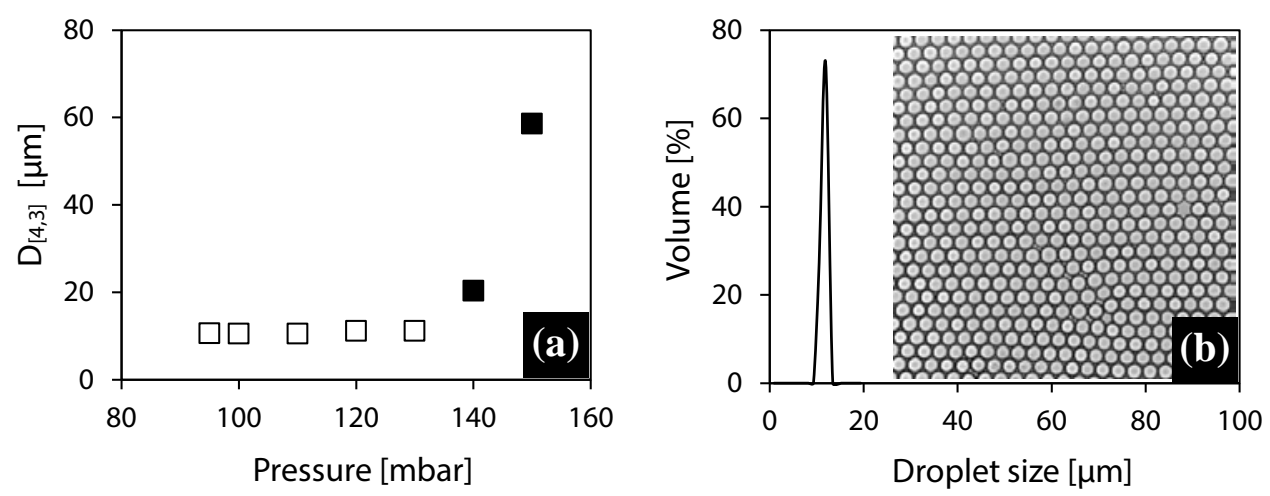

Fig. 5.2 (a) Effect of dispersed phase pressure on droplet size, and (b) droplet size distribution of an emulsion produced at 130 mbar using multi-EDGE device; span is 0.1. The inset is an optical micrograph of the droplets.
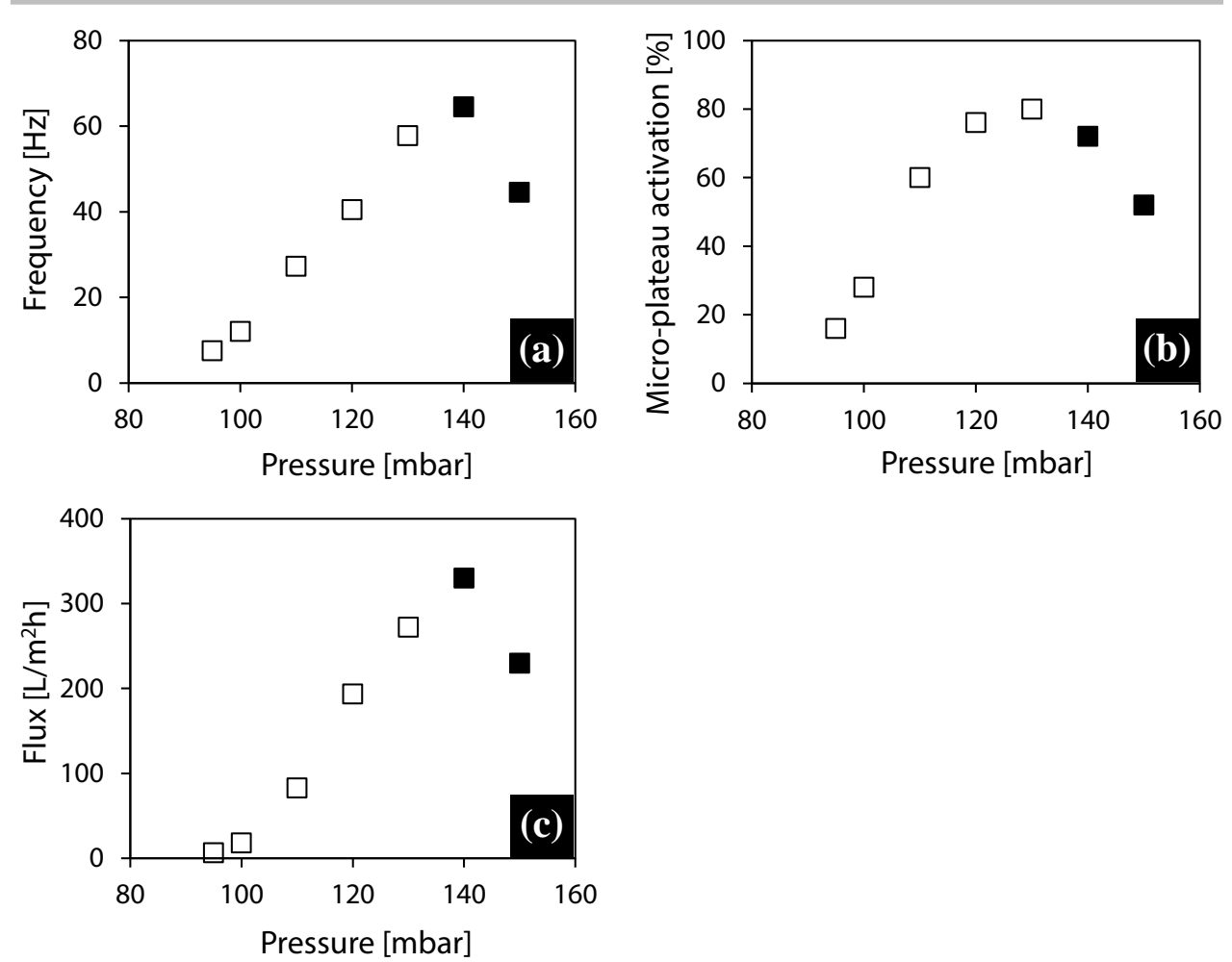

Fig. 5.3 Effect of dispersed phase pressure on (a) frequency, (b) micro-plateau activation, and (c) hexadecane flux. The filled symbols denote the blow-up occurrence. 
Table 5.2 gives an overview of the results obtained with partitioned and multi-EDGE devices. The droplet size obtained with multi-EDGE is comparable to that of the first regime in the partitioned EDGE device, but the second regime was not observed (as discussed later). The maximum droplet formation frequency is an order of magnitude lower in multi-EDGE, which is due to the much lower pressure stability that is codetermined by the much lower flow resistance (i.e. the height) of the main plateau. Besides, the flow resistance distribution over the entire plateau (i.e. main and microplateaus) influences the activation of micro-plateaus. Both aspects will be discussed later.

The difference between the results of partitioned and multi-EDGE devices can be better understood through the flux criterion derived for spontaneous emulsification in microchannels, ${ }^{11}$ in which droplet detachment takes place when the oil flux from the neck to the droplet exceeds that from the supply channel to the neck keeping the droplet connected. This flux criterion is dominated by interfacial forces up to a certain maximum pressure, or up to a certain maximum oil velocity as termed by other researchers. ${ }^{12,13}$ Beyond this point, viscous forces dominate and prevent the neck from collapsing, therewith leading to blow-up.

The geometry of partitioned and multi-EDGE devices are more complex, but in essence the total flow can be split up in two parts. In line with what is described above for microchannels, one is the oil supply through the main plateau to the micro-plateau, and the other one is from micro-plateau (through neck) to droplet. The high flow resistance in the main plateau of the partitioned EDGE leads to steady flow toward the

Table 5.2 Pressure stability and throughput of partitioned EDGE and multi-EDGE devices for the preparation of hexadecane droplets.

\begin{tabular}{llll}
\hline & $\begin{array}{l}\text { Pressure } \\
\text { stability }[\mathrm{mbar}]\end{array}$ & $\begin{array}{l}\text { Droplet } \\
\text { diameter }[\mu \mathrm{m}]\end{array}$ & $\begin{array}{l}\text { Max. frequency per } \\
\text { micro-plateau }[\mathrm{Hz}]\end{array}$ \\
\hline Multi-EDGE $[5 \times 2]$ & - & - & - \\
Multi-EDGE $[10 \times 2]$ & $95-130$ & 10 & 58 \\
Partitioned EDGE $[5 \times 2]$ & $115-1000\left(1^{\text {st }}\right)$ & 9 & 1049 \\
& $1400-2100\left(2^{\text {nd }}\right)$ & 28 & 137 \\
\hline
\end{tabular}


$5 \times 2 \mu \mathrm{m}$ micro-plateaus that activate uniformly and form droplets over a wide pressure range (115-1000 mbar) due to the steady oil supply from main plateau to the microplateaus. In multi-EDGE devices, which have relatively lower flow resistance in the main plateau, the oil flows much more readily to the micro-plateaus. At this stage, the activation pressure of the micro-plateaus needs to be exceeded for invasion and subsequent droplet formation to take place. This resistance difference between the micro-plateaus and main plateau (i.e. resistance distribution over the entire plateau structure) determines the droplet formation behaviour and pressure stability of the emulsification process. For instance, when using multi-EDGEs with $5 \times 2 \mu \mathrm{m}$ microplateaus, it was not possible to form monodisperse droplets; as soon as the activation pressure of the micro-plateaus was reached (>110 mbar) few necks formed, but at the same time the oil flow over the activated micro-plateaus was so high that the necks could not collapse and blow-up occurred immediately. When using multi-EDGE with $10 \times 2 \mu \mathrm{m}$ micro-plateaus, the activation pressure was reached at $95 \mathrm{mbar}$ (lower than for $5 \times 2 \mu \mathrm{m}$ ones) and the oil supply through main plateau to micro-plateaus was consequently lower. In this case, the neck was still capable to collapse and form droplets at relatively low applied pressures. However, above $130 \mathrm{mbar}$ the oil flow over the activated micro-plateaus became so high that the neck could not collapse anymore and blow-up occurred. Since the flux increases rather linearly with applied pressure (Fig. 5.3c), the lower maximum pressure explains why the throughput obtained on single micro-plateau level is much lower in multi-EDGE than in partitioned EDGE. For productivity reasons, a shallow main plateau is preferred.

This makes us postulate that the flow resistance ratio between micro-plateau and main plateau, which is always $>1$ in our work, should not be too high to maintain monodisperse droplet formation and prevent early blow-up. This is in agreement with the work of Gijsbertsen-Abrahamse et al. ${ }^{14}$ on cross-flow emulsification; membranes with a lower ratio of pore resistance and sublayer resistance resulted in better control over droplet formation, and thereby narrower droplet size distribution.

To be complete, it should be mentioned that unlike the partitioned EDGE devices, multi-EDGE devices with $10 \times 2 \mu \mathrm{m}$ micro-plateaus did not show a second monodisperse droplet formation regime (Table 5.2). Again, this is most probably related to the flow resistance distribution, but it is difficult to substantiate since the underlying mechanism is hardly understood. 
We now compare multi-EDGE with straight-through microchannels (MCs), being the most similar upscaled microfluidic emulsification designs to multi-EDGE (Fig. 5.4). In asymmetric straight-through MCs, circular channels lead to larger rectangular slits on the top surface, ${ }^{15}$ resulting in a resistance ratio smaller than 1. In this regard, they differ from multi-EDGE devices in which the resistance ratio is always significantly greater than 1 (see also Fig. 5.4). This difference is thought to influence microchannel activation; for straight-through MCs, the fraction of active channels decreased with decreasing oil viscosity and slit size (which are related to the droplet size). For instance, while $50 \%$ and $95 \%$ of the channels were active for the preparation of $30 \mu \mathrm{m}$ tetradecane and soybean oil droplets at 2700 and $120 \mathrm{~L} \mathrm{~m}^{-2} \mathrm{~h}^{-1}$, respectively, ${ }^{16}$ only $12 \%$ of the channels were active in the preparation of $9.8 \mu \mathrm{m}$ soybean oil droplets using symmetric straight-through MCs. ${ }^{17}$ For small droplets $(<10 \mu \mathrm{m})$, multi-EDGE devices hold a competitive advantage due to the high micro-plateau activation. This is in line with the findings of Gijsbertsen-Abrahamse et al. ${ }^{14,18}$ for cross-flow emulsification; more pores become active with increasing resistance ratio (pore/sublayer).

Regarding the comparison on throughput, this should ideally be done for the same droplet size and oil viscosity, but we could not find a MC study in which the same droplet size was used in combination with the same oil viscosity. However, a derived comparison is possible; findings of MC studies suggest that the $2700 \mathrm{~L} \mathrm{~m}^{-2} \mathrm{~h}^{-1}$ throughput of $30 \mu \mathrm{m}$ tetradecane droplets would be an order of magnitude lower when $10 \mu \mathrm{m}$ droplets are targeted. Therefore, the current design of multi-EDGE, with its $272 \mathrm{~L} \mathrm{~m}^{-2} \mathrm{~h}^{-1}$ throughput for $10 \mu \mathrm{m}$ hexadecane droplets, is similar to straight-through MCs, while there is still room for further improvement.
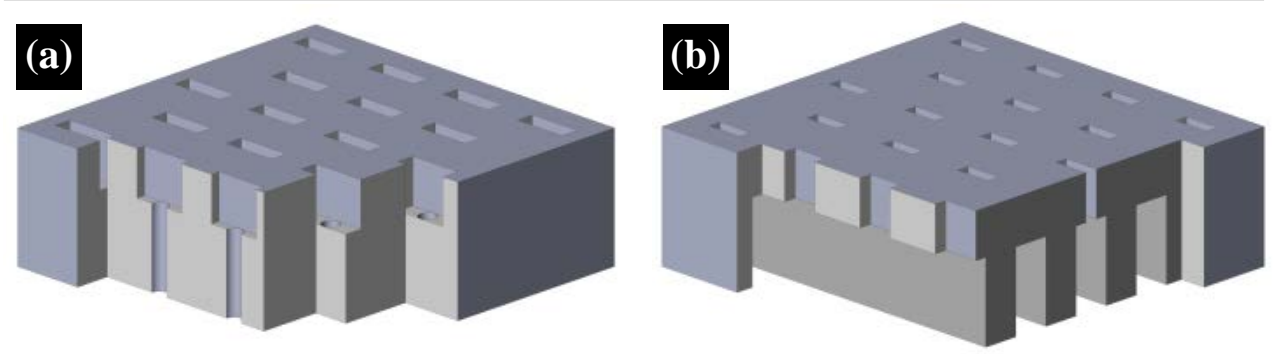

Fig. 5.4 Schematic 3D representation of asymmetric straight-through MCs (a), in comparison with multi-EDGE (b). Oil is pushed through the circular channels at the bottom and droplets form at the mouth of the slits on top. 


\subsection{Conclusion}

In conclusion, this work has shown that multi-EDGE devices enable stable production of $10 \mu \mathrm{m}$ monodisperse hexadecane droplets at $\sim 0.3 \mathrm{~m}^{3} \mathrm{~m}^{-2} \mathrm{~h}^{-1}$ over long periods of time, which brings the device close to industrially relevant scales. We are convinced that the device can be improved further, and for this construction limitations need to be mitigated. We like to challenge constructors of microfluidics to help us making multi-EDGE a break-through technology.

\section{References}

1 E. W. Esch, A. Bahinski and D. Huh, Nat. Rev. Drug Discov., 2015, 14, 248-260.

2 R. Riahi, A. Tamayol, S. A. M. Shaegh, A. M. Ghaemmaghami, M. R. Dokmeci and A. Khademshosseini, Curr. Opin. Chem. Eng., 2015, 7, 101-112.

3 K. S. Elvira, X. C. i Solvas, R. C. R. Wootton and A. J. DeMello, Nat. Chem., 2013, 5, 905915.

4 E. Brouzes, M. Medkova, N. Savenelli, D. Marran, M. Twardowski, J. B. Hutchison, J. M. Rothberg, D. R. Link, N. Perrimon and M. L. Samuels, Proc. Natl. Acad. Sci. U. S. A., 2009, 106, 14195-14200.

5 W. Jung, J. Han, J.-W. Choi and C. H. Ahn, Microelectron. Eng., 2015, 132, 46-57.

6 G. M. Whitesides, Nature, 2006, 442, 368-373.

7 T. Krebs, K. Schroën and R. Boom, Lab Chip, 2012, 12, 1060-1070.

8 W. Engl, R. Backov and P. Panizza, Curr. Opin. Colloid Interface Sci., 2008, 13, 206-216.

9 G. T. Vladisavljević, I. Kobayashi and M. Nakajima, Microfluid. Nanofluid., 2012, 13, $151-$ 178.

10 S. Sahin and K. Schroën, Lab Chip, 2015, 15, 2486-2495.

11 K. C. van Dijke, K. Schroën and R. Boom, Langmuir, 2008, 24, 10107-10115.

12 S. Sugiura, M. Nakajima, N. Kumazawa, S. Iwamoto and M. Seki, J. Phys. Chem. B, 2002, 106, 9405-9409.

13 I. Kobayashi, M. Nakajima and S. Mukataka, Colloids Surfaces A Physicochem. Eng. Asp., 2003, 229, 33-41.

14 A. J. Gijsbertsen-Abrahamse, A. van der Padt and R. M. Boom, J. Memb. Sci., 2004, 230, 149-159.

15 I. Kobayashi, S. Mukataka and M. Nakajima, Langmuir, 2005, 21, 7629-7632. 
16 G. T. Vladisavljević, I. Kobayashi and M. Nakajima, Microfluid. Nanofluid., 2011, 10, $1199-$ 1209.

17 I. Kobayashi, T. Takano, R. Maeda, Y. Wada, K. Uemura and M. Nakajima, Microfluid. Nanofluid., 2007, 4, 167-177.

18 A. J. Gijsbertsen-Abrahamse, A. van der Padt and R. M. Boom, J. Memb. Sci., 2003, 217, 141-150. 


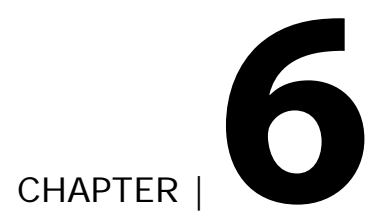

\section{High throughput production of double emulsions using packed bed premix emulsification}




\section{Abstract}

We explored the potential of packed bed premix emulsification for homogenizing food-grade coarse w/o/w emulsions. Using packed beds with different glass bead sizes (30-90 $\mu \mathrm{m})$ at different applied pressures (200-600 kPa), emulsions with reasonably uniform droplet size (span $~ 0.75)$ were produced successfully at high fluxes (100-800 $\left.\mathrm{m}^{3} \mathrm{~m}^{-2} \mathrm{~h}^{-1}\right)$. Sodium chloride was used as a release marker: after five homogenization cycles, the produced emulsions were found to retain almost all of their initial content (99\%). As was previously found for single emulsions, the packed bed system proved to be effective in breaking up the w/o/w emulsion droplets, with droplet to pore size ratios as low as 0.3 . Results were analysed through the pore Reynolds number, $R e_{p}$, which characterizes the flow inside the packed bed, and were related back to the droplet break-up mechanisms occurring. At high $R e_{p}$, droplet break-up was expected to be governed by shear forces while at low $R e_{p}$, there is a shift from shear-based to spontaneous droplet break-up. 


\subsection{Introduction}

Double emulsions (DEs) are emulsions of emulsions and if they can be prepared in sufficient quantity, which is far from trivial due to their inherent fragility, they possess great potential for application amongst others in food, pharmaceutics, cosmetics and chemicals. ${ }^{1}$ For example, low calorie food products, ${ }^{2-4}$ taste masking ${ }^{1,5}$ encapsulation and controlled release of flavour and functional ingredients, ${ }^{3,5-7}$ or drug delivery systems ${ }^{1,8}$ may become a reality through application of double emulsions. As mentioned, double emulsions are fragile and inherently difficult to make, which often results either in low encapsulation efficiency and/or fast release of the encapsulated component. Both aspects are used to characterize and compare preparation processes for double emulsions. ' Controlling the stability and/or instability of DEs is important; on the one hand, the amount of encapsulated material should be as high as possible and the product should be stable on the shelf, while on the other hand, the DEs should become unstable upon experiencing a specific trigger. These are often contradictory demands, and many studies have addressed the challenges and possible strategies related to the stability of $\mathrm{w} / \mathrm{o} / \mathrm{w}$ emulsions, mostly through selection of the formulation and controlling droplet size..$^{3,5,6,9-13}$ The progress made in this field is encouraging (i.e. in relation to formulation parameter studies of DEs), although it also should be mentioned that clear guidelines that connect the various product (and process) parameters are not available, and we think that this is essential to make a product reproducibly. The interested reader is referred through to a recent review on double emulsions and the aspects that affect their stability. ${ }^{5}$

Clearly, the method of dispersion is of great importance, as it influences the initial encapsulation efficiency; however this aspect has received much less attention in literature. Using classic emulsification methods, only widely distributed large droplets can be produced at low-shear conditions, otherwise the internal phase is destroyed through the shearing action of the emulsification device, which results in low encapsulation efficiency. ${ }^{1}$ For instance the encapsulation efficiency obtained with a laboratory mixer at high shear rate was $50-60 \%{ }^{14}$ Therefore, production processes that allow adequate control over the preparation process and suppress release during the production have to be developed. There are already some examples of microchannel 
and membrane processes reported to yield encapsulation efficiencies higher than $90 \% \cdot{ }^{15,16}$

For the production of single emulsions, techniques based on microstructured devices, such as membranes and microfluidic devices, are known to be much less energy intensive as classic emulsification technology. ${ }^{17,18}$ In the preparation of single emulsions, microfluidic devices are known for their outstanding control over droplet size and size distribution. In this aspect, they clearly outperform membrane emulsification systems while they lag behind in terms of productivity. ${ }^{19-26}$ In some cases it even has been reported that microstructured devices can be used for double emulsion preparation. . $16,27-30^{-30}$

When using microstructured devices, emulsification is mostly carried out starting from two phases that are dispersed into each other as is for example the case in cross-flow membrane emulsification (ME), but alternatively also a coarse emulsion may be used as a starting point, as is the case in premix membrane emulsification. Compared to crossflow ME, premix ME allows higher dispersed phase fractions at high production rates at the expense of a lower but still reasonable monodispersity. ${ }^{31}$

The regular membranes used in premix membrane emulsification, such as Shirasu porous glass (SPG) and polymeric membranes are sensitive to depth fouling and the fouled pores are not accessible to cleaning agents, which limits the use of these systems. ${ }^{32,33}$ It is also expected that the internal phase of the double emulsions interacts with the membrane, and that will result in untimely release of the encapsulated component. Clearly interactions with the membrane need to be minimized, and this makes the recently introduced metal sieves with straight-through pores an interesting alternative, also because they allow operation at much higher fluxes as reported for regular membranes when used for single emulsion production. ${ }^{34}$ Likewise, using a supported packed bed of micron-sized glass beads, acting as a dynamic membrane, allows for the system to be disintegrated, cleaned and reused afterwards. ${ }^{33}$ For o/w emulsification, both metal sieves and packed bed system were reported to have at least an order of magnitude higher fluxes than often reported for SPG membranes, while the packed bed system gave better monodispersity ( ppan $=0.75$ ) than metal sieves alone $($ span $=1.0-1.4)$. The significant difference in droplet size distribution was 
suggested to be due to the change in droplet break-up mechanism, going from inertia to constriction for sieves and packed beds respectively. ${ }^{32,35}$

In this paper, we explore the potential of packed bed systems for the preparation of $\mathrm{w} / \mathrm{o} / \mathrm{w}$ double emulsions, and compare the obtained results with those of other premix emulsification studies. We investigated various parameters, such as applied pressure, bed structure, and number of homogenization cycles, and report droplet size and distribution, and fluxes. Besides we relate the results back to droplet break-up mechanism through analysis of the pore Reynolds number (as defined in Equation 6.9). Encapsulation stability and release characteristics of the emulsions during storage are not the major scope of this work, so this aspect will only be discussed briefly.

\subsection{Experimental}

\subsubsection{Chemicals}

MilliQ ultra-pure water was used for the preparation of the aqueous phases. Sunflower oil was purchased from a local supermarket (Wageningen, The Netherlands). Sodium chloride ( $\mathrm{NaCl}$ ) (Merck KGaA, Darmstadt, Germany) was used as a release marker in the inner aqueous phase. Glucose monohydrate (Merck, Darmstadt, Germany) was incorporated in the outer aqueous phase to counterbalance the osmotic pressure exerted by $\mathrm{NaCl}$ in the inner aqueous phase. Tween 20 (Sigma, USA) and polyglycerol polyricinoleate (PGPR) (Givaudan, Vernier, Switzerland) were used as water and oil soluble emulsifiers, respectively, as described in the next section. All components are food grade.

\subsubsection{Coarse w/o/w preparation}

For each experiment, a $300 \mathrm{~mL}$ batch of $\mathrm{w} / \mathrm{o} / \mathrm{w}$ emulsion was prepared at room temperature $\left(23-27^{\circ} \mathrm{C}\right)$ in two steps. For the preparation of the primary w/o emulsion, $1 \mathrm{M} \mathrm{NaCl}$ solution was dispersed at $25 \% \mathrm{v} / \mathrm{v}$ into sunflower oil containing 5\% PGPR using an Ultra-Turrax homogenizer (IKA ${ }^{\oplus} \mathrm{T}-18$ basic, Staufen, Germany) at $11000 \mathrm{rpm}$ for $6 \mathrm{~min}$. The typical Sauter mean diameter, $d_{32}$, of the inner water droplets was $0.22 \pm 0.01 \mu \mathrm{m}$ with a span of $2 \pm 0.1$; please note that this emulsion could be reproducibly obtained. The secondary emulsion $(\mathrm{w} / \mathrm{o} / \mathrm{w})$ was prepared by gradually 
adding $15 \mathrm{~mL}$ of the primary emulsion (w/o) to the outer aqueous phase ( $285 \mathrm{~mL}$ of $2 \mathrm{M}$ glucose monohydrate solution containing $0.5 \% \mathrm{v} / \mathrm{v}$ Tween 20 ) under mixing on a magnetic stirrer (IKA ${ }^{\circledast}$ KMO 2 basic, Staufen, Germany) at $700 \mathrm{rpm}$ for $16 \mathrm{~min}$. The coarse double emulsion had typical Sauter mean diameters, $d_{32}$, of $45 \mu \mathrm{m}$ with an average span of 4 .

The Sauter mean diameter, $d_{32}$, is defined as follows:

$d_{32}=\frac{6}{S_{v}}=\left(\sum_{i=1}^{n_{S}} \frac{v_{i}}{d_{i}}\right)^{-1}$

where $S_{v}$ is the droplet surface area per unit volume, $v_{i}$ is the volume fraction of droplets in the $i^{\text {th }}$ size class of the discretized distribution, $d_{i}$ is the mean droplet diameter in that class, and $n_{s}$ is the number of size classes.

The span, indicating the uniformity of the droplet size distribution, is defined as:

$\delta=\frac{d_{90}-d_{10}}{d_{50}}$

where $d_{x}$ is the droplet diameter corresponding to $x \%$ volume on a cumulative droplet size distribution curve.

\subsubsection{Experimental setup and emulsification procedure}

The premix emulsification setup is schematically presented in Fig. 6.1. The pressure vessel was connected to a nitrogen supply and the packed bed module. The packed bed module consisted of a column made of polymethyl methacrylate (built by the mechanical workshop of Wageningen University), at the bottom of which a nickel sieve (described in Section 6.2.4) was placed between two rubber O-rings. The nickel sieve served as a support to the layer of hydrophilic glass beads placed on it.

The prepared $300 \mathrm{~mL}$ premix w/o/w emulsion was placed in the pressure vessel, and the vessel was pressurized through the nitrogen supply; typical applied pressures were 
200-600 kPa. The emulsification was started by opening the outlet valve of the packed bed column and the homogenized emulsion was collected in a flask placed on an electrical balance connected to a computer through which the increase in mass per second was recorded. The flux across the packed bed, $J$, was calculated from the mass flow rate, $\phi_{m}$, through the following formula:

$J=\frac{\phi_{m}}{\rho_{e} A}$

where $\rho_{e}$ is the emulsion density and $A$ is the effective surface area of the packed bed.

The homogenization cycle was repeated five times and samples from each pass were collected for sizing with the Mastersizer as described in Section 6.2.6. The oil droplet size of the obtained emulsions was very reproducible ( $<5 \%$ error), as was the case for single emulsions. This is illustrated in Fig. 6.2 with two examples of size distributions obtained for duplicated experiments.

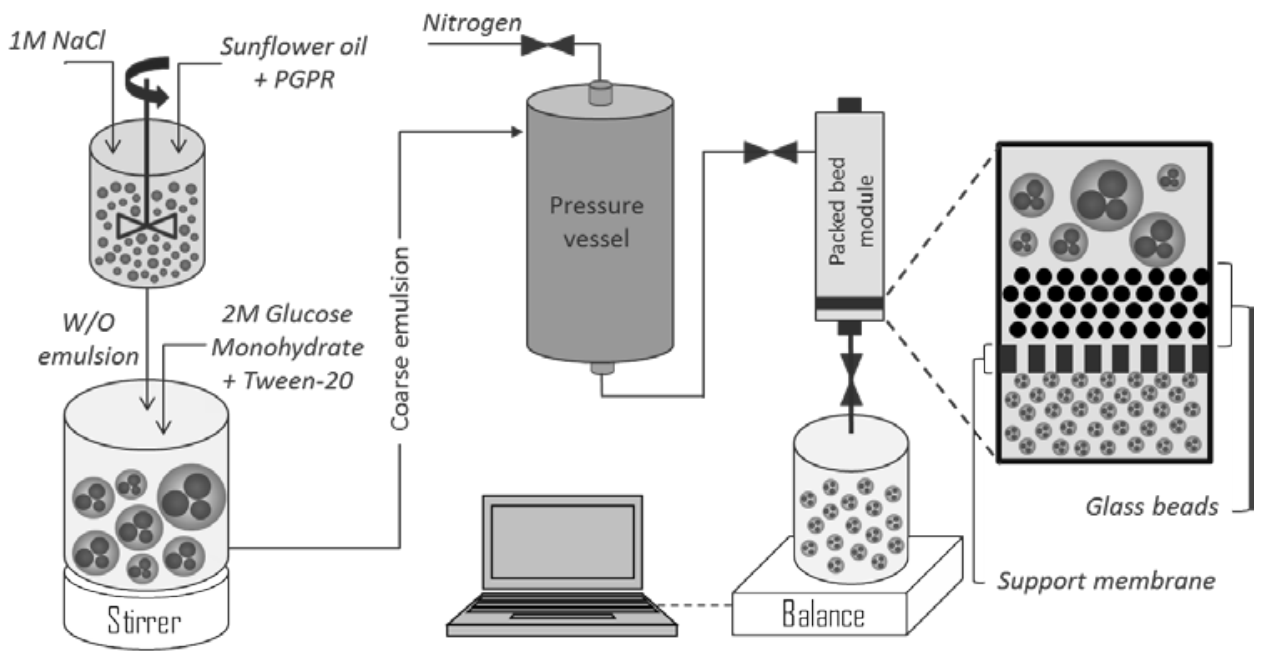

Fig. 6.1 Schematic representation of the experimental setup and emulsification procedure. 


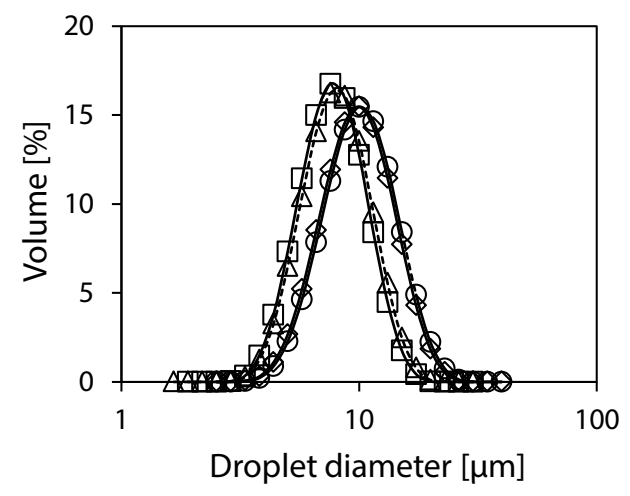

Fig. 6.2 The size distribution of oil droplets containing inner water droplets for two duplicate experiments conducted at $400 \mathrm{kPa}$ and at a bed height, $H_{\text {bed, }}$ of $2 \mathrm{~mm}$. Two different bead sizes, $d_{b}$, were used: ( $\square$ ) and $(\Delta) d_{b}=55 \mu \mathrm{m}$; (०) and $(\diamond) d_{b}=30 \mu \mathrm{m}$.

\subsubsection{Nickel sieve}

The nickel sieves used as a support were obtained from Veco B.V., Eerbeek, The Netherlands. The specifications and SEM images of the sieve used are given in Table 6.1. In our experiments the sieves were placed in the column in such a way that their front side was facing the glass beads, although it should be mentioned that placing the sieve the other way around had no influence on the results.

Table 6.1 Specifications of the nickel sieve used, with its front and back side SEM images.

Sieve specifications
Pore size: $11.6 \times 331 \mu \mathrm{m}$
Thickness: $350 \mu \mathrm{m}$
Porosity: $3.95 \%$
Effective surface area: $1.43 \mathrm{~cm}^{2}$




\subsubsection{Packed bed and characterisation of the flow}

The packed bed module was prepared by packing glass beads of different sizes on the support sieve. A close-up of the packed bed is sketched at the right side of Fig. 6.1, and the characteristics of the glass beads used and resulting packed bed are given in Table 6.2. Five different bead size fractions were obtained by sieving from a stock of glass beads (100HFL, Pneumix SMG-AF) with a wide size distribution (30-200 $\mu \mathrm{m})$ as described in the work of Nazir et al. ${ }^{35}$

The porosity of the packed bed, $\varepsilon$, was calculated as:

$\varepsilon=1-\frac{\rho_{b}}{\rho_{p}}$

where $\rho_{b}$ and $\rho_{p}$ are the measured bulk and particle density of the beads.

To determine the structural properties of the packed bed, the adopted capillary model for fixed beds proposed by Comity and Renaud was used. ${ }^{36}$ Pore diameter, $d_{p}$, was defined as follows:

$d_{p}=\frac{4 \varepsilon}{A_{v d}(1-\varepsilon)}$

Table 6.2 Characteristics of the glass beads and resulting packed bed.

\begin{tabular}{|c|c|c|c|}
\hline \multicolumn{2}{|l|}{ Bead specifications } & \multicolumn{2}{|l|}{ Bed properties } \\
\hline Diameter, $d_{b}[\mu \mathrm{m}]$ & Span, $\delta[-]$ & Pore diameter, $d_{p}[\mu \mathrm{m}]$ & Porosity, $\varepsilon[-]$ \\
\hline 30 & 1.14 & 13.33 & 0.4 \\
\hline 55 & 0.82 & 24.44 & 0.4 \\
\hline 65 & 0.65 & 28.89 & 0.4 \\
\hline 78 & 0.65 & 33.33 & 0.4 \\
\hline 90 & 0.64 & 40.00 & 0.4 \\
\hline
\end{tabular}


where $A_{v d}$ is the specific surface area, which is the ratio of a particle's surface area to its volume.

For a spherical particle, glass bead in this case:

$A_{v d}=\frac{6}{d_{b}}$

The bed tortuosity, $\xi$, was calculated as:

$\xi=1+q \ln (1 / \varepsilon)$

where $q$ is 0.41 for tightly packed spheres.

The average pore velocity, $v_{p}$, was calculated as:

$v_{p}=\frac{v_{o} \xi}{\varepsilon}$

where $v_{o}$ is the superficial velocity equal to flux across the packed bed, $J$. The flow inside the packed bed is characterized using the pore Reynolds number, $R e_{p}$, which is defined as:

$R e_{p}=\frac{\rho_{e} v_{p} d_{p}}{\eta_{e}}$

where $\eta_{e}$ is the emulsion viscosity.

\subsubsection{Characterization of $w / o / w$ emulsions}

The size (distribution) of the oil droplets in all w/o/w emulsions was determined with a laser diffraction particle size analyser (Mastersizer 2000, Malvern Instruments Ltd., UK). 
Although the oil droplets contained small inner water droplets which may induce inhomogeneity in laser diffraction signal, the dispersed phase was assumed to be pure sunflower oil. For a random selection of samples, it was checked whether the measured droplet size values were in agreement with microscopic observations, and this was always the case. The average of three readings from the Mastersizer was taken for droplet size and droplet size distribution (span).

\subsubsection{Encapsulation efficiency}

Encapsulation efficiency (EE \%) was expressed as the percentage of $\mathrm{NaCl}$ retained in the oil droplets relative to the total amount added. Both for freshly prepared and stored $\mathrm{w} / \mathrm{o} / \mathrm{w}$ samples, encapsulation efficiency was determined by quantifying the amount of $\mathrm{NaCl}$ released through conductivity measurement (SevenMulti meter, Mettler Toledo International Inc., USA) and using a calibration curve. The encapsulation efficiency was calculated as follows:

$\mathrm{EE} \%=\left(\frac{C_{\text {total }}-C_{w 2}}{C_{\text {total }}}\right) \times 100$

where $C_{w 2}$ is the concentration of $\mathrm{NaCl}$ released into the outer aqueous phase and $C_{\text {total }}$ is the concentration of $\mathrm{NaCl}$ in case all $\mathrm{NaCl}$ in the inner aqueous phase were released into the outer aqueous phase.

\subsection{Results and discussion}

For the preparation of single emulsions using packed bed premix emulsification, Nazir and co-workers established scaling relations taking into account process parameters such as bead size, bed height and applied pressure. ${ }^{35}$ The dynamics of double emulsion droplets and their break-up mechanism are not well understood, ${ }^{37}$ therefore it is expected that the scaling relations derived by Nazir et al. ${ }^{35}$ may not hold. In the present work, we first have briefly discussed the effects of some of the process parameters individually, and compiled the results into a dimensionless plot from which conclusions 
regarding droplet break-up mechanisms were made. Besides, the effect of process settings on the encapsulation efficiency was investigated.

\subsubsection{Applied pressure}

First the effect of applied pressure on flux was investigated for a bed with $65 \mu \mathrm{m}$ glass beads of $2 \mathrm{~mm}$ height (see Fig. 6.3). The flux increased fairly linearly with pressure especially at the $3^{\text {rd }}$ and $5^{\text {th }}$ passes, which is as expected for a single phase system. The actual flux values were in agreement with those found for single emulsions. ${ }^{35}$ The linear behaviour indicates that in general the double emulsions behaved as one liquid, and that the droplets did not accumulate before or while passing the bed. Possibly, the data point measured at $500 \mathrm{kPa}$ for the first pass was an exception; for these settings we repeatedly found that the flux increased less than expected, and this could indicate that emulsion droplets (slightly) accumulated in or before the bed. This could also be the case for other passes for which the flux values were slightly lower as for the first pass; there were simply more droplets present due to the refinement that took place, and those may have increased the effective viscosity in the pores and the packed bed leading to slightly lower fluxes.

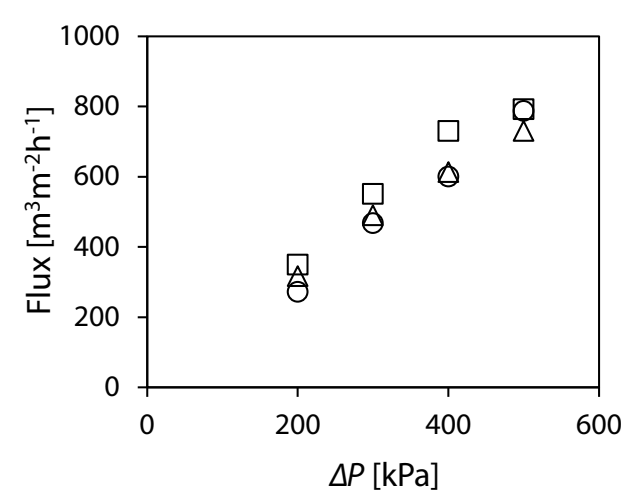

Fig. 6.3 Transmembrane flux obtained through the $65 \mu \mathrm{m}$ glass beads at a bed height, $H_{\text {bed, }}$ of 2 $\mathrm{mm}$ as a function of applied pressure, $\Delta \mathrm{P}:(\square) 1^{\text {st }}$ pass, $(\Delta) 3^{\text {rd }}$ pass, $(\circ) 5^{\text {th }}$ pass. 
When comparing the obtained fluxes with literature, it is clear that they are much higher than the highest reported fluxes (at $150 \mathrm{kPa}$ ) for the production of w/o/w by premix membrane emulsification (ME) with SPG membranes (10.7 $\mu \mathrm{m}$ mean pore diameter, porosity of $55.2 \%$ and tortuosity of 1.3$),{ }^{29,38}$ while there is room for further improvement by increasing the pressure in the current investigation. On the other hand, the fluxes obtained are a factor of 3 lower than those reported by Nazir et al. ${ }^{35}$ for single emulsions using packed bed systems. This is because the double emulsion had 3.6 times higher apparent viscosity (3.6 mPa s) than single emulsions (i.e. flux scales reciprocally with viscosity).

In Fig. 6.4, the size of the droplets relative to the calculated pore size, and the span of the obtained droplet size distribution are shown. The size of the droplets was always smaller than the pore size, and this indicates that the bed was rather effective in droplet break-up, as was previously reported for single emulsions. In SPG cross-flow membrane emulsification, the size of the droplets that are generated is always 2-10 times the pore size ${ }^{39}$ in spontaneous emulsification microfluidics, the droplet size is 3-6 times that of the smallest dimension of the droplet formation unit, $25,28,40,41$ therewith indicating the differences between the methods.
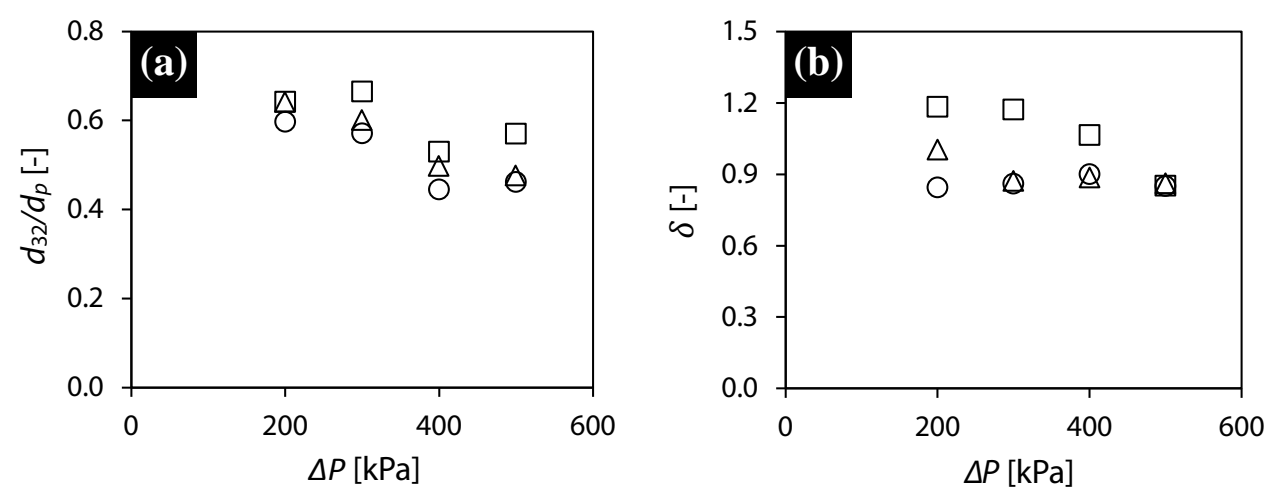

Fig. 6.4 (a) Dimensionless droplet diameter, $d_{32} / d_{p}$, and (b) droplet span, $\delta$, obtained through the $65 \mu \mathrm{m}$ glass beads at a bed height, $H_{\text {bed, }}$ of $2 \mathrm{~mm}$ as a function of applied pressure, $\Delta \mathrm{P}:(\square) 1^{\text {st }}$ pass, $(\Delta) 3^{\text {rd }}$ pass, $(0) 5^{\text {th }}$ pass. 
As expected, a higher size reduction was achieved at higher applied pressure, which is associated with the higher shear stresses inside the pore labyrinth as a result of increased flow velocity. Possibly, also the number of active pores increased, but that can only explain the observation if the velocity in the pores was also higher at high pressure. Given the size of the pores it is expected that they were all active, and that increasing the pressure mainly influenced the average velocity in the pores, not so much the amount of active pores. At all applied pressures, the largest average droplet size reduction was found after the first pass after which only a slight reduction was observed.

The droplet size distribution after the first pass was wider at low applied pressures compared to the higher ones, but the eventually obtained span was independent of the applied pressure (Fig. 6.4b). This is attributed to the higher pore velocity at higher pressures leading to more efficient droplet break-up, which has led to the final span being reached after less passes.

\subsubsection{Droplet break-up mechanism}

In premix emulsification, droplet break-up can be governed by localized shear forces (see also previous section), interfacial tension effects and steric hindrance between droplets. ${ }^{42}$ While under different conditions, one mechanism may dominate the droplet break-up, all three are expected to operate simultaneously. The interested reader is referred to a recent review on premix emulsification by Nazir et al. ${ }^{31}$ for more information.

To distinguish between different droplet break-up mechanisms, we performed a series of experiments, systematically varying the bead size, bed height and applied pressure as shown in Table 6.3, leading to a wide range of process conditions. In Fig. 6.5a, the final droplet to pore size ratios obtained after the fifth pass are plotted against the corresponding pore Reynolds number which characterizes the flow inside the packed bed as discussed in Section 6.2.5.

In Fig. 6.5a, two regions can be distinguished, one at high $R e_{p}$ at which the size reductions coincided regardless of the bead size and bed height used, and one at low $R e_{p}$, in which the size reductions did not coincide. This transition between the two 
regions took place at $R e_{p}$ between 1 and 2 . In the high $R e_{p}$ region, it is expected that shear forces dominated droplet break-up, as was also found in the work of Nazir et al. ${ }^{35}$ for single emulsions. At low $R e_{p}$ the obtained values were scattered, and they were even more scattered as found for single emulsions. We expect that part of the explanation for this lies in a transition from shear-based to spontaneous droplet breakup with, in the latter case, small beads being more efficient in droplet break-up. ${ }^{35}$ It should be mentioned that the effects are not completely in line with what was observed for single emulsions; the highest and lowest size reductions were achieved

Table 6.3 Process conditions for the experiments plotted in Fig. 6.5 with corresponding symbols.

\begin{tabular}{llll}
\hline Experiment & Bead size $[\mu \mathrm{m}]$ & Applied pressure $[\mathrm{kPa}]$ & Bed height $[\mathrm{mm}]$ \\
\hline$(0)$ & $30,55,65,78,90$ & 400 & 2 \\
$(\diamond)$ & 65 & 400 & $2,5,20,40$ \\
$(\square)$ & 65 & $200,300,400,500$ & 2 \\
$(\Delta)$ & 55 & $200,400,600$ & 2 \\
$(\Delta)$ & 30 & $200,400,600$ & 2 \\
\hline
\end{tabular}
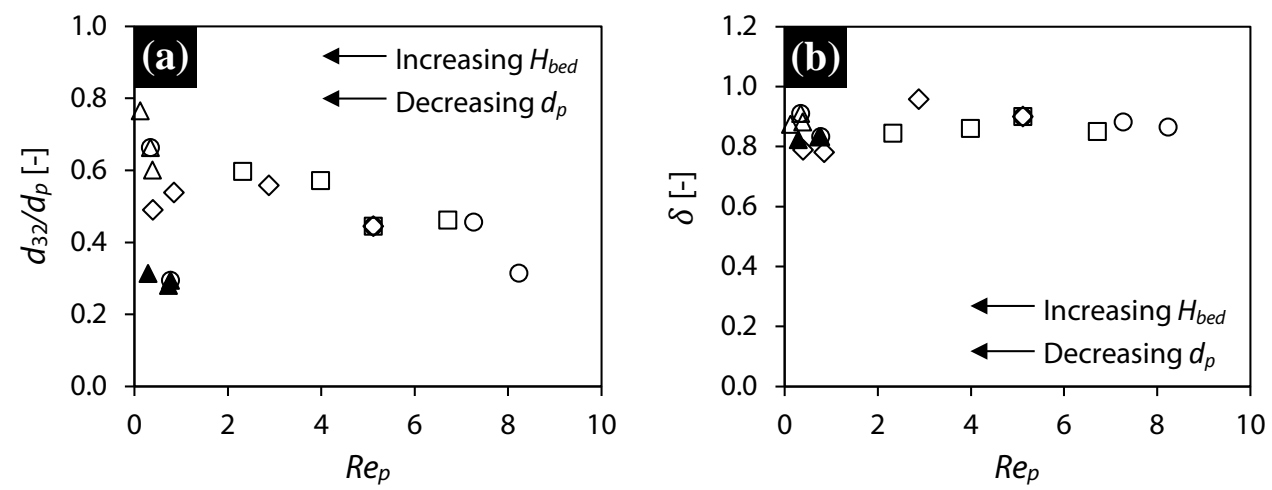

Fig. 6.5 (a) Dimensionless droplet diameter, $d_{32} / d_{p}$, and (b) droplet span, $\delta$, as a function of the pore Reynolds number, $R e_{p}$. In both figures, $\Delta P$ varied ( $\square$ ) for the $65 \mu \mathrm{m}$ beads, $(\Delta)$ for the $55 \mu \mathrm{m}$ beads, and $(\Delta)$ for the $30 \mu \mathrm{m}$ beads; (o) pore size, $d_{p}$, varied through bead size, $\mathrm{db}$; $(\diamond)$ bed height, $H_{\text {bed, }}$ varied from 2 to $40 \mathrm{~mm}$ for the $65 \mu \mathrm{m}$ beads. 
with 55 and $30 \mu \mathrm{m}$ glass beads, respectively, and an intermediate reduction was achieved with $65 \mu \mathrm{m}$ beads.

In an attempt to explain this, we analysed the results of similar premix emulsification studies, ${ }^{35,38}$ and compared them with our findings. Nazir et al. ${ }^{35}$ found that a packed bed of smaller beads was more effective in droplet break-up in the constriction dominated spontaneous emulsification region (at low $R e_{p}$ ) for the homogenization of o/w emulsions, for which they used 55 and $78 \mu \mathrm{m}$ glass beads. At the low $R e_{p}$ region in the current study, we also observed a similar trend in droplet size reduction with bead size used. However, the smallest beads $(30 \mu \mathrm{m})$, being less efficient in size reduction, seemed to be the exception to the rule. The droplet size decreased considerably upon increasing the applied pressure, and this could indicate that at low pressure the internal droplets interact with the glass beads, possibly leading to congestion of droplets and even re-coalescence inside the bed, and less efficient break-up. This explanation could be in line with the findings of Vladisavljević et al. ${ }^{38}$ for premix membrane emulsification using SPG membranes with various pore sizes (5.4 to $20.3 \mu \mathrm{m}$ ). They found that more homogenization cycles are needed for smaller pores to attain a similar droplet size reduction.

In all cases, the droplet size was smaller than the pore size, with a lowest droplet to pore size ratio of around 0.3 both at low and high pore Reynolds numbers. A similar overall size reduction was also reported by Nazir et al. ${ }^{35}$ for the preparation of o/w emulsions using packed bed systems, although it should be mentioned that the highest pore Reynolds numbers given in their study were typically a factor of 4 higher as reached in the current study due to viscosity differences. In some cases, the droplet to pore size ratios obtained in our work were significantly higher than those reported for single emulsions. This is attributed to the deformation resistance of highly viscous dispersed phase (w/o) in our system, ${ }^{37}$ which has led to less effective droplet break-up.

Compared to many other premix membrane emulsification studies focused on double emulsions, the size reductions we obtained are at the lower end of the reported range of $0.2-3.5,15,29,38,43$ which shows the effectiveness of the packed bed system in breaking up the double emulsion droplets.

Interestingly enough, in spite of all the mechanisms happening simultaneously, the span values were reasonably low and in close proximity, which suggests that under all 
considered conditions, also the largest droplets in the starter emulsion were effectively reduced relative to the pore size used (Fig. 6.5b). This can partly be explained by the high viscosity ratio we used, for which Nazir et al. ${ }^{44}$ also showed that in general droplet size distribution is narrower compared to those obtained at lower viscosity ratios.

\subsubsection{Encapsulation efficiency}

Besides appreciable size reductions, premix membrane emulsification of w/o/w emulsions with packed bed also yielded high encapsulation efficiencies. Table 6.4 shows the encapsulation efficiencies of double emulsions homogenized by passing five times through packed beds at various process conditions. Irrespective of the process conditions, double emulsion droplets were successfully homogenized, while retaining high percentages of their content.

Experiments conducted with larger beads $(65,78$ and $90 \mu \mathrm{m})$ resulted in encapsulation efficiencies greater than $98 \%$. On the other hand, in experiments with 30 and $55 \mu \mathrm{m}$ beads, more of the encapsulated substance was released during homogenization (and this could also hint at interactions with the beads), however the encapsulation efficiencies were still above 90\%. Fig. 6.6 shows the droplet size distribution of

Table 6.4 Encapsulation efficiencies immediately after $5^{\text {th }}$ pass at different process conditions.

\begin{tabular}{lllllllc}
\hline $\begin{array}{l}\text { Bead } \\
\text { size } \\
{[\mu \mathrm{m}]}\end{array}$ & $\begin{array}{l}\text { Bed } \\
\text { height } \\
{[\mathrm{mm}]}\end{array}$ & $\begin{array}{l}\text { Applied } \\
\text { pressure } \\
{[\mathrm{kPa}]}\end{array}$ & $\begin{array}{l}\text { Encapsulation } \\
\text { Efficiency }[\%]\end{array}$ & $\begin{array}{l}\text { Bead } \\
\text { size } \\
{[\mu \mathrm{m}]}\end{array}$ & $\begin{array}{l}\text { Bed } \\
\text { height } \\
{[\mathrm{mm}]}\end{array}$ & $\begin{array}{l}\text { Applied } \\
\text { pressure } \\
{[\mathrm{kPa}]}\end{array}$ & $\begin{array}{l}\text { Encapsulation } \\
\text { Efficiency [\%] }\end{array}$ \\
\hline 90 & 2 & 400 & $>99$ & 65 & 40 & 400 & $>98$ \\
78 & 2 & 400 & $>99$ & 55 & 2 & 200 & $>97$ \\
65 & 2 & 200 & $>99$ & 55 & 2 & 400 & $>95$ \\
65 & 2 & 300 & $>99$ & 55 & 2 & 600 & $>95$ \\
65 & 2 & 400 & $>99$ & 30 & 2 & 200 & $>94$ \\
65 & 2 & 500 & $>99$ & 30 & 2 & 400 & $>94^{a}$ \\
65 & 5 & 400 & $>99$ & 30 & 2 & 400 & $>94^{a}$ \\
65 & 20 & 400 & $>99$ & 30 & 2 & 600 & $>91$ \\
\hline
\end{tabular}

\footnotetext{
${ }^{a}$ duplicate experiments
} 

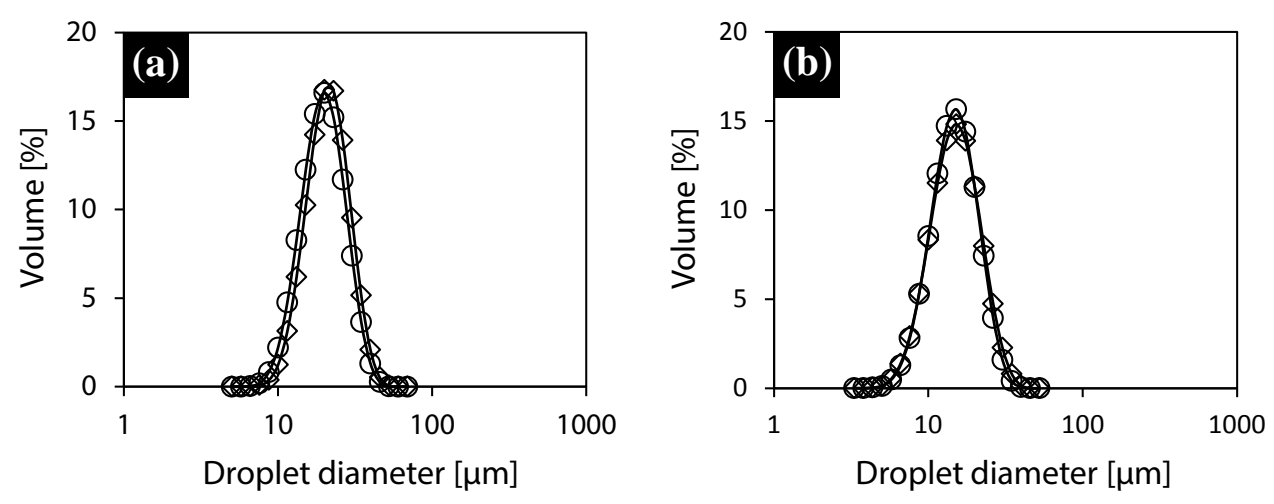

Fig. 6.6 Droplet size distribution of double emulsions: $(\circ) 5^{\text {th }}$ pass freshly prepared and $(\diamond) 5^{\text {th }}$ pass after 1 day storage at $23-27^{\circ} \mathrm{C}$. Processing parameters at which emulsions prepared were: (a) $d_{b}=65 \mu \mathrm{m}, H_{\text {bed }}=2 \mathrm{~mm}, \Delta \mathrm{P}=200 \mathrm{kPa}$, (b) $d_{b}=65 \mu \mathrm{m}, H_{\text {bed }}=2 \mathrm{~mm}, \Delta \mathrm{P}=400 \mathrm{kPa}$.

emulsions from two experiments right after preparation and after 1 day storage at room temperature. Despite the release occurring during storage, the droplet size distributions remained unchanged. As mentioned, the mechanism of release is outside the scope of the current study, but experimental results suggest that the release was diffusion controlled since the oil droplet size distribution was constant during storage, and the inner water droplets were clearly noticed in microscopy. In conclusion, the results showed that packed bed premix emulsification is a gentle technique capable of homogenizing w/o/w double emulsions without releasing the inner droplets.

\subsection{Conclusion}

Results show that a packed bed premix emulsification system is well-suited for the preparation of w/o/w emulsions. Along with the high throughput, the process allows high encapsulation efficiency and provides reasonably narrow droplet size distribution. Droplet size reductions achieved are comparable to those reported for single emulsions. Consistency of the experimental results indicates the robustness of the process. Considering the above mentioned features and adding scalability, ease of operation, and cleanability of the system, this method can meet many of the industrial demands for large-scale production of (double) emulsions. 


\section{Nomenclature}

$d_{32} \quad$ Sauter mean droplet diameter, see also Equation $6.1[\mathrm{~m}]$

$S_{v} \quad$ droplet surface area per unit volume $\left[\mathrm{m}^{-1}\right]$

$v_{i} \quad$ volume fraction of droplets in the $i^{\text {th }}$ size class [dimensionless]

$d_{i} \quad$ mean droplet diameter in the $i^{\text {th }}$ size class [m]

$n_{s} \quad$ number of size classes [dimensionless]

$d_{x} \quad$ droplet diameter corresponding to $x \%$ volume on a cumulative droplet size distribution curve $[\mathrm{m}]$

$J \quad$ flux $\left[\mathrm{m}^{3} \mathrm{~m}^{-2} \mathrm{~s}^{-1}=\mathrm{m} \mathrm{s}^{-1}\right]$

$A \quad$ effective surface area of packed bed $\left[\mathrm{m}^{2}\right]$

$H_{\text {bed }} \quad$ packed bed height [m]

$d_{b} \quad$ glass bead diameter $[\mathrm{m}]$

$d_{p} \quad$ pore diameter $[\mathrm{m}]$

$A_{v d} \quad$ specific surface area $\left[\mathrm{m}^{2} \mathrm{~m}^{-3}\right]$

$q \quad$ constant in Equation 6.7 [dimensionless]

$v_{o} \quad$ superficial velocity $\left[\mathrm{m} \mathrm{s}^{-1}\right]$

$v_{p} \quad$ pore velocity $\left[\mathrm{m} \mathrm{s}^{-1}\right]$

$R e_{p} \quad$ pore Reynolds number [dimensionless]

$C_{w 2} \quad$ concentration of released $\mathrm{NaCl}\left[\mathrm{mol} \mathrm{L}^{-1}\right]$

$C_{\text {total }}$ concentration of $\mathrm{NaCl}$ if all released $\left[\mathrm{mol} \mathrm{L}^{-1}\right]$

\section{Greek letters}

\begin{tabular}{|c|c|}
\hline$P$ & transmembrane pressure $[\mathrm{Pa}]$ \\
\hline$\rho_{e}$ & emulsion density [ $\left.\mathrm{kg} \mathrm{m}^{-3}\right]$ \\
\hline$\phi_{m}$ & mass flow rate $\left[\mathrm{g} \mathrm{s}^{-1}\right]$ \\
\hline 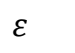 & porosity [dimensionless] \\
\hline$\xi$ & bed tortuosity [dimensionless] \\
\hline$\rho_{b}$ & bulk density $\left[\mathrm{kg} \mathrm{m}^{-3}\right]$ \\
\hline$\rho_{p}$ & particle density $\left[\mathrm{kg} \mathrm{m}^{-3}\right]$ \\
\hline$\eta_{e}$ & emulsion viscosity [Pa s] \\
\hline & droplet span [dimensionless] \\
\hline
\end{tabular}




\section{References}

1 S. van der Graaf, C. G. P. H. Schroën and R. M. Boom, J. Memb. Sci., 2005, 251, 7-15.

2 B. de Cindio and D. Cacace, Int. J. Food Sci. Technol., 1995, 30, 505-514.

3 N. Garti, LWT-Food Sci. Technol., 1997, 30, 222-235.

4 C. Lobato-Calleros, E. Rodriguez, O. Sandoval-Castilla, E. J. Vernon-Carter and J. Alvarez-Ramirez, Food Res. Int., 2006, 39, 678-685.

5 G. Muschiolik, Curr. Opin. Colloid Interface Sci., 2007, 12, 213-220.

6 M. Bonnet, M. Cansell, A. Berkaoui, M. H. Ropers, M. Anton and F. Leal-Calderon, Food Hydrocolloids, 2009, 23, 92-101.

7 S. J. Choi, E. A. Decker and D. J. McClements, Food Chem., 2009, 116, 271-276.

8 T. Hino, A. Yamamoto, S. Shimabayashi, M. Tanaka and D. Tsujii, J. Control. Release, 2000, 69, 413-419.

9 M. Bonnet, M. Cansell, F. Placin, E. David-Briand, M. Anton and F. Leal-Calderon, J. Agric. Food Chem., 2010, 58, 7762-7769.

10 M. Bonnet, M. Cansell, F. Placin, J. Monteil, M. Anton and F. Leal-Calderon, Colloids Surfaces B Biointerfaces, 2010, 78, 44-52.

11 L. Sapei, M. A. Naqvi and D. Rousseau, Food Hydrocolloids, 2012, 27, 316-323.

12 J. Weiss and G. Muschiolik, J. Dispers. Sci. Technol., 2007, 28, 703-716.

13 W. Yafei, Z. Tao and H. Gang, Langmuir, 2006, 22, 67-73.

14 E. Dickinson, J. Evison and R. K. Owusu, Food Hydrocolloids, 1991, 5, 481-485.

15 M. Shima, Y. Kobayashi, T. Fujii, M. Tanaka, Y. Kimura, S. Adachi and R. Matsuno, Food Hydrocolloids, 2004, 18, 61-70.

16 S. Sugiura, M. Nakajima, K. Yamamoto, S. Iwamoto, T. Oda, M. Satake and M. Seki, J. Colloid Interface Sci., 2004, 270, 221-228.

17 A. J. Gijsbertsen-Abrahamse, A. van der Padt and R. M. Boom, J. Memb. Sci., 2004, 230, 149-159.

18 S. Sugiura, M. Nakajima, S. Iwamoto and M. Seki, Langmuir, 2001, 17, 5562-5566.

19 S. L. Anna, N. Bontoux and H. A. Stone, Appl. Phys. Lett., 2003, 82, 364-366.

20 P. Garstecki, H. A. Stone and G. M. Whitesides, Phys. Rev. Lett., 2005, 94, 164501.

21 D. R. Link, S. L. Anna, D. A. Weitz and H. A. Stone, Phys. Rev. Lett., 2004, 92, 054503.

22 A. A. Maan, K. Schroën and R. Boom, Microfluid. Nanofluid., 2013, 14, 187-196.

23 M. L. J. Steegmans, K. G. P. H. Schroën and R. M. Boom, Langmuir, 2009, 25, 3396-3401. 
24 S. Sugiura, M. Nakajima and M. Seki, J. Am. Oil Chem. Soc., 2002, 79, 515-519.

25 K. van Dijke, R. de Ruiter, K. Schroën and R. Boom, Soft Matter, 2010, 6, 321-330.

26 G. T. Vladisavljević, I. Kobayashi and M. Nakajima, Powder Technol., 2008, 183, 37-45.

27 T. Nisisako, Chem. Eng. Technol., 2008, 31, 1091-1098.

28 K. C. van Dijke, K. Schroën, A. van der Padt and R. Boom, J. Food Eng., 2010, 97, 348-354.

29 G. T. Vladisavljevic, M. Shimizu and T. Nakashima, J. Memb. Sci., 2004, 244, 97-106.

30 C.-X. Zhao, Adv. Drug Deliv. Rev., 2013, 65, 1420-1446.

31 A. Nazir, K. Schroën and R. Boom, J. Memb. Sci., 2010, 362, 1-11.

32 A. Nazir, K. Schroën and R. Boom, Chem. Eng. Sci., 2013, 93, 173-180.

33 E. A. van der Zwan, C. G. P. H. Schroën and R. M. Boom, AIChE J., 2008, 54, 2190-2197.

34 A. Nazir, K. Schroën and R. Boom, J. Memb. Sci., 2011, 383, 116-123.

35 A. Nazir, R. M. Boom and K. Schroën, Chem. Eng. Sci., 2013, 92, 190-197.

36 J. Comiti and M. Renaud, Chem. Eng. Sci., 1989, 44, 1539-1545.

37 Y. Chen, X. Liu and M. Shi, Appl. Phys. Lett., 2013, 102, 051609.

38 G. T. Vladisavljević, M. Shimizu and T. Nakashima, J. Memb. Sci., 2006, 284, 373-383.

39 C. Charcosset, I. Limayem and H. Fessi, J. Chem. Technol. Biotechnol., 2004, 79, 209-218.

40 I. Kobayashi, S. Mukataka and M. Nakajima, Langmuir, 2004, 20, 9868-9877.

41 S. Sugiura, M. Nakajima, N. Kumazawa, S. Iwamoto and M. Seki, J. Phys. Chem. B, 2002, 106, 9405-9409.

42 E. van der Zwan, K. Schroën, K. van Dijke and R. Boom, Colloids Surfaces A Physicochem. Eng. Asp., 2006, 277, 223-229.

43 J. Surh, G. T. Vladisavljević, S. Mun and D. J. McClements, J. Agric. Food Chem., 2007, 55, 175-184.

44 A. Nazir, R. M. Boom and K. Schroën, Chem. Eng. Sci., 2014, 116, 547-557. 



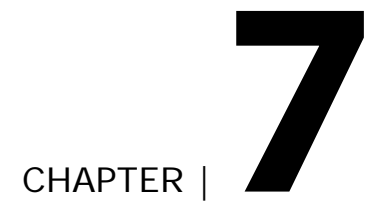

General discussion 


\subsection{Outline}

In this chapter, we start with a brief overview of microstructured emulsification devices with their respective pros and cons, link that to the progress made in this thesis, and round off with our vision on industrial use of microstructured emulsification devices.

\subsection{Microstructured emulsification devices}

Knowledge about formation of single droplets from one droplet formation unit is available and scaling relations have been suggested. ${ }^{1}$ However, for practical application much more is needed; Table 7.1 gives a qualitative comparison of microstructured emulsification methods for various aspects that are also considered important when upscaling. Please note that these aspects can be interrelated, e.g. poor flow control can result in polydispersity.

The essence of these methods are explained in the first chapter, and more detailed information can be found elsewhere. ${ }^{2}$ Emulsions made by microstructured devices are in general very monodisperse (except for the premix system), and can be made at much lower energy input than used in traditional techniques. Due to their very low energy input, they operate under mild conditions and do not cause product damage. Some of these processes are much easier to control than the others; e.g. in premix emulsification, the emulsion is refined as a whole, while in spontaneous emulsification the to-be-dispersed phase needs to be controlled, and in shear-based systems both phases need to be controlled precisely. Related to this, there is also a limit to the flexibility regarding the emulsion composition that can be produced with these techniques. In premix emulsification, high dispersed phase fractions can be produced ( 60\%), however generally emulsions over $30 \%$ tend to be less monodisperse due to more coalescence events during processing. For direct membrane emulsification, dispersed phase fraction is limited to $\sim 10 \%$, whereas higher fractions are possible at the expense of monodispersity. In principle, spontaneous emulsification techniques allow higher dispersed phase fractions without compromising monodispersity, compared to shear-based systems.

The droplet generation rate from a single shear-based unit may be several thousands per second, but the volume that is emulsified is very low, and it is even lower for 
spontaneous emulsification devices due to lower droplet generation rates. For a production scale that is relevant to food, many droplet formation units need to work in tandem; membranes have many pores, while microfluidic units would need to be parallelized, which is not straight forward. In parallelized microfluidics the various droplet formation units may interact, and even droplets that form at neighboring units may induce polydispersity. In this regard, EDGE devices are unique since they allow multiple droplet formation from one unit, which is a great benefit when considering upscaling.

Despite the advantages they hold, microstructured devices are at the same time prone to risks that do not apply to conventional systems, such as wettability changes (see chapter 2). Although this risk is minimum for premix emulsification in which the dispersed phase does not get in contact with membrane, in direct emulsification systems including the EDGE devices, surfaces are in contact with both phases, and wettability needs to be controlled to allow for stable operation.

Because we think that several advantages of microfluidic emulsification are combined in EDGE devices, making them attractive candidates for upscaling, we have made them the focal point of this thesis.

Table 7.1 Qualitative comparison of microstructured emulsification devices on various aspects that are important when scaling up. The comparison is for single pore or droplet formation unit, and + or - means the technology is advantageous or disadvantageous for a given aspect.

\begin{tabular}{lllll}
\hline & \multicolumn{2}{l}{ Membrane } & Microfluidics \\
\cline { 2 - 5 } & Direct & Premix & Shear-based & Spontaneous \\
\hline Monodispersity & ++ & + & +++ & +++ \\
Process control & - & ++ & -- & ++ \\
Throughput & ++ & ++ & ++ & - \\
Ease of parallelization & + & + & -- & - \\
Energy input & + & + & + & ++ \\
Formulation flexibility & - & + & -- & +
\end{tabular}

Shear-based: T-, Y-junctions, flow focusing devices; Spontaneous: Microchannels and regular EDGE devices. 


\subsection{Main findings}

A large part of this thesis was dedicated to understand and improve the main limitations of EDGE emulsification such as wettability, throughput and mass parallelization (see also Table 7.1). Unlike what general knowledge seems to indicate chapter $\mathbf{2}$ showed that the effect of a surface active components should not be limited to the liquid/liquid interface, but rather the interaction with all interfaces should be taken into account, also that of the involved liquids with the solid surface. In this regard, the findings of chapter $\mathbf{2}$ add to the understanding of wettability effects in spontaneous emulsification devices, and also other microfluidic devices can benefit from these insights.

To increase the productivity of EDGE devices, regular EDGE designs were adjusted by adding micro plateaus onto the main plateaus. This resulted in very high operational stability (i.e. pressure stability) and consequently a 100 fold increase in productivity was achieved, as elaborated in chapter 3. It was surprising that very monodisperse droplets at two distinct sizes could be produced using the same device.

The underlying droplet formation mechanism(s) of the two regimes were investigated in chapter 4, in which both the geometry of the micro-plateaus and product properties were varied. The micro-plateau geometry was shown to be essential for having the second monodisperse droplet formation regime. In the first regime, the droplet size seemed to follow a similar trend as found for microchannels; the droplet size decreased with increasing viscosity ratio, and leveled off at higher ratios. The second regime seemed to be ruled by the increased flow resistance of the micro-plateau in combination with the viscosity ratio of the liquids.

Because the results were very encouraging, the partitioned EDGE design was translated into an upscaled device, and the so-called multi-EDGE device was fabricated and tested in chapter 5. The multi-EDGE device, with 75000 micro-plateaus in parallel, was calculated to generate $\sim 10 \mu \mathrm{m}$ hexadecane droplets at $272 \mathrm{~L} \mathrm{~m}^{-2} \mathrm{~h}^{-1}$. Despite the low viscosity and small size of the droplets, eighty percent activation of the micro-plateaus were active, indicating their ease of parallelization. The productivity of multi-EDGE devices can be improved an order of magnitude if the technical limitations are mitigated to fabricate the optimal design. 
In chapter 6, a different microstructured system, a packed bed system was used to homogenize food grade w/o/w double emulsions. The process was shown to be robust and yield high encapsulation efficiency. Due to the pores that are larger than the droplet sizes, extremely high throughputs were obtained, and no serious fouling was observed. The window of operation was similar as that for single emulsions.

\subsection{Upscaling}

Any new technique needs to compete with conventional technology that is capable of producing large amounts of emulsion, and clearly in this respect microstructured devices cannot compete (yet).

Assuming that all aspects that are discussed for single units also hold at large-scale, we calculated dimensions of prospective equipment based on various microstructures. Table 7.2 gives estimates for the surface area that various devices require to produce a $30 \%$ sunflower oil emulsion with a droplet size of 5-10 micrometres at $1 \mathrm{~m}^{3} \mathrm{~h}^{-1}$ throughput.

Results obtained with direct membrane emulsification have been analysed by Gijsbertsen-Abrahamse and co-workers, ${ }^{3}$ and they found membrane areas of around $10 \mathrm{~m}^{2}$ for Shirasu Porous Glass membranes that have the highest reported fluxes. They concluded that the fluxes obtained for direct membrane emulsification were too low to make them economically interesting.

For the same productivity, the required area for shear-based microfluidic devices would be two orders of magnitude lower, based on their much higher droplet formation frequency. However, in practice it will be rather difficult to keep the process conditions the same for all channels. Some authors have 'solved' this by feeding all channels individually, but obviously that would not be a very practical solution since that would require a lot of pumps and tubing. Others have chosen to work from a central feeding area; a nice example in which 144 units operate in parallel producing droplets that are around 100 micrometres is by Nisisako and Torii. ${ }^{4}$ These droplets are, however, relatively large and it is expected that for small droplets this cannot be achieved this easily, since many more units would need to be operated in parallel and at much higher pressure. 
In that respect, the first 'upscaled' microfluidic device - the so-called microsieve, ${ }^{5}$ was more interesting. Based on the membrane resistance, a typical surface area was estimated to be between 0.1 and $1 \mathrm{~m}^{2}$; however, later it was found that pore activation was very low. ${ }^{6}$ In order to circumvent this, the sieves would need to be much thicker, therewith increasing the required area several orders of magnitude. ${ }^{6}$

Also spontaneous emulsification technologies have been scaled up, and straightthrough emulsification devices with several thousands of microchannels were developed, ${ }^{7-12}$ that would require two orders of magnitude higher areas when compared to shear-based systems. This is mostly because of the low pore activation when making droplets smaller than 10 micrometres; due to pressure gradients, specific pores are fed preferentially, as was the case for microsieves. In multi-EDGE devices specific geometry allows more stable operation and remarkably high pore activation, leading to a much lower area for the same productivity.

Please note that the estimated areas in Table 7.2 for membranes would be the closest to reality as they intrinsically comprise many droplet formation units (i.e. pores). For microchannels and multi-EDGE devices experimental validation was obtained from several thousands of parallelized units, while the estimations for microsieves and shearbased microfluidics rely on the performance of individual units assuming ideal mass parallelization. Realizing the projected areas at large-scale is still a major challenge especially for shear-based devices, which in practice would make them less suitable than what Table 7.2 suggests.

Table 7.2 Emulsification device area needed to produce $30 \%$ sunflower oil containing emulsion at $1 \mathrm{~m}^{3} \mathrm{~h}^{-1}$. The droplet size is between 5 and 10 micrometres.

\begin{tabular}{ll}
\hline Emulsification device & Device area $\left[\mathrm{m}^{2}\right]$ \\
\hline SPG membranes & $1-10$ \\
Microsieves & $0.1-1$ \\
Shear-based microfluidics & $0.1-60$ \\
Straight-through microchannels & 500 \\
Regular EDGE (straight-through) & 50 \\
Partitioned/multi-EDGE (straight-through) & $1-15$ \\
\hline
\end{tabular}




\subsection{Future prospects}

Previously we have pointed out the major issues that would delay or prevent largescale application. In this section, we propose a research strategy that will help speed up development and hopefully lead to applications in industry. We also discuss the additional aspects related to industrial application of the technology.

\subsubsection{Research and development}

Research and development of microfluidic systems is costly and time consuming. If the devices could be prepared more easily, this would allow for the needed flexibility in testing of new designs and construction materials in relation to new emulsion formulations. In this regard, in house fabrication of microfluidic devices at low cost would be a major step, and for that table top photolithography machines have become available recently (e.g. by LOT-Quantum Design). These machines do not need external masks and do not require clean room facilities, which would speed up prototyping considerably. Besides, similar technologies could be used for the production of largescale devices in the future.

In microfluidic emulsification, the main focus has been on the preparation of few monodisperse droplets and/or particles to study their formation mechanisms. However, characterization (e.g. rheology, stability, etc.) of the resulting emulsions is hardly undertaken, simply because the obtained sample volumes are so small. In chapter $\mathbf{5}$ we have shown that emulsions can be produced at high throughputs in laboratory-scale devices, and this opens the field of characterization of truly monodisperse emulsions.

Further, computer simulations clearly facilitate faster development of a microfluidic technology. Just to name a few, Abrahamse and co-workers ${ }^{13}$ and Rayner and colleagues $^{14}$ investigated direct membrane emulsification; Kobayshi's group ${ }^{10-12}$ and van Dijke et al. ${ }^{15}$ modeled microchannel emulsification, while the latter group also modeled EDGE emulsification. ${ }^{16}$ Based on these works, scaling relations were derived that are needed for appropriate designs, and similarly, the findings of chapters 2-5 of this thesis could be simulated to elucidate the droplet formation process in even greater detail. 


\subsubsection{Application aspects}

When the results of this thesis are considered, industrially relevant productivities are possible with the packed bed premix emulsification system (chapter 6) and are within reach for microfluidic EDGE devices (chapter 3 and chapter 5). The required area of a multi-EDGE device for industrial application can be reached best via stacking several multi-EDGE sheets in such a way that pressure drops are minimized in the dispersed phase. The stacked units can be fed through a central supply; a number of viable concepts were suggested elsewhere. ${ }^{17}$

Besides this, the construction material is of great importance, not just for the wettability issues described in chapter $\mathbf{2}$, but also to allow appropriate cleaning, safety, and structure integrity. For instance, glass is not traceable by X-ray or magnet, and would not be appreciated in food products. The preferred construction material of the food industry is stainless steel, and although Kobayashi et al. ${ }^{18}$ successfully prepared $350 \mu \mathrm{m}$ soybean and silicon oil droplets using $100 \mu \mathrm{m}$ deep stainless steel microchannels, it has severe limitations as a construction material at (sub-) micrometre scale that are needed to prepare small droplets (also for EDGE devices). When considering also other construction materials, the advances in micromachining including 3D printing technologies are very promising, and current limitations are expected to be overcome in the near future.

For most industrial processes, sanitation of the production lines is essential, and the employed equipment is designed in such a way that it complies with hygienic design standards. Closed chip systems (chapters 2-4) would not be practical at large-scales as some parts may be inaccessible to cleaning agents. However, open systems like multi-EDGE (chapter 5) and packed bed designs (chapter 6) are compatible with standard inline cleaning procedures that are used for industrial membrane filtration processes.

As mentioned before, due to their characteristic length-scales microstructured devices have several advantages over conventional processes, but for the same reason they are prone to other risks that do not apply to conventional homogenizers. For example, if the emulsion components are not completely dissolved (lumps etc.), the homogenizer will facilitate that process, but a microfluidic system would need to be fed with relatively clean liquids. This can be circumvented very easily, but will be considered a 
step outside the comfort zone for people that are used to work with conventional homogenizers.

\subsection{Concluding remarks}

Considering the progress made in the last decades, including the findings of this thesis, targets regarding industrial throughput seem to be within reach, and the rewards for investing in EDGE and other microstructured emulsification systems could be great. The principles that are valid for production of standard emulsions also apply to preparation of solid and hollow particles, ${ }^{19,20}$ capsules $^{21}$ double emulsions, ${ }^{22,23}$ particlestabilized emulsions, ${ }^{24}$ foams, ${ }^{25,26}$ and that makes the technology very flexible. We already found that with $0.2 \mu \mathrm{m}$ plateaus $\sim 1 \mu \mathrm{m}$ monodisperse oil droplets could be prepared (Fig. 7.1a), and besides it was possible to produce particle stabilized oil droplets over a remarkable pressure range (Fig. 7.1b).

In our opinion, the technical challenges for industrial use of the microstructured emulsification processes are well-identified in the microfluidics community, and the knowledge to tackle them is converging rapidly. At this stage, possible end users of these emulsification technologies should feel encouraged to start thinking about
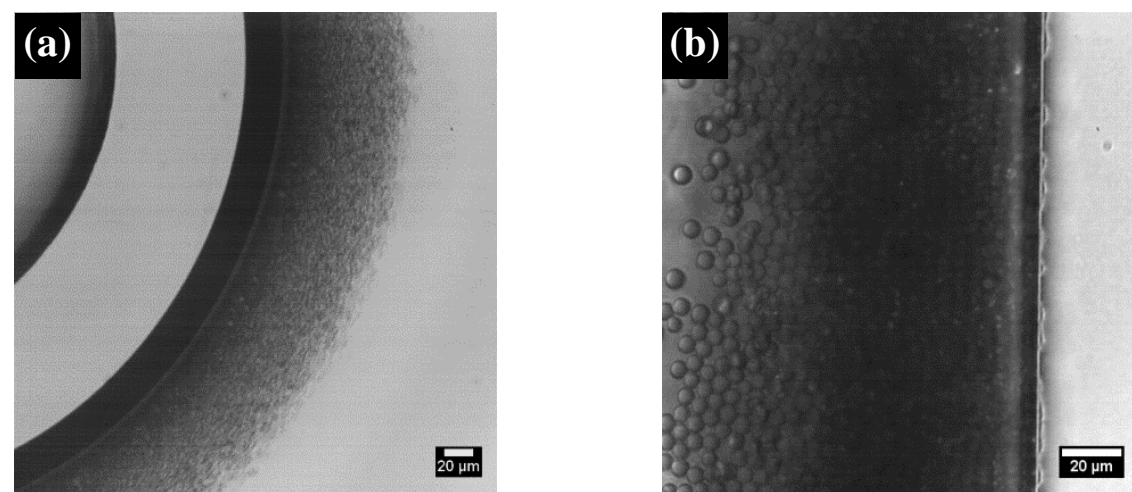

Fig. 7.1 (a) Monodisperse oil droplets of $\sim 1 \mu \mathrm{m}$ prepared with very shallow plateaus, and (b) particle stabilized $6 \mu \mathrm{m}$ monodisperse oil droplets. 
product concepts that will benefit from droplet monodispersity. The throughputs that are needed for emulsion characterization and/or product development studies are currently possible, and this could lead to a new stage in product design.

We also envision that the proof of principle does not necessarily need to be within the food industry, possibly the added value for pharmaceuticals and cosmetics can be greater. We believe that once few commercial applications become available, the technology will be adopted much more readily in other fields.

\section{References}

1 K. Schroën, S. Sahin, K. van Dijke, S. van der Graaf, M. Zijffers-Steegmans, T. Krebs and R. Boom, Encycl. Microfluid. Nanofluid., 2014.

2 K. Schroën, O. Bliznyuk, K. Muijlwijk, S. Sahin and C. C. Berton-Carabin, Curr. Opin. Food Sci., 2015, 3, 33-40.

3 A. J. Gijsbertsen-Abrahamse, A. van der Padt and R. M. Boom, J. Memb. Sci., 2004, 230, 149-159.

4 T. Nisisako and T. Torii, Lab Chip, 2008, 8, 287-293.

5 C. J. M. van Rijn, Nano and micro engineered membrane technology, Elsevier, Amsterdam, 2004.

6 A. J. Abrahamse, R. Van Lierop, R. G. M. Van der Sman, a. Van der Padt and R. M. Boom, J. Memb. Sci., 2002, 204, 125-137.

7 I. Kobayashi, X. Lou, S. Mukataka and M. Nakajima, J. Am. Oil Chem. Soc., 2005, 82, 6571.

8 S. Sugiura, M. Nakajima, S. Iwamoto and M. Seki, Langmuir, 2001, 17, 5562-5566.

9 G. T. Vladisavljević, I. Kobayashi and M. Nakajima, Microfluid. Nanofluid., 2012, 13, 151 178.

10 I. Kobayashi, K. Uemura and M. Nakajima, J. Chem. Eng. Japan, 2006, 39, 855-863.

11 I. Kobayashi, M. a. Neves, K. Uemura and M. Nakajima, Procedia Food Sci., 2011, 1, $123-$ 130.

12 I. Kobayashi, G. T. Vladisavljević, K. Uemura and M. Nakajima, Chem. Eng. Sci., 2011, 66, 5556-5565.

13 A. J. Abrahamse, A. Van der Padt, R. M. Boom and W. B. C. De Heij, AIChE J., 2001, 47, 1285-1291. 
14 M. Rayner, G. Trägårdh, C. Trägårdh and P. Dejmek, J. Colloid Interface Sci., 2004, 279, 175-185.

15 K. C. van Dijke, K. Schroën and R. Boom, Langmuir, 2008, 24, 10107-10115.

16 K. van Dijke, R. de Ruiter, K. Schroën and R. Boom, Soft Matter, 2010, 6, 321-330.

17 K. C. van Dijke, Emulsification with microstructures, Wageningen, 2009.

18 I. Kobayashi, Y. Wada, Y. Hori, M. A. Neves, K. Uemura and M. Nakajima, Chem. Eng. Technol., 2012, 35, 1865-1871.

19 H. Sawalha, N. Purwanti, A. Rinzema, K. Schroën and R. Boom, 2008, 310, 484-493.

20 H. Sawalha, Y. Fan, K. Schroën and R. Boom, J. Memb. Sci., 2008, 325, 665-671.

21 F. Rossier Miranda, C. Schroën and R. Boom, Langmuir, 2010, 26, 19106-19113.

22 S. van der Graaf, C. G. P. H. Schroën and R. M. Boom, J. Memb. Sci., 2005, 251, 7-15.

23 G. Muschiolik, Curr. Opin. Colloid Interface Sci., 2007, 12, 213-220.

24 C. C. Berton-Carabin and K. Schroën, Annu. Rev. Food Sci. Technol., 2015, 6, 263-297.

25 A. Nazir, A. A. Maan, S. Sahin, R. M. Boom and K. Schroën, Food Bioprod. Process., 2015, 94, 561-564.

26 K. C. van Dijke, K. Schroën, A. van der Padt and R. Boom, J. Food Eng., 2010, 97, 348-354. 



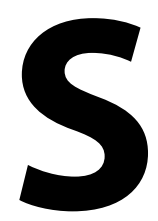

Summary 


\section{Summary}

Emulsions, which are dispersions of two immiscible liquids (e.g. oil and water), are part of our daily life through many products that we use such as milk, mayonnaise, salad dressings, ice cream, lotions, shampoos, medicines, wall paints, etc. Many quality attributes of these products such as stability, texture, colour, visual and sensorial perception are affected by droplet size and size distribution.

Conventional emulsification technologies such as high pressure homogenizers have poor control on droplet size distribution, they are energy intensive and not suited for fragile multiple emulsions. In the last decades, alternative emulsification concepts that employ microengineered structures have been developed. They can produce uniform droplets of a specific size using orders of magnitude less energy, and are suitable for multiple emulsions.

However, most of these techniques generate one droplet at a time and the productivity of a single droplet generation unit is very low. To reach significant throughput, many units need to be run in parallel, which is far from trivial especially for the production of droplets below 10 micrometres. In this regard, EDGE (Edge-based Droplet GEneration) devices are better suited for upscaling since they can generate multiple uniform droplets simultaneously from one droplet formation unit.

Unlike standard upscaling in industry, the characteristic dimension remains the same for microstructured (EDGE) devices, and issues related to upscaling were found to be linked to (sub-) micrometre scale (e.g. wettability and flow geometry). In EDGE emulsification, the contact surfaces need to be wetted well by the continuous phase, and in chapter $\mathbf{2}$ we show that the interactions of the liquids and surfactants with all available surfaces/interfaces influence wettability. In general, oils that have strong interaction with the surface can only be emulsified successfully in combination with surfactants that bind strongly to the surface. Also the pressure range in which droplets can be produced is greatly influenced by these interactions, e.g. proteins showed much wider pressure stability and an order of magnitude higher productivity, therewith also showing that EDGE emulsification is well suited for food-grade emulsions; that is as long as an appropriate combination of construction material and emulsion components is used. 
Also the geometry of the EDGE devices can be used to increase productivity. Previous research indicated that higher resistance on the plateau can improve the pressure stability, which inspired us to redesign the droplet formation units and place regularly spaced micron-sized partitions on the main plateaus, as reported in chapter $\mathbf{3}$. The micro-plateaus were positioned such that the number of droplet formation points was increased compared to regular EDGE, and it was found that the additional flow resistance resulted in remarkably wide pressure range while supplying oil to all microplateaus that were equally active, thereby leading to two orders of magnitude higher droplet productivity. Interestingly, at high pressures a second wide range generating approximately three times larger uniform droplets was discovered.

In chapter 3, only one partitioned EDGE geometry was investigated for hexadecane and $0.5 \%$ SDS solution; therefore, in chapter 4 the underlying droplet formation mechanisms was investigated further by systematically varying the geometry of the micro-plateaus and the viscosity of the liquids. It was found that the micro-plateau geometry greatly influenced emulsification behaviour. The second regime, in which large droplets were formed, was only observed for narrow micro-plateaus, suggesting that a certain minimum flow resistance is needed for the second regime to occur. In the first regime, in which small droplets were formed, droplet size was dependent on the viscosity ratio of the liquids, in a similar way to that found for regular EDGE devices.

The partitioned EDGE devices were upscaled in chapter $\mathbf{5}$ with 75000 micro-plateaus. This first upscaled device, the so-called multi-EDGE, was used to produce monodisperse hexadecane droplets of $\sim 10$ micrometres at $0.3 \mathrm{~m}^{3} \mathrm{~m}^{-2} \mathrm{~h}^{-1}$ (80\% microplateau activation). As expected, the differences in plateau geometry (due to technical limitations) compared to the devices reported in chapter 3 led to an order of magnitude lower productivity. Nonetheless, the initial results were promising, and provided clear leads to improve the productivity further. Last but not least, with the current multi-EDGE device enough product can be made to conduct rheology and stability tests for truly monodisperse emulsions.

In chapter 6, we studied a different microstructured device, the packed bed premix emulsification equipment, and showed that food-grade double emulsions (containing $5 \% \mathrm{v} / \mathrm{v}$ primary emulsion) can be refined at high throughputs, typically in the range of $100-800 \mathrm{~m}^{3} \mathrm{~m}^{-2} \mathrm{~h}^{-1}$, while keeping their encapsulation yield above $90 \%$. Droplet size 
reduction was similar to that found for single emulsions; the refined droplets were smaller than the pore sizes of the packed bed, and no marked fouling was observed under the conditions tested. Further, the process was robust and reproducible, making the technique a genuine option for double emulsion production.

In the last chapter, chapter 7, we compare microstructured emulsification techniques on various aspects, and explain how the findings of this thesis help mitigate the identified bottlenecks (e.g. wettability, parallelization, productivity) that prevent upscaling of the technology. Finally, we conclude with an outlook on upscaling and discuss the aspects related to possible applications of the technology in the future. 




\section{Acknowledgements}

Although only my name appears on the cover of this dissertation, there are many people who contributed to this work and supported me during this journey, and it is not an easy task to duly thank all. To avoid forgetting anyone, I will only mention a few people who were most directly involved in the production of this dissertation, and I hope the people that are not mentioned but I am grateful for know it anyway. So, thank you all my friends, colleagues, students, collaborators, co-authors and paranymphs.

My special thanks to Karin, who witnessed almost every stage of this production. It has been a pleasure to work with you, and I have learned a lot from you. Thank you for the supervision, support and motivation. Thank you for your selfless time for meetings, even from ten thousand miles away. Thank you for many more at and outside work.

Food Process Engineering group is a big club and I owe thanks to many people there. Thank you Remko for making the most out of the limited times we could share, and providing endless ideas. Working in well-organized labs and not being bothered by administrative stuff might be a luxury for many researchers, but not for us because we have had Jos, Maurice, Martin, Jarno, Marjan and Joyce; thank you for all your assistance. I am also indepted to the invisible heroes from the mechanical workshop of the university, especially Eric and Johan for crafting tailor-made experimental setups and solutions. Thank you Anja Janssen, Tim Baks, and Ralf Hartemink for your guidance during my master studies that helped me to start this PhD project.

Son olarak sevgili ailem, geniş ailem, en uzaktayken bile en yakın olduğunuz için, tüm fedakârlıklarınız için, cesaretlendirdiğiniz ve kelimelere dökemediğim her şey için yürekten teşekkür ederim. Hakkınız ödenmez, sağ olun var olun.

\section{Samí}





\section{About the author}

Sami Şahin was born in 1986 in Of, Turkey. After completing his secondary eduaction in Trabzon in 2004, he started his higher education at Gaziantep University, Turkey, where he obtained his BSc degree in Food Engineering in 2009. In the last year of his BSc curriculum, he visited Wageningen University as an Erasmus exchange student, and during his visit he was awarded the Food Valley Ambassadors scholarship to follow a master programme in food technology in the same university.

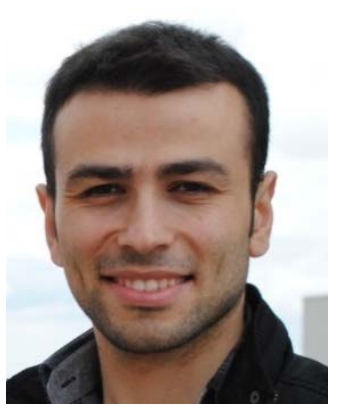
He received his MSc degree with the specialization in Product and Process Design. He completed his master thesis in collaboration with FrieslandCampina where he afterwards worked for a year under a special training programme following his master thesis. In his MSc thesis and training programme, he worked on various membrane separation processes for the valorisation of milk and whey streams. In 2011, he started his PhD research at the Laboratory of Food Process Engineering (FPE) at Wageningen University. His project, the results of which are presented in this thesis, was part of NanoNextNL, a micro and nanotechnology consortium of the Netherlands. Next to his curricular activities, he has been executing his role as Food Valley Ambassador to facilitate the collaboration between the Turkish and Dutch enterprises, development agencies, universities and industrial players. Currently, Sami works as a postdoc at FPE. 



\section{List of publications}

Maan, A. A., Sahin, S., Mujawar, L. H., Boom, R. \& Schroën, K. Effect of surface wettability on microfluidic EDGE emulsification. J. Colloid Interface Sci. 403, 157-159 (2013).

Schroën, K., Sahin, S., van Dijke, K., van der Graaf, S., Zijffers-Steegmans, M., Krebs, T. \& Boom, R. Emulsion preparation with micro-structured systems. Encycl. Microfluid. Nanofluid. (2014).

Sahin, S., Sawalha, H. \& Schroën, K. High throughput production of double emulsions using packed bed premix emulsification. Food Res. Int. 66, 78-85 (2014).

Nazir, A., Maan, A. A., Sahin, S., Boom, R. M. \& Schroën, K. Foam preparation at highthroughput using a novel packed bed system. Food Bioprod. Process. 94, 561-564 (2015).

Schroën, K., Bliznyuk, O., Muijlwijk, K., Sahin S. \& Berton-Carabin, C.C. Microfluidic emulsification devices: from micrometer insights to large-scale food emulsion production. Curr. Opin. Food Sci., 3, 33-40 (2015).

Sahin, S. \& Schroën, K. Partitioned EDGE devices for high throughput production of monodisperse emulsion droplets with two distinct sizes. Lab Chip 15, 2486-2495 (2015).

Sawalha, H, Sahin, S. \& Schroën, K. Preparation of polylactide microcapsules at a high throughput with a packed-bed premix emulsification system. J. Appl. Polym. Sci. 133, 43536 (2016).

Sahin, S., Bliznyuk, O., Rovalino Cordova, A., \& Schroën, K. Microfluidic EDGE emulsification: the importance of interface interactions on droplet formation and pressure stability. Sci. Rep. 6, 26407 (2016).

Schroën, K., Ferrando, M., De Lamo-Castellví, S., Sahin, S. \& Güell, C. Linking findings in microfluidics to membrane emulsification process design: the importance of wettability and component interactions with interfaces. Accepted for publication in Membranes (2016).

Sahin, S., Rovalino Cordova, A., \& Schroën, K. Droplet formation mechanisms in partitioned DGE devices: geometry and viscosity effects. Sumbitted for publication.

Sahin, S., Strofyllas, M., \& Schroën, K. Upscaling microfluidic emulsification to industrially relevant throughputs: the importance of (sub-) structure design. Sumbitted for publication. 



\section{Overview of completed training activities}

\section{Discipline specific activities}

\section{Courses}

Sustainability Analysis in Food Production Systems in Wageningen (NL) 2011

CFD for Chemical Engineers in Delft (NL) 2011

Food Structure and Rheology in Wageningen (NL) 2012

Fundamentals and Practice of Process Intensification in Delft (NL) 2013

\section{Conferences and Workshops}

Netherlands Process Technology Symposium in Arnhem (NL) 2011

MicroNano Conference'11 in Ede (NL) 2011

$7^{\text {th }}$ Baltic Conference on Food Science and Technology in Kaunas (LT) ${ }^{a} \quad 2012$

$14^{\text {th }}$ European Student Colloid Conference in Potsdam (DE) ${ }^{a} \quad 2013$

$9^{\text {th }}$ European Congress of Chemical Engineering in The Hague (NL) ${ }^{a} \quad 2013$

MicroNano Conference'13 in Ede (NL) ${ }^{b}$

$2^{\text {nd }}$ Intl. Conference on Microfluidic Handling Systems in Freiburg (DE) ${ }^{a} \quad 2014$

Nanocity 14 in Utrecht (NL) $)^{a, b}$

Xs2HiTek Accelerate Micro Nano Innovation in Eindhoven (NL) 2014

MicroNano Future4Profit in Leusden (NL) ${ }^{b}$

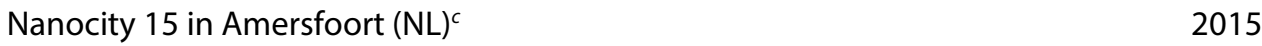

\section{General Courses}

Project and Time Management in Wageningen (NL) 2011

Information Literacy PhD including EndNote Introduction in Wageningen(NL) 2011

VLAG PhD Week in Baarlo (NL) 2012

Scientific Writing in Wageningen (NL) 2012

IP \& Valorisation Awareness in Soesterberg (NL) 2013

Risk Analysis and Technology Assessment (RATA) in Amersfoort (NL) 2013

Analytic Storytelling in Utrecht (NL) 2014

\section{Optional Activities}

Scientific PhD Excursion to Finland and Baltic States ${ }^{b}$

Scientific PhD Excursion to Chile and Brazil ${ }^{b}$

Food Process Engineering Group Meetings ${ }^{b} \quad$ 2011-2015

$\begin{array}{ll}\text { NanoNextNL Project Meetings } & \text { 2011-2015 }\end{array}$

${ }^{a}$ Poster, ${ }^{b}$ Oral, ${ }^{c}$ Demonstration 
This thesis is part of NanoNextNL, a micro and nanotechnology innovation consortium of the Government of the Netherlands and 130 partners from academia and industry. 